\title{
RAPE COMPLAINANTS ON TRIAL: DEFENCE QUESTIONING APPROACHES AND WITNESS \\ EMOTIONALITY
}

\author{
by \\ Lauren Patricia McManamon
}

\begin{abstract}
A thesis
submitted to the Victoria University of Wellington

in fulfilment of the requirements for the degree of

Masters in Psychology
\end{abstract}

Victoria University of Wellington 



\section{Dedication}

This thesis is for all the people whose stories of rape remain untold in the courts. 


\section{Acknowledgements}

Firstly I would like to thank my supervisors Dr. Ann Weatherall and Elisabeth McDonald.

Their unwavering support and passion was greatly appreciated. The thoughtful advice and guidance they gave me greatly aided in this project.

I would also like to thank my family and friends for seeing me through this process. They gifted me much needed joy and care during research on a very difficult topic.

Finally a special thanks to my fellow students who offered insights into the analysis. 


\begin{abstract}
Sexual offending has always been a crime that is difficult to prosecute. Despite efforts to reform the criminal justice process, prosecuting sexual offending remains problematic (McDonald \& Souness, 2011). In particular, the trial process has a reportedly traumatising effect on complainants, and this dissuades others from going to court. This issue is exacerbated in cases where the perpetrator and victim are acquainted. Compared to unknown perpetrators, there is more of a perceived possibility that the complainant consented. This puts her testimony under heightened scrutiny and makes her credibility all the more salient to the trial. Cross-examination therefore becomes an important point in the trial. However it is also identified as the point in the process where the complainant becomes retraumatised. While there is a consensus that the cross-examination is traumatic, no studies have analysed how trauma unfolds in the courtroom. This research offers some insight into aspects of crossexamination that distress complainants and potentially inhibit the prosecution of sexual offending. It uses three New Zealand District Court cross-examinations where the perpetrator is an ex-partner. The study firstly presents findings on how defence counsel construct questions and what information they house within them. It finds that defence counsel predominantly ask questions that request confirmation. These questions were used in series to construct inconsistencies in the complainant's testimony. They were also used to mount challenges and accusations. Furthermore this study makes preliminary observations that defence counsel questions house prejudicial stereotypes about rape. Such questions misrepresent the reality of sexual offending and serve to undermine the complainant's credibility. Secondly, the study presents preliminary findings from two cases in which the defence reissued questions in pursuit of a particular response. This occurred where the complainant resisted answering on the terms of the question. The defence treated this as inadequate and subsequently reissued the question. When defence pursued responses in this way, complainants displayed signs of emotionality in the courtroom. It was also found that after continual resistance in two cases the defence concluded the line of questioning with a three-part list. The list challenged the complainant's credibility. This study makes preliminary observations that complainants display emotion when the counsel tells them their answers are inadequate and reissue questions repeatedly. Initial insight is offered into how defence counsel conduct the cross-examination and how it impacts the prosecution of sexual offending. This study also recommends improved education and awareness-raising for justice sector professionals to address complainant trauma and rape myths in cross-examination.
\end{abstract}




\section{Table of Contents}

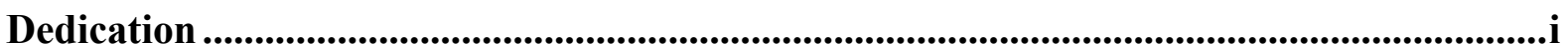

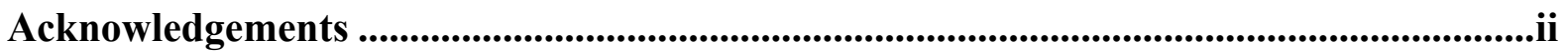

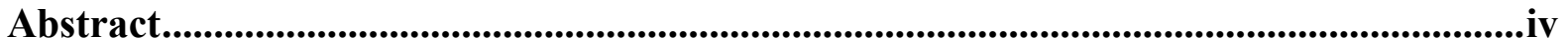

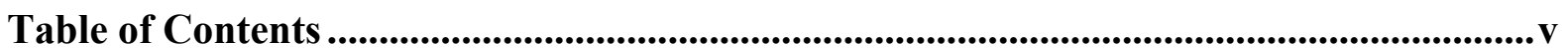

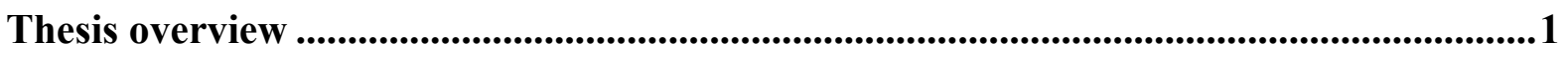

Chapter One: Socio-Legal Context for Sexual Offending.......................................................2

The Legal Framework for Sexual Offending ....................................................................

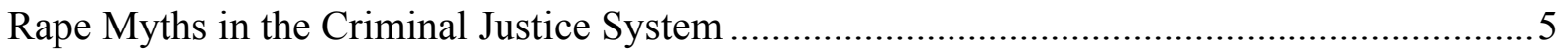

Institutional Processes and Roles in Criminal Trials .......................................................... 10

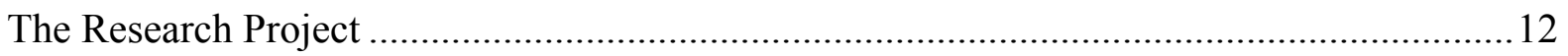

Chapter Two: Methodology in Discursive Psychology and Conversation Analysis ........14

Summary of the Discursive Psychology Methodological Approach .....................................16

Domains of Conversation Analysis Applicable in the Courtroom ...................................... 16

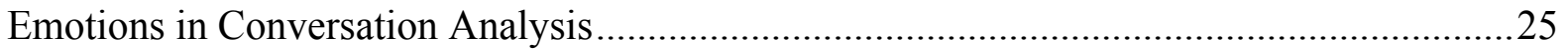

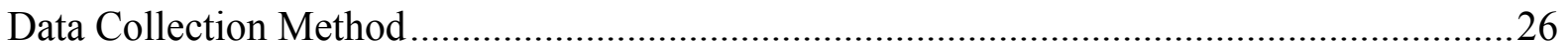

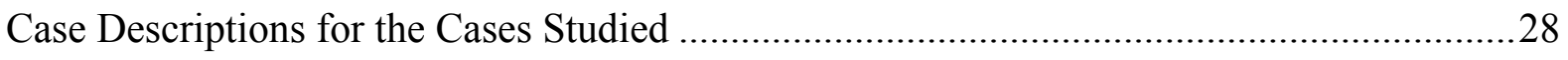

Chapter Three: Sequential Organisation of Questioning .................................................32

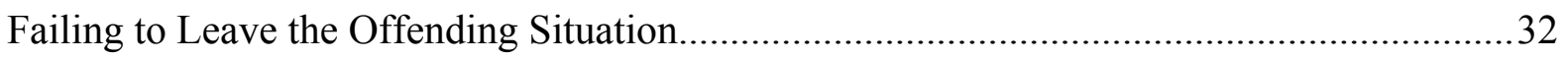

Failure to Tell, and Delayed Reporting to Police ............................................................. 39

Emotion Categories in Defence Questioning and Accusations ...........................................45

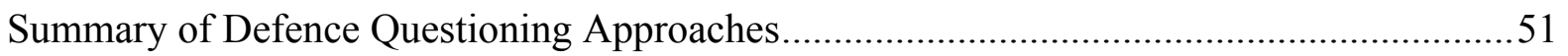

Chapter Four: Questioning Approaches to Non-Aligned Responses...................................53

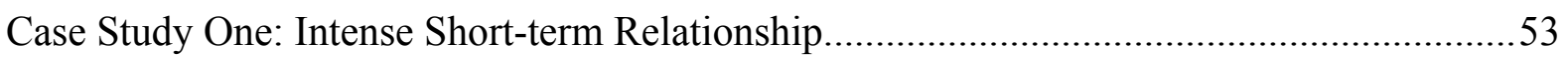

Case Study Two: Young Woman, First Serious Relationship ...........................................57

Concluding Complainant Resistance: Three-part Lists .....................................................63

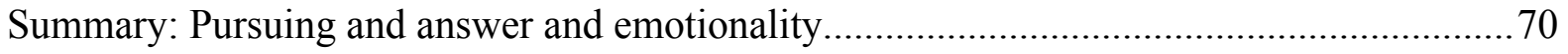

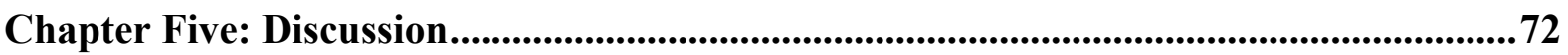

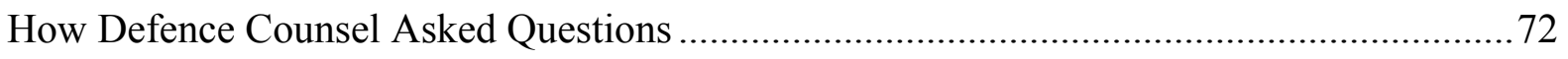

Defence Pursuing Responses and Complainant Emotionality ........................................... 75

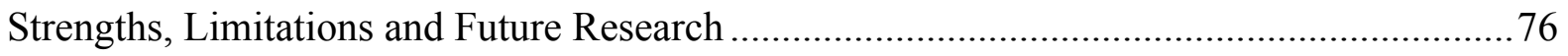




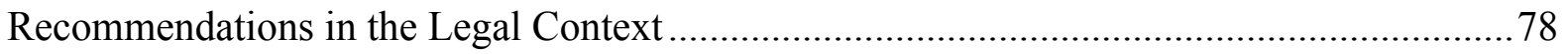

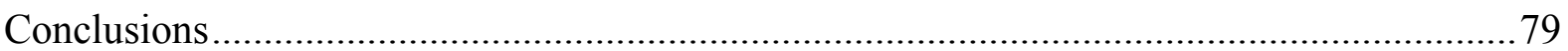

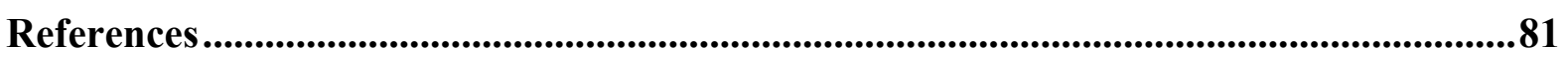

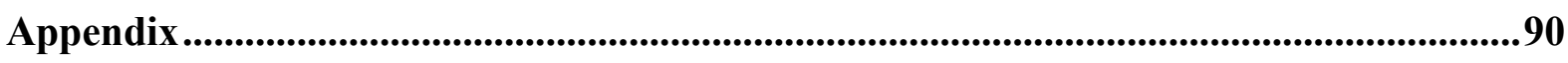




\section{Thesis overview}

The introductory chapter of this thesis outlines the social and cultural background of sexual violence against women in the legal context. It discusses the literature on society's discourses that scaffold a culture of normalising and excusing sexual violence. Firstly it explains how the 'real rape' stereotype has come about and how it affects intimate partner violence. From there it expands on other commonly-held beliefs about rape that prejudice society against victims of sexual crimes. These beliefs are then contexualised within the criminal justice system and the relevant legislation; the aim being to set the context for understanding how courtroom participants organise their talk in sexual offending crossexaminations.

The second chapter provides the methodological approaches used in this study. It outlines the methodology of discursive psychology, conversation analysis and discusses the bridge between the two. An overview of the foundations of conversation analysis is then provided. It also describes in full the data used in this research, and how it was gathered and analysed. This study used data from three rape complainant cross-examinations from New Zealand District Court trials. Two of these cases were all in English. The third complainant spoke English as a second language and required an interpreter to give evidence.

The data analysis begins in chapter three which sets out three recurring lines of questioning used by defence counsels in these cases. These are 'leaving a situation', 'not disclosing the offending' and 'inconsistent/excessive emotions'. Comment is also made on how the defence's questions incorporate these key lines of questioning using the clearest examples from the data. It also explores the discursive aspects of these lines of questioning. The overall aim of chapter three is to explore the sorts of challenges put to the complainant, and how questions place both her character and actions on trial.

Chapter four is a second analytic chapter. It identifies two approaches the defence uses when complainants display resistance to their questions. Firstly, it looks at instances where the defence counsel pursues a response to elicit alignment from the complainant. Secondly, it examines instances where the defence counsel poses three-part lists to make a generalisation about the complainant's character. It also observes displays of emotion from the witness during cross-examination.

Chapter five discusses the findings. It makes recommendations on improving crossexaminations to reduce courtroom trauma for rape complainants. 


\section{Chapter One: Socio-Legal Context for Sexual Offending}

Sexual violence against women is a worldwide problem for every jurisdiction. In spite of rape being recognised as a serious crime in statute, there are significant problems in its policing and prosecution in court. This is due in part to an international normalisation of sexual violence (World Health Organisation, 2010). Society has developed a culture of minimising and downplaying harm caused to women. Accepting sexual violence as a part of our culture has consequences for prosecuting it as a crime. It is underreported with a low conviction rate (Ministry of Justice, 2010). Even after decades of social awareness, it continues to be a challenge for the criminal justice system.

Cross-examination is an important aspect of the trial process where issues regarding sexual violence continually arise. One such problem is that complainants are asked about very intimate, sometimes irrelevant details of the offending in a public arena (Brereton, 1997). As a result of practices such as this, complainants describe testifying as being worse than the actual sexual assault (McDonald, 1996; Konradi, 2007). Feelings of intense guilt, self-blame, anxiety, powerlessness and embarrassment are common emotions felt as a consequence of sexual offending at the time of the event (Thomas, 1994). These feelings can resurface during cross-examination. This is due in part to complainants feeling as if they are personally being put on trial over the accused (McDonald, 1996; Konradi, 2007). It is unjust that victims of a crime are unduly harmed and feel persecuted by the trial process.

Society's approach to sexual offending therefore presents two principal challenges for prosecution. Firstly, police, lawyers and researchers point to cultural discourses that normalise sexual violence against women. These act as a deterrent for both victims and legal enforcers throughout the justice system (Jordan, 2004; Bechhofer \& Parrot, 1991). Secondly, victims report being retraumatised by the trial process (McDonald, 1996; Konradi, 2007). Together these issues contribute to low reporting, low conviction rates and low complainant satisfaction with their part in the process.

In spite of a decade of law reform, outcomes for sexual offending have been resistant to change (McDonald \& Souness, 2011). There continues to be high attrition rates for sexual 
offending cases. ${ }^{1}$ Police point to a combination of several factors when they are asked why cases do not proceed. These factors tend to show a mindfulness of the trial process and crossexamination. If they signal a poor prospect of a conviction, they could end the investigation (Jordan, 2004). This may be where there are concerns over the complainant's credibility. Cases also have poor prospects if they are date rape, acquaintance rape and partner rape. In these cases, police may have been sure the victim was raped, but thought the jury would not believe her. This is due in part to the apparent ease with which the defence can damage the complainant's credibility during cross-examination (Mossman, MacGibbon Kingi \& Jordan, 2009). This indicates that foreseeable issues in the courtroom influence earlier decisions whether or not to prosecute rape cases.

Alternatively, complainants may decide to withdraw from the process. As they are often the only witness giving evidence, the case cannot continue. A fear of the process and a fear of not being believed can contribute to complainant withdrawal (Mossman, Jordan, MacGibbon, Kingi, \& Moore, 2009; Mossman, MacGibbon et al., 2009). The fear appears to be well founded. Police, Crown prosecutors and judges, all report that they would not recommend a loved one go through the process because it is too traumatising (Mossman, MacGibbon et al., 2009; Thomas, 1994).

High attrition and low prosecution represents a significant failure in being able to enforce the law with respect to intimate partner sexual violence. This has ongoing serious implications for the safety of women in New Zealand. If this country can foster a justice system in which testifying is less traumatic, then it is likely that more women will remain in the process. With the courtroom being such a deterrent to bringing sexual offending cases, it is an important institution to study. Understanding how the cross-examination both discredits and traumatises complainants may also help in the treatment of future cases.

\section{The Legal Framework for Sexual Offending}

In New Zealand, rape is defined under section 128 of the Crimes Act 1961 (NZ) and has two requirements. Firstly, there must be a penetrative sexual connection. Secondly, the accused must have a 'reasonable belief' that the complainant had not consented.

'Reasonableness' is an objective standard. It tests what a hypothetical 'reasonable person'

\footnotetext{
${ }^{1}$ A Women's Affairs report by Triggs, Mossman, Jordan \& Kingi (2009) tracked attrition rates of sexual offending cases 2005 to 2007 . They found that of 1,955 cases $16 \%$ were brought to trial. Overall $13 \%$ concluded with pre-trial guilty pleas $(5 \%)$ and convictions $(8 \%)$.
} 
would have done and believed, rather than what a person with the accused's characteristics believed. Judges and juries use the facts of the case to decide these two elements; what was said, done, or not done will inform these decisions.

Sexual offending trials often put the complainant's testimony at the centre of the process. Firstly, in most sexual offending trials, consent or lack thereof, is the central issue. The defence counsel asserts that sexual activity occurred, but it was consensual. Secondly, her oral evidence is often the only key evidence. ${ }^{2}$ There is rarely corroborating physical evidence (Van de Zandt, 1998). Thirdly unlike the complainant, the accused is not required to testify about the offending. The accused can, and routinely does, exercise his right to silence (Bill of Rights Act 1990 (NZ), s 25(d)). As the complainant's testimony is usually the only key evidence, her character and her credibility are put under intense scrutiny.

The scrutiny faced by rape complainants is greater than witnesses to other types of crime. There is a belief that rape complainants are more likely to bring false complaints over other witnesses, even though there is no evidence to suggest this (Torrey, 1991). This attitude has been reflected throughout the justice system since the 17th century. Sir Matthew Hale referred to rape charges as 'easily to be made and hard to be proved and harder to defend by the party accused, tho' never so innocent' (Sir Matthew Hale, cited in (Gavey, 2005)). This belief, and others like it, makes it near impossible to establish in the minds of a juries and judges that a rape occurred (Torrey, 1991).

Consent becomes more of a contentious issue when the victim and perpetrator are acquainted or are in a relationship. Firstly it is a commonly accepted myth that 'real rape' is a violent attack perpetuated by a stranger (Bechhofer \& Parrot, 1991). In reality, most perpetrators are an acquaintance, friend or partner of the victim (Bechhofer \& Parrot, 1991). This type of offending is often referred to 'date rape', 'acquaintance rape' or 'partner rape. ${ }^{3}$ Secondly, partner rape occurs within in a context where consensual sex is a possibility (Bechhofer \& Parrot, 1991). There is a general presumption that consensual sex is more likely to occur between known participants. Conversely, there is a belief that people are much less likely to have consensual intercourse with strangers. As a result there is a greater emphasis in partner rape cases on the complainant's credibility and her consent.

\footnotetext{
${ }^{2}$ For simplicity, this thesis consistently attaches the feminine pronoun to complainants and the male pronoun to the accused. In all three cases studied the complainant was female and the accused male. It is acknowledged that partner rapes occur across sex and genders.

${ }^{3}$ This study uses the term 'partner rape' for consistency throughout, and because the study focusses on cases in which the alleged offender is well-known to the complainant.
} 


\section{Rape Myths in the Criminal Justice System}

Previous literature has found that a complainant's credibility is influenced by social norms about women, their relationships and their sexuality. In most cases, these social norms deny and excuse sexual offending based on how complainants should have behaved at the time of the sexual offending. The mistrust of rape complainants is therefore an ongoing issue for feminist scholars and the justice system. The common perceptions about rape victims that arise within the justice system will be discussed below.

In determining if an activity is rape in legal settings, people rely on their own knowledge and beliefs about what factors constitute non-consensual sex. Society maintains several inflexible, preconceived ideas about the circumstances of sexual offending. For example, if the victim is near other people during the alleged event, she would cry out for help; non-consensual sex is violent and leaves physical evidence behind; rape victims always tell someone about the offending straight away (Quilter, 2011). If the circumstances do not align with these preconceived ideas, the more likely it is that decision-makers judge the complaint to be false (Quilter, 2011). However, there is no evidence to support the suggestion that complainants who depart from expectations are necessarily lying (Freckelton, 1998). In reality victims have a multitude of different reactions to sexual offending that differ from these commonly-held rape beliefs (Thomas, 1994).

The misperceptions about what constitutes rape are often referred to as 'rape myths'. The term 'myth' is used because these are prejudiced, inaccurate beliefs (Burt, 1991). They prescribe a narrow set of behaviours and characteristics that 'genuine' complainants exhibit. Rape myths are more closely defined as being either descriptive or prescriptive beliefs about sexual offending that deny, downplay, or justify the sexually aggressive behaviour and/or blame victims for the sexually aggressive behaviour committed against them (Gerger, Kley, Bohner, \& Siebler, 2007).

\section{Victim-blaming.}

Victim behaviour is one aspect of rape mythology that can result in the attribution of culpability to the victim. Victims can be blamed for partaking in behaviour that is perceived as reckless or negligent. If the they drank too much, went back to the perpetrator's home, wore provocative clothes, or flirted with the perpetrator then she 'contributed' to the offending (Temkin, 2010). Two common misperceptions arise from 'irresponsible' behaviour. One is that the complainant 'deserved' what happened because they were not 
more prudent. The second is that they consented and then claimed non-consent because they later regret what happened. This belief is so prevalent that victims are known to blame themselves for the offending (Bechhofer \& Parrot, 1991). Self-blame subsequently results in victims not realising the incident as a crime.

Studies have observed victim culpability in situations where drugs and alcohol are involved. Finch \& Munro, (2005) conducted a UK study on jury decision-making using a single trial simulation and two mock juries. Participants watched the trial and deliberated on the guilt of the accused. In the scenario, two people who knew each other were at a party and ultimately engaged in intercourse. They consumed various levels of intoxicants to test the boundaries of victim culpability. The study found evidence consistent with wider findings on rape stereotypes. The mock jurors were emphatic that if she consented - regardless of how intoxicated she was and why she became intoxicated - she should not be able to retrospectively revoke consent. The mock jurors were of the opinion that women who had not monitored their drinking should bear responsibility for not taking care of herself. This attitude, again, reflects wider beliefs that women will consent to sexual activity at the time and retrospectively revoke consent out of regret. Finch \& Munro (2005) concluded that jurors might use extra-legal cultural stereotypes in their decision-making - even when the law has legislated otherwise.

\section{Complainant propensity to consent.}

Finch \& Munro (2005) also found that mock jurors were insistent on knowing the woman's sexual history. Mock jurors wanted to know if she was the 'sort of woman' who would engage in casual sex. This attitude reflects a presumption that a woman who engages in casual sex is more likely to consent in general. This type of thinking is an issue because it denies 'promiscuous' women the right to say 'no' (McDonald, 1994). Most jurisdictions, including New Zealand, have legislated to exclude sexual history evidence for this reason (Ministry of Justice, 2008). Section 44 of the Evidence Act 2006 (NZ) excludes sexual history evidence with non-defendants unless it would be substantially helpful in deciding the case.

The complainant's sexual history can usually be excluded from evidence. However, defence can sometimes find ways to align to the woman's sexuality in the courtroom. Matoesian (2001) found that defence counsel could achieve this end by citing the interactions between the accused and complainant. He analysed the Kennedy-Smith trial using conversation analysis; he identified defence counsel arguments linking the social cues 
between the accused and the complainant that may have been indicative of consensual sex. For example, evidence that the complainant was romantically interested in the accused aligns with concepts of consensual sex. The implication is that people tend to engage in consensual sexual encounters with people they find attractive.

\section{Victim's failure to prevent the crime.}

Another way of reducing witness credibility in general is to demonstrate that they did not actively resist or take action to minimise the offending. Defence counsel achieve this by emphasising where complainants did not behave like 'genuine' victims (Ehrlich, 2008). Ehrlich (2008) found that defence counsel constructed the facts of the case to make escaping and resisting realistic options. The defence then indicated that the complainant was accountable for not taking evasive action. This practice invokes a standard of victim behaviour that makes a complaint more 'genuine' and believable. Genuine victims are those who take steps to prevent or minimise the offending, such as calling to someone for help (Ehrlich, 2008).

Studies suggest that these cultural beliefs translate through to the jury room. Ellison \& Munro (2009) conducted a mock jury experiment involving nine rape mini trial reconstructions. Using a discursive approach, they found that extra-legal cultural beliefs regarding the complainant's behaviour had an impact on her credibility. Mock jurors were of the belief that there were 'normal' responses to sexual violence. They perceived that no matter the situation, a woman would, and should, try to fend off an attacker. Women who did not react in this expected manner were treated with greater suspicion.

\section{Complainant's reporting behaviours following sexual offending.}

In line with not resisting, not reporting an attack can also cast doubt on a complaint of rape. It is an unfounded social norm that 'genuine' victims report a sexual crime as soon as practicable. Van de Zandt (1998) found that defence counsel used arguments of delayed reporting to undermine the complainant's testimony. The study tracked 150 sexual assault cases through the District Court of New South Wales over a year. It found that the defence counsel made complainants accountable for delayed reporting in half of the cases. This was in spite of the fact that $81 \%$ of complainants had reported the incident within seven days.

Mock jurors also perceived that delays in reporting weaken the complainant's credibility (Ellison \& Munro, 2009). In one mock case, the complainant had waited three days before reporting. A juror stated that 'for you to sit down and plan that you are going to 
get revenge on somebody, it needs to be thought out' (Ellison \& Munro, 2009). There was therefore a perceived correlation between delaying reporting and fabricating a complaint. Some jurors had a broader awareness of factors contributing to a delay. However others frequently stated that if they were in the complainant's position, they would have called the police as soon as possible. This implies that jurors are receptive to arguments of both delayed reporting and are open to the introduction of a motive for false complaints.

Judges have also been receptive to delayed reporting arguments. Historically, judges have applied a rule of recent complaint where a complainant who reported at the nearest practicable opportunity had more credibility (Thomas, 2008). For example in $R v$ Neil [1994] 12 CRNZ 158 at 160 Eichelbaum stated that 'a prompt spontaneous complaint is likely to be true'. Conversely, a complainant who delays reporting appears less true. In Van de Zandt's (1998) study, one judge stated that it was 'common sense' and another 'normal' to report an assault at the earliest opportunity. This highlights significant judicial acceptance of myths regarding delayed reporting around that period.

In reality, a victim may hesitate before involving the police for a number of legitimate reasons. Some people tell a trusted person right away. Others keep it private out of a fear they will not be believed (Bechhofer \& Parrot, 1991). Some blame themselves and therefore do not realise it as a crime (Bechhofer \& Parrot, 1991). New Zealand reports also indicate that shame and self-blame are factors that discourage people from reporting sexual violence to the police (Mossman, MacGibbon et al., 2009). Both are legitimate ways to respond to offending and do not indicate that one victim is more genuine over the other.

There is provision in New Zealand law to counteract the prejudicial effect of delayed reporting on complainants. Judges have the power to warn a jury if there is a suggestion that the complainant delayed reporting the crime. The judge may tell the jury that there can be good reasons for the victim to delay making a complaint (Evidence Act 2006 (NZ), s 127(2)). This subverts the 'recent complaint' rule developed by judges (Thomas, 2008). However there is an argument that the beliefs are so entrenched, legislative intervention like this does not have the desired effect (Quilter, 2011).

\section{Complainant motive to falsely report.}

Failing to act on the crime can open the way for defence to introduce possible motives for fabricating complaints. Delayed reporting, lack of evidence of resistance, and other omissions provide an opportunity to incite motive. The underlying belief at the centre of this argument is that women use rape complaints as a way to effect personal gain (Jordan, 2004; 
Gavey, 2005). This thinking relies on the belief that complaints are easily made and hard to disprove. The belief is that women commonly make false complaints with ease against men for an ulterior motive (Van de Zandt, 1998).

One salient motive in rape cases is anger. This stems from the belief that women act on their emotion, in particular anger, to report rape falsely. The belief is that women are motivated by their anger to seek revenge on a man who wronged them - especially against expartners (Gavey, 2005; Jordan, 2004). Jordan (2004) found evidence for this thinking in her study of New Zealand police sexual assault reports. The study examined police perceptions of women's credibility in sexual assault complaints. Police reported a wariness of complaints toward (ex-) partners for this reason. They perceived that anger and revenge were realistic motivations for making a false complaint in these cases; that is, that women 'scorned' will lay false charges against an ex-partner to get revenge on them.

Van de Zandt (1998) found similar patterns in both defence counsel arguments and judges' summing-up. Attention was drawn to the possibility that the complainant somehow personally benefitted from a complaint. While the list was by no means exhaustive, motives cited were: to get revenge on the accused, feelings of guilt or regret after consensual sex, to evade paying money owed to the accused, to cover up adulterous behaviour and because of concurrent child custody proceedings. The suggestion is that genuine complaints are mutually exclusive from having a reason to report them. True complaints are only made in the interest of apprehending a criminal.

This thinking was exhibited recently in the New Zealand District Court in Police $v$ Taape [2012] DC LHTT CRI-2011-00002611 [11 April 2012]. A co-worker allegedly assaulted the complainant in a locker room she had been cleaning. While she was deemed credible by the judge, he said this about the complainant's veracity:

Motive is not a necessary element as far as proof is concerned, but of course if she had a motive to lie then it would be something that I would be able to use in assessing her credibility and veracity (para 29).

A woman is deemed less credible if she has a possible reason to complain aside from reporting a crime. This type of thinking lends itself to a general untrustworthiness of women in relation to sexual crimes. It reinforces the belief that rape is an easily fabricated crime pervades the justice system. 


\section{Institutional Processes and Roles in Criminal Trials}

In New Zealand the courtroom institution is set in the context of the Westminster legal system, which means that the trial is adversarial. Important principles include that the accused is innocent until proven guilty and should have the right to a fair trial (New Zealand Bill of Rights Act 1990, s25); and the accused may uphold their right to silence (New Zealand Bill of Rights Act 1990, s23(4)). The principles of natural justice, including having access to the evidence against the accused and their rights of appeal are also strongly held and applied. These principles are embodied in New Zealand legislation, including the Bill of Rights Act 1990, Criminal Procedure Act 2011 (NZ) and its associated regulations and court rules, and as discussed earlier, the Evidence Act 2006 (NZ). The salient features of the law, as it is relevant to the institutional roles and processes in cross-examination conversations are discussed below.

\section{The trial process.}

The Criminal Procedure Act 2011 (s107) sets out the general procedure of jury trials. After an introduction of the case, the prosecution calls the witness to present evidence against the accused. This is the evidence-in-chief. The purpose is to establish a case that will prove beyond reasonable doubt that the accused committed the crime. It is the prosecutor's role to assist the court; they do not provide legal representation for the complainant.

Once the evidence-in-chief is completed, the cross-examination begins. The prosecution does not receive advance warning as to the defence's lines of questioning, as this would interfere with the authenticity of the cross-examination. The purpose of the crossexamination is to allow the defence the opportunity to challenge the complainant's evidencein-chief. The accused may not personally cross-examine a sexual offence complainant. If they are representing themselves, they must have a lawyer to conduct the cross-examination (Evidence Act 2006 (NZ), s 95). The prosecution may then re-examine the witness. This is in order to question the witness on factual matters that arose during the cross-examination (Evidence Act 2006 (NZ), s 97).

\section{How complainants give evidence.}

Criminal trials take place between the Crown and the accused. The victim is not a party to the trial. In rape trials, the Crown is represented by a Crown prosecutor. The victim is referred to in court as the complainant, and in the cross-examination she takes the role of a 
witness. Having provided oral and written testimony earlier in the process, her only role in the courtroom is to provide oral evidence for the prosecution. She is there to tell a narrative that lends toward convicting the accused. When the complainant gives evidence, she may do so in one of two ways. She may speak in front of the court as a regular witness would. In sexual offending cases (usually in the presence of the jury, judge and accused). She may also have a support person near them to provide moral support (Evidence Act 2006, s79). Alternatively, she may testify and be cross-examined over CCTV that is live-streamed into the courtroom or from behind a panel (Evidence Act 2006, s116).

\section{Limitations on defence counsel questioning and admissibility of evidence.}

Defence counsel have legislative constraints on how they may conduct the crossexamination and how they may go about establishing the facts of the case. Firstly, they are limited by rules surrounding general admissibility of evidence (Evidence Act 2006). At its core, any evidence must be both relevant and reliable; this means that irrelevant and immaterial matters can be excluded. Judges ultimately decide the evidence that is admissible in any one case. Secondly, the manner of asking questions may also be limited. A judge may generally disallow any question that is improper, unfair, misleading, needlessly repetitive or expressed in language that is too complicated for the witness to understand (Evidence Act 2006 (NZ), s 85(1)).

Temkin (2000) suggests that judges have the discretion to disallow prejudicial stereotypes about complainants. She argues that rape myths mislead the court and therefore could fall under the purview of this section. The discretion of the judges is not often used in relation to limiting repeated questions or disallowing misleading evidence in sexual offending cross-examinations. Judges have expressed a concern about balancing the accused's right to an effective defence and the complainant's wellbeing (Thomas, 1994). In practice, this means that questioning is not overly restricted, even if the questioning is distressing or problematic for the complainant.

Finally, and specific to sexual offending cases, no questions may inquire about the complainant's sexual history with non-defendants without leave of a judge (Evidence Act 2006 (NZ) (s 44)). This legislation limits the potential for the court to give weight to a woman's sexual history. However if the complainant is, or was, in a sexual relationship with the defendant, then questions may be asked about their sexual history together. It should be noted that New Zealand is one of the few Western jurisdictions that still allow questions on the complainant's sexual history with the defendant. 
Overall, the perception is that there are few constraints on defence counsel questioning rules. Complainants can feel there are no limits to defence counsel questioning (Konradi, 2007). Many report feelings of being retraumatised and put on trial by the crossexamination (McDonald, 1996; Konradi, 2007). Complainants perceive that the defence asks intimate personal questions that are immaterial to the offending in order to embarrass them. They also felt angered by the defence's ability to repeat questions, as it was fatiguing and 'wore them out' (Konradi, 2007). They also felt defence used repeated questions as a means to 'trap' them in answers they'd later regret. It indicates that there is a tension between the rights of the victim and the rights of the accused when mounting their case.

\section{Calls for reform.}

Recently there have been calls for substantive reform in the prosecution of sexual offending (see McDonald \& Tinsley, 2011a). In relation to 'rape myths' and the trial process, several recommendations have been made. Tinsley (2011) recommends creating a Sexual Violence Advisory Group, which would have input in challenging rape myths within the judicial and local community. This recommendation is based on recent reform in Scotland to improve the prosecution of sexual offending. Part of this includes training courses for legal counsel who prosecute sexual offending.

Finn, McDonald \& Tinsley (2011) have also proposed that a judge alone ought to hear sexual offending trials. They consider judges with specialist training are less likely to rely on erroneous misconceptions about sexual offending. Specialists are in the best place to make accurate determinations of guilt or innocence. Alternatively, they recommend introducing lay assessors if there is concern about removing community participation from the court.

Specific to courtroom examination, McDonald and Tinsley (2011b) propose amending the Evidence Act 2006 (NZ). They recommend including a provision that the judge may disallow unduly intimidating questions. This is to address cross-examination practices that put the complainant under unnecessary stress. While cross-examination is by nature stressful, defence intimidation may in fact prevent the witness from giving the best evidence (McDonald \& Tinsley, 2011b).

\section{The Research Project}

This study uses the cross-examination of partner rape complainants to explore these issues and whether or not they are observable in proceedings. It uses audio recording 
transcripts from New Zealand District Court cross-examinations as data. Firstly, this study identifies how the defence counsel approaches questions. It identifies how participants progress the cross-examination using their version of events. This work is interested in how the defence counsel challenges the complainant and her testimony by focusing on question sequences that undermine her credibility.

This research therefore draws upon discursive psychology informed by conversation analysis as its mehodological approach. It looks at both how participants talk and how they co-evaluate and categorise the facts of the case. The purpose is to explore recurring questioning practices and defence arguments against complainants. It does so in light of common beliefs about rape and rape victims. Through doing so, it hopes to add another dimension to discussions on sexual offending. It displays both how defence ask questions in series and what inferences are housed within those questions. It also shows how complainants respond.

Secondly, this study looks at situations in which the defence counsel orients to complainants' responses as being insufficient. It follows case studies of continual disagreement and misalignment between participants. Specifically, it analyses instances of misalignment where complainants exhibit emotionality. Interview studies point to defence counsel questioning practices as a source of trauma for complainants (Konradi, 2007). This study uses conversation analysis to understand more about the nature of complainant emotionality during cross-examination. It follows series of questions where the defence counsel re-issues questions in pursuit of alignment. It also comments on complainant response design and co-occurring emotionality. 


\section{Chapter Two: Methodology in Discursive Psychology and Conversation Analysis}

Discursive psychology is an approach that treats psychology as an object - in and for interaction (Potter, 2005). It emerged from a 'crisis' in social psychology that seriously questioned the validity of experimental studies of human behaviour (Potter \& Wetherell, 1987). Instead of using experimental design, psychological topics are examined as they are observable during talk-in-interaction. This approach distinguishes it from more traditional psychological approaches that focus on technical aspects of cognitive states as they occur in the mind (Potter, 2005). In comparison, discursive psychology analyses peoples' interactions through observing how participants together display joing understanding through their talk and other communications. It focuses on the participants themselves and their actions and displays (Potter, 2005). The analysis therefore investigates how 'psychology' and 'reality' are produced, dealt with, and made relevant by the participant in, and through, those interactions (Hepburn \& Wiggins, 2004).

Discursive psychology has become increasingly interested in institutional settings (Hepburn \& Wiggins, 2004). Institutional settings are those in which there is some sort of business that participants are mutually attentive to. This includes setting such as therapy, courtrooms, doctors' consultations, police interrogations and child protection helplines (Perakyla, Antaki, Vehvilainen \& Leudar, 2008; Stokoe \& Edwards, 2008; Hepburn, 2004). The purpose of discursive psychology is to see how participants accomplish interactions and what observable practices they use to get there. In studying institutional interaction, discursive psychology has employed conversation analysis as a tool to help in understanding the interaction (Hepburn \& Wiggins, 2004).

Conversation analysis is therefore situated within discursive psychology as a method for analysing naturally occurring dialogues, commonly referred to as 'talk' (Wooffitt, 2001). It focuses on the participants' conduct and how they orient to relevant parts of the conversation; by doing so the method avoids imposing preconceived researcher frameworks onto an analysis of the interaction. Conversation analysis is therefore focused on what people do rather than who people are unless their identity becomes relevant to the conversation. Conversation analysis carries with it several base assumptions. This includes the principle that language is a basis for social action and interaction; another is that talk is highly 
organised (Wooffitt, 2001) which allows researchers to identify and explore patterns in interaction.

Over time alternative strands of discursive psychology have been developed, some of which are considered analytically at odds with each other. The two major conflicting branches are constructivism, and ethnomethodology and conversation analysis.

Constructivism came from a focus on participants' competing constructions of descriptions and versions about the world and reality (Potter, 2005). Ethnomethodology focuses on the study of practical activities and participants' conduct as they understand it (Garfinkel, 1967). Some researchers prefer a 'purer' ethnomethodological approach and are against analysing constructions (Potter, 2005). They argue that drawing upon constructions and categories risks imposing the researcher's beliefs on the analysis.

However, there is a history of researchers using participants' descriptions of people within conversation analysis. Most of this has drawn from Sacks' (1992) work on 'members' categories'. Members' Category Analysis (MCA) refers to the conversation analytic study of participant use of, and orientations to, social categories (Sacks, 1992). 'Categories' can be any person ascription such as male, female, teacher, Catholic, mechanic, young, elderly and so on. Given that a person can be described in numerous ways on any particular occasion, the analytic question arises as to why that category exists. The categories are inference-rich (Sacks, 1992) and house collective knowledge that is everybody can draw from. Amongst this knowledge are 'category-bound' activities, which is the term given to the behaviours that are tied to the category. Therefore, the analysis of category-bound activities includes their associations with a membership category.

Feminist researchers have used MCA to investigate how gender is demonstrably relevant to interactions. Stokoe \& Smithson (2001) identified how participants could invoke different sorts of gender categories to convey different classifications of females. They examined the category 'woman' and the way it relates to gender and class. In one case, participants used 'women' to describe female university students. The same speaker subsequently used 'girls' in place of 'women' when talking about customers in a 'working class pub'. They argued that even though there was no explicit explanation about the categorical difference, the change showed that 'girls' did different conversational work to 'women'. They suggested that by using these different categories of female, the speaker was likely to convey different category bound activities associated with them. 
There are potential limitations in the application of MCA relevant to the courtroom. Feminist researchers have argued that participants members categories are too limiting as English conversations rarely index categories such as race and gender explicitly (Kitzinger, 2000). Secondly, participants' categories rarely vocalise silent power discrepancies between participants such as man and woman and lawyer and witness (Billig, 1999). Neglecting the 'top-down' feature of culture can risk an analysis with few opportunities to comment on oppressive constraints (Speer, 2005). This risk is present in the courtroom. Lawyers and witnesses rarely make an explicit mention of their roles as 'lawyer' and 'witness'. However, participants in a courtroom show an orientation to these roles in the sorts of actions taken during the interaction, which are discussed in more detail next.

\section{Summary of the Discursive Psychology Methodological Approach}

This thesis is positioned within different branches of discursive psychology and uses conversation analysis to analyse how participants accomplish cross-examinations. It is interested in both how cross-examination is conducted and how participants mutually evaluate the facts of the case. It therefore adds to the discussion between conversation analysis and constructivism. This approach specifically uses conversation analysis, drawing upon participants' constructions of rape and rape victims.

Past studies have found that defence counsel draw from common misconceptions about rape and rape complainants in their arguments (Ehrlich, 2008; Matoesian, 2001). Often these misconceptions undermine the complainant as a credible witness. Drawing on MCA, descriptions of participants' member categories are used to assess the social implications of rape myths and common misconceptions about rape. The use of these tools together enables a more thorough analysis of the both the manner and content of courtroom talk. It is hoped that this study will contribute to advancing a wider debate on complainant re-traumatisation and courtroom talk that impedes the prosecution of perpetrators.

\section{Domains of Conversation Analysis Applicable in the Courtroom}

From a conversation analytic perspective, the purpose of courtroom interactions is to tell convincing factual narratives for judges and juries. It is from these narratives that the judge or jury decides the culpability of parties involved in the courtroom interaction. Therefore the business at hand in the court involves: establishing the facts of the matter, 
determining the seriousness of the crime, and ascertaining the guilt or innocence of the defendant (Komter, 2013). The prosecution and their witnesses are there to prove the defendant's guilt. The defence is there to mitigate it. This is true across all legal cases, and not only in relation to sexual offending.

The trial interaction is not rigid; turn length and turn order are not predetermined. However, the nature of the institution informs participants' roles and their actions in the courtroom (Atkinson \& Drew, 1979). In courtroom cross-examinations the institutional business is achieved through a series of question-answer interactions (Atkinson \& Drew, 1979; Dupret, 2011). The institutional roles guide the distribution of these turns. For example, as a general rule the defence counsel asks questions to elicit facts and observations relevant to the case. It is the witness' role to respond to questions to establish a factual narrative (Atkinson \& Drew, 1979).

Conversation analysis has shown how both professionals (legal counsel) and laypeople (witnesses) orient to the task at hand in the courtroom. Witnesses and counsel design their conduct around the kinds of goals they each pursue (Drew, 1992). For example, in studying interrogative questions Raymond (2003) suggests that cross-examining lawyers design their talk to best reflect their client's version of events. Conversely, witnesses display a resistance to aligning with the defence counsel's version of events (Ehrlich \& Sidnell, 2006). Participants' understandings of their goals are observable through the actions they perform to move the event forward (Heritage, 2005).

Courtroom talk is designed for a generally silent audience who decides the case. In cases of serious offending such as rape, the audience is usually a jury, but it may also be a judge. It is upon the jury to determine the accuracy and truth of the arguments made in court. They must hear, understand, and most importantly believe, one of the two versions of the events produced in court. Court participants therefore design their talk in order to be favourable to the jury (Komter, 2013: p.613-615).

While it is not possible to analyse actual jury deliberations, researchers have made some suggestions about how jurors decide a case. Garfinkel (1967) analysed jury deliberations and how they come to their decision. They decide 'the facts' of the case in relation to their common sense understandings of how the world works (Garfinkel, 1967: p.106). The 'facts' that best align with common sense knowledge are more likely to be accepted as true. There is some research to suggest that legal counsel appeal to common knowledge when examining witnesses. They show an orientation to common sense knowledge by making rich social inferences to aid the jury's decision making (Matoesian, 
2001; Drew, 1992). The benefit of using shared knowledge means the jury can understand the relevance of the facts without spelling out the details (Komter, 2013: p.616). Legal counsel can effectively speak to the jury without allowing the witness to rebut any damaging social inferences (Drew, 1992).

Having outlined how the courtroom operates as an institution, this thesis offers further explanation of the specific tools needed for analysis. Conversation analysis has identified some important domains of organisation that are fundamental to the progression of talk and the joint accomplishment of action. These include sequence organisation (Schegloff, 2007), preference (Pomerantz, 1984) and question design and courtroom practices (Atkinson \& Drew, 1979; Drew, 1990; 1992)

\section{Sequential and sequence organisation.}

Schegloff (2007) sets out the foundation of organisation of talk-in-interaction. In conversation analysis actions are accomplished in 'turns' of talk. In English, the basic shape of a turn takes the form of one or more sentences, clauses, phrases and lexical items. Grammar is one key indication of when a turn is possibly complete. Another is through observing the practices of co-participants and how they accomplish actions. Researchers observed how participants design and respond to talk; in doing so they can see what the action was and what it accomplished.

In general people wait until the end of a turn before taking up speakership and speak one at a time (Sacks, Schegloff, \& Jefferson, 1974). There are two ways a next speaker may be designated. A current speaker may address the next speaker with a turn that requires a responsive action (Schegloff, 2007). If no one is designated as a next speaker, anyone can self-select to take the next turn - including the current speaker. In courtroom crossexamination talk the turns are predominantly made up of questions and answers from defence counsel and witness. The turn after the witness' answer recurs back to the defence counsel so they may ask the next question (Komter, 2013: p.620).

In conversation analysis questions and answers are considered sequences of 'adjacency pairs' and come under the domain of 'sequence organisation'. Sequences are a vehicle for accomplishing social action (Schegloff, 2007). Schegloff and Sacks (1973) identified features of adjacency pairs. Adjacency pairs are an action that takes two paired actions to accomplish; they have several salient features. They are produced adjacent to each other, are produced by different speakers, and are ordered with a first part and second part; for example, a pair involving a question, and then a relevant response to that question. When 
there is no relevant response there is a noticeable absence. It marks a breakdown in progressivity for moving the conversation forward. Questions are 'first pair parts' and always precede answers. Answers are 'second pair parts' and produced in response to questions.

\section{Preference organisation.}

Another important concept in conversation analysis is preference organisation. When a first pair part is launched, it 'prefers' a certain answer or choice of answers. One way to observe preference is through how a speaker's turn is constructed. For example questions can be 'tilted' for certain answers depending on their formation. Raymond (2003) analysed preference in relation to yes/no questions. These are questions that make a 'yes' or 'no' answer the next relevant turn. 'Do you live at home?' prefers a 'yes' response as it is positively formulated (Do you). Conversely 'You didn't say anything?' prefers a 'no' as it is negatively formulated (You didn't). In general speakers tend to design questions to elicit confirmation. In response, recipients tend to provide answers that minimise disconfirmation.

Alignment is central to the organisation of preference. For most first pair parts, alignment occurs where the second speaker agrees or takes up the first part (Pomerantz, 1984). In general sequence organisation is conducted in such a way that acceptances and agreements are 'preferred' and rejections, declinings and disagreements are 'dispreferred'. For example, yes-no questions alignment is indexed by providing the preferred 'yes' or 'no' answer. A dispreferred response indicates the second speaker is distancing them from the speaker of the first pair part (Schlegoff, 2007).

Several features mark disagreement, disconfirmation and rejection. They are often delayed, prefaced with palliatives, and are disrupted by perturbations (Pomerantz, 1984; (Pomerantz \& Heritage, 2013). There are also varying degrees of disagreement, indicated by how the turn is constructed. Strong disagreement is indexed by exclusive disagreement components (Pomerantz, 1984). An example would be 'No, you're not dumb'. The 'no' preface indicates a speaker is explicitly disagreeing with a speaker. Partial disagreement is weaker as it includes some agreement components that partially align with the other speaker (Pomerantz, 1984).

\section{Question design.}

Question design is integral to how participants show alignment (or lack thereof) with each other. Aside from preference, another way questions constrain participants is through establishing agendas (Hayano, 2013). For example, a polar question set out two sorts of 
agendas; the topical agenda (the subject matter of the question) and the action agenda (what the speaker is doing with the question) (Hayano, 2013). For the most part, recipients conform to both agendas. However it is possible for them to align with one while misaligning with the other.

In news interviews, Heritage (2003) found that interviewees could evade a question by responding to the topical agenda, but not adhering to the action agenda. The interviewer would ask 'Do you quite like him?'. The interviewee would respond with, 'It's not a matter of likes or dislikes, it's a matter of working together'. These responses adhere to the topic (liking or not liking someone) but resist the action agenda through not conforming to the question terms (yes/no). When recipients respond in this manner, questioners often treat the answers as being inadequate. They then reissue the question in order to elicit an answer that conforms to both agendas (Clayman, 1993; Heritage, 2003).

Question design is of particular relevance in courtroom interaction. Questions are the vehicle through which courtroom business is accomplished (Atkinson \& Drew, 1979). Defence counsels ask questions in order to progress the interaction. They do so in order to test the witness' testimony. The way in which defence counsel ask questions is an important part of analysing courtroom interaction.

In conversation analysis, questions are not always defined by grammatical syntax. Rather questions are recognised as actions produced and responded to by co-participants (Schegloff, 2007: p. 7-8). In their simplest form, questions for the most part are a form of social action designed to seek information. A question such as 'Where do you live?' can grammatically be recognised as a request for information. Similarly, if a recipient responds to a prior turn as seeking information, it shows they are treating that turn as a question. By observing how speakers produce their respective turns, analysts can understand what participants are doing.

\section{Interrogatives, limited choice and tag questions.}

Defence counsel use a variety of question forms when cross-examining witnesses. For the most part typical questions are closed yes-no (Dillon, 1990). Yes-no or limited choice questions make only a small set of answers relevant. Compared to open questions such as 'What are you doing', closed yes-no questions invite only limited information from the recipient (Woodbury, 1984). By asking yes-no questions, the defence counsel can exert more control over the trajectory of the interaction. This helps ensure that the interaction focuses on the points that lend greater credibility to the defence. 
Yes-no, or limited choice, questions can put pressure on the recipient to align with them (Pomerantz, 1984: p.63-64; Schegloff, 2007). These questions are therefore considered restrictive (Raymond, 2003). A question can appear to give the recipient the right to answer using their full suite of knowledge. However it can also place constraints on their answer and can restrict the terms with which their speakership rights may be exercised (Heritage \& Raymond, 2012). For this reason, defence counsel use far more binary, or polar, questions than open questions in cross-examination (Dillon, 1990).

Some interrogatives can be heard more as assertions than simple questions. In analysing news interviews, Heritage (2002) observed that recipients treated negative interrogatives (don't you... isn't it true...) as 'taking a stance' rather than 'seeking information'. He suggested that negative question formulation was a strong way to project an expected answer. It is expected that negative-interrogatives would appear in crossexamination. Assertions and accusations are actions that the defence uses in crossexamination (Atkinson \& Drew, 1979).

Tag questions are a variant of interrogatives. They still make a 'yes/no' answer relevant. But the question is 'tagged' onto the end of a statement. Like negative interrogatives, they signal a specific attitude as well as an expected response (Kimps, 2007). This is due in part to the fact that tag questions display the questioner's level of knowledge (Heritage, 2012). They infer that the questioner knows the answer and is seeking confirmation.

Tags can also take a number of forms, such as 'truth tags' ('right?' 'correct?' 'is that true?'), 'reverse polarity tags' ('that doesn't make sense, does it?') and 'constant polarity tags' ('it's true, is it?'). A distinction can be made between reverse polarity tags 'it's true, isn't it?' and constant polarity tags 'it's true, is it?' (Kimps, 2007). Like negative interrogatives, reverse polarity tags are more assertive of the speaker's position (McGregor, 1995).

\section{Epistemic knowledge.}

Conversation analysis has found that in general participants orient to each other's rights and obligations to know things. Epistemic knowledge operates on the idea that every community to which we belong sustains a shared mutually understood culture and body of expertise (Heritage, 2013). Heritage (2013) describes epistemic knowledge as having two components: epistemic status and epistemic stance. Epistemic status refers to the participants' 
comparative access and rights to knowledge. In courtrooms, the witnesses have the best epistemic status from having seen or experienced the crime. Yet their version of events must be tested in cross-examination to ensure its veracity. The defence counsel is there to test their version of the events in cross-examination.

Epistemic stance on the other hand concerns the expression and claims to knowledge (Heritage, 2013: p.377). It can be expressed on a gradient of knowledge from shallow (less knowledgeable) to deep (more knowledgeable). In terms of question design, 'Who are were you talking to?' displays weaker epistemic stance than 'Were you talking to Steve?' (Heritage, 2012). The latter stance displays greater epistemic knowledge because the speaker can name Steve. The tag question 'You were talking to Steve, weren't you?' is even stronger, as it infers the speaker knows it to be true, and is seeking confirmation (Heritage, 2012). It is with the receipt of the claim to epistemic knowledge that we can understand how people are positioned on the epistemic gradient.

Epistemic knowledge and question design have implications for courtroom interaction. The complainant has primary epistemic access to the events having experienced them. Yet the defence counsel can presuppose and assert facts within controlling questions. An example of a presupposition is 'Do you know that Tom is ill?'. The question presupposes that Tom is ill, as the question only confirms the recipient's level of knowledge (do you know) (Ehrlich \& Sidnell, 2006). In court the defence counsel's presuppositions can be damaging descriptions that undermine the complainant's testimony. On the stand, reworking presuppositions in such a manner requires the recipient to respond outside of a 'yes' or 'no'. They also often require alternative descriptions or corrections from the recipient (Drew, 1992). Yet when witnesses respond outside of 'yes' or 'no', counsel can attempt to compel a type-conforming answer (Ehrlich \& Sidnell, 2006). Ehrlich and Sidnell (2006) found that witnesses who could avoid agreeing with presuppositions usurped control over the topical agenda in the cross-examination.

\section{Questions in series.}

In the courtroom, legal counsel progress the interaction forward using series of questions. Often, these questions build to assertions, challenges and arguments in crossexamination. Building up an accusation makes it harder to defeat with a simple 'flat denial'. They anticipate that the witness will not want to agree with the defence counsel's attempt to place culpability on them. Therefore doing preliminary work to detract from a rejection from a witness is important. If a denial cannot be produced that accounts for or addresses all of 
those facts, a witness has also failed to answer the accusation (Atkinson \& Drew, 1979). Accusations are therefore accomplished by a sequence of questions that are centred on establishing facts before an accusation is launched. The result is that the witness who wishes to deny the accusation must account for multiple components as well as address the main accusation.

An example would be legal counsels' construction of three-part lists. Drew (1990) identified that in the courtroom three-part lists are used to generalise an action, description or element of a witness' testimony. The components of three-part lists have a common property which, taken together, act as a rhetoric device that can make a generalisation about someone or something (Lakoff, 1987: p.5). One defence counsel approach is to build three individual components about a witness through a series of questions. These three components are then put to the witness in order to make a generalisation about them or their testimony.

\section{Questioning techniques: Noticing actions and omissions.}

Atkinson and Drew (1979) found that accusations are routinely designed to 'notice' failures to act. In this case the term 'notice' refers to talk in which a participant draws attention to an action or omission. In studying complaints, Schegloff (1996) argues that when participants notice an absence it highlights what is expected or normative in a situation. If the absence is in relation to someone's action, it calls them to account for their behaviour. In cross-examination the defence counsel's noticings often occur in relation to preventative actions that they could have taken (Atkinson \& Drew, 1979). It makes witness accountable for not doing more to prevent the crime.

Another observation about failures to act is that they are not all equal. Buttny (1993) reports that failures to act can either be attributed to one-off events or to a person's character. The more a person repeats this behaviour, the more attributable it is to the person. The behaviour no longer situational, rather it becomes an ascribed character trait. Personascriptions are therefore more serious failures and detrimental to a person's reputation. They suggest that a person has failed not because of a momentary lapse, but because of their faulty character (Goffman, 1981).

\section{Questioning techniques: Contrastive devices.}

Challenges to witness testimony and character are sometimes achieved through contrastive devices (Drew, 1990, 1992). Contrastive devices are a technique that involves juxtaposing two facts in order to create an inconsistency. This inconsistency poses a puzzle 
that carries with it negative inferences for the witness. An example of this came up in Drew's (1992) analysis of sexual offending cross-examination. The defence counsel contrasted the fact that the complainant had an unlisted number, but the defendant had her number at the time. This created an implied puzzle as to how he acquired her number; either the complainant gave it to him; or he got it through other means. After the complainant confirmed this implication, the problem was left unsolved for the jury; meaning the complainant does not have the turn space to reconcile the inconsistency, by accounting for it herself.

\section{Resistance techniques.}

When the defence counsel's turn is accusatory or implies blame, it can be either denied or accepted by the witness. Atkinson and Drew (1979) found that witnesses commonly resist blame accusations by minimising the effect of their actions. Witnesses attempt this through giving responses that excuse their limited agency to take action. In this way, they are able to minimise the harm to their credibility. The witness demonstrated that they could not act rather than that they chose not to act. These types of responses show the witness lacked the requisite agency to act in a manner preventative toward the crime; that is, they could not be blamed for failing to take action because of events and situations outside their control.

Another way witnesses avoid aligning with the defence's questions is through providing alternative descriptions. Drew (1992) found that rather than answer 'yes' or 'no' to the defence's interrogatives they would respond with a replacement description. This indexes the importance of word selection and repair in cross-examination. 'Repair' is defined as a practice in which participants disturb the current course of action in order to attend to possible source of 'trouble' (Sacks, Schegloff \& Jefferson, 1974). 'Trouble' is thought of in terms of issues in speaking, hearing or understanding (Kitzinger, 2013)). It includes problems with using 'wrong' words, an unavailability of a word when needed, incorrect understandings and so on (Schegloff, 1997: p.210).

Drew (1992) found a common feature of cross-examination were disagreementimplicit second pair parts. This occurs where the defence counsel launches a question containing incorrect presuppositions. The witness responds with an alternative description of the events. For example, if the defence counsel asked 'and you went to a bar?', and the complainant respond with 'it's a club', this provides an alternative description that replaces the defence's word choice 'bar'. It is likely that her correction could have something to do 
with the relative social connotations around the word 'bar' (Matoesian, 1993). People can associate bars with places in which to find romantic or sexual partners. This could explain why the witness replaced 'bar' with 'club'. Leaving the word 'bar' without repair could infer her intent to find a sexual partner that night. By doing so, it could increase the jury's perception that she had consented to sexual activity.

\section{Emotions in Conversation Analysis}

This research is also interested in displays and categorisations of emotion in the courtroom. Previous research has indicated that rape complainants self-report being retraumatised when they are witnesses in a trial. This work examines how and if emotion occurs during talk in cross-examination. Discursively, emotion is a passing, temporary state that participants can hear, understand and orient to (Ruusuvuori, 2013). This could be in the form of descriptions or categories of emotions as well as visual displays of emotion.

Edwards (1999) describes a number of ways participants can use emotion as a conversational resource. Participants can construct emotions as being either event-driven or dispositional. The distinction relates to the difference between circumstances motivating someone's anger (event-driven) and being an 'angry person' (dispositional). Emotions can also be depicted as being either controllable actions or passive reactions (Edwards, 1999). For example, between the two, passive emotion, 'I felt angry', compared to an action emotion, 'lashing out in anger'.

In terms of displays of emotional displays, this work is also interested in complainant emotionality during cross-examination. This study seeks to identify the features of the crossexamination that are associated with complainant distress and trauma. In Konradi's (2007) interview studies complainants drew attention to some features of cross-examinations that caused them distress. Complainants cited being asked detailed personal questions that made them feel embarrassed. They also reported experiencing fatigue and distress when the defence repeated questions. They were also concerned about being 'trapped' into answers they would later regret.

Crying is a relatively new area of investigation in conversation analysis. Hepburn (2004) pioneered work on crying in her research on calls to a child protection helpline as well as everyday talk. She sought to understand the management of crying in these calls. She also identified that there are some specific features and indicators for crying. Wobbly or tremolo speech can be the first marker of the onset of a crying episode. Such a speech pattern can also 
allow the speaker to talk without major disruption while also signalling distress. High pitch rises during speech can occur during talk through an episode of crying.

Hepburn and Potter's (2007) work on crying-in-interaction has looked at receipts of crying. Recipients offer various sympathetic responses ranging from minimal sympathy receipts such as 'mmm' and 'on the record' to more expressive sympathy such as 'oh my god'. When recipients are aware of another speaker's upset, they resist introducing talk that might exacerbate emotion (Hepburn \& Potter, 2007). However, it is expected that there will be minimal or no empathetic receipts from defence counsel. In an interview with rape complainants, Konradi (2007) found that a lack of respect and sympathy from the defence counsel was problematic to the interaction. This is possibly due to the nature of the courtroom institution. The defence counsel and the complainant represent different 'sides' of the interaction.

In summary, this work uses discursive psychology to study courtroom interaction by engaging conversation analysis. It seeks to understand how courtroom talk is accomplished by participants and what effects it has on complainants. To do so it draws upon general domains of conversation analysis. This includes sequential and sequence organisation, preference, question design, word selection and specific courtroom techniques. It also studies participants' descriptions of their versions of events. It comments on their evaluations and constructions in relation to broader common social beliefs about rape and rape victims. In doing so, it hopes to inform current debates about cross-examination and its effects on victims.

\section{Data Collection Method}

\section{Procedure for case selection.}

The New Zealand Judicial Research Committee was notified of this research before data collection began, explaining the purpose of this study and how the data was to be collected. Once approval was given, a search began for cases that were appropriate for this research. Preferred cases were those where the complainant and defendant were acquainted and where there was little corroborating evidence. Police, prosecutors and legal academics identified acquaintance rape cases as the hardest to prosecute. Such cases are arguably also the most susceptible to rape culture discourses. By limiting the search to these cases, the complainant's testimony becomes an integral part of the case. If the complainant and 
defendant are known to each other, the legal issue is usually constrained to reasonable belief in consent and not identification. Restricting the legal issues in this manner, the most problematic cases for prosecution were targeted.

Cases were sought in two ways. Elisabeth McDonald, Associate Professor in Law, wrote to colleagues who were Crown prosecutors and judges asking if they knew of cases that would be appropriate for this research. Case 1 was identified through a response from the presiding judge. Cases 2 and 3 were found through the Brookers and LexisNexis case database accessed through Victoria University Wellington. The searches used 'rape', 'sexual assault' and 'unlawful sexual connection' as terms to find results. All cases between 2006 and 2013 were briefly read to ascertain whether they would be appropriate. The Evidence Act 2006 (NZ) reformed the way in which sexual cases were conducted, which was why this was the earlier limit for this search. Of these cases, twenty were identified as potential cases for this research. After conferring with study co-supervisor, Elisabeth McDonald, seven were selected to pursue further as candidates for this research. For these seven cases, letters were sent to the court registrar pursuant to the Criminal Procedure Rules 2012 (NZ) outlining the purpose of the research, the proposed treatment of the data and a request for the audio and written transcripts of the complainant's cross-examination. Three letters received positive responses, and of those, the three sound transcripts were locatable by the Ministry of Justice.

This study therefore analyses three New Zealand cross-examinations of sexual offence complainants. Cases 1 and 2 lasted approximately two hours while Case 3 lasted one hour forty minutes. The participants in these cases were the judge, the defence counsel, the complainant, the prosecutor and the jury. While the jury had the ability to put a question to the complainant, this was not exercised in any of the cases. The jury was therefore a passive audience. As the complainant spoke English as a second language, the court interpreter was a participant to translate questions and responses. The complainants were all female and over the legal age to consent to sexual activity.

\section{Ethics and judge approvals.}

Even though court documents are publicly accessible, this study sought approval from the Victoria University Wellington School of Psychology Human Ethics Committee due to the sensitive nature of this data. Ethics approval was granted on the condition that all data would be anonymised and stored in a safe location (both electronically and physically) to protect the identity of the complainants. Requests were then sent to the necessary court registrars to access the cross-examinations. 
Every person has the right to access material related to court proceedings, as the records are public information (Criminal Procedure Rules 2012, reg 6.4). Any person may therefore request to access criminal court files (which include cross-examination documentation) (Criminal Procedure Rules 2012, reg 6.8).

However, in New Zealand, complainants of sexual offences are granted confidentiality and anonymity in public reporting of the crime (Criminal Procedure Act 2011, s203). Therefore, documentation of the complainant's evidence in particular is protected.

Where the document contains evidence of a complainant a judge must first permit the release of the data (Criminal Procedure Rules 2012, reg 6.9 (2-3(a)). A judge may grant or deny access depending on whether they think the release would be appropriate (reg 6.10 (1)). They may take into consideration the protection of confidentiality and privacy interests (reg 6.10 (2)(c). In this study, the names of all participants are protected; in the transcripts, the names of all natural persons have been changed according to conversation analysis convention. The data was anonymised using Audacity for Mac (ver 2.0.2) and transcribed using Microsoft Word.

\section{Case Descriptions for the Cases Studied}

The next section provides an overview of each of the three cases studied. The overviews are based on the written summaries of the cases and the information contained in the audio transcripts of the cases. Each of the case studies is given a generic title. All names given are pseudonyms. The titles are used in the analysis and discussion.

\section{Case 1: Intense Short Term Relationship.}

The complainant spoke English as a second language and had lived in New Zealand for some years prior to the sexual offending. She had yet to become conversant in English and therefore gave evidence through an interpreter during her testimony. The complainant and accused met the day before the first sexual offence took place. The previous day they had exchanged cell phone numbers and arranged for the accused to visit the complainant at her home that night. He stayed there for several hours while they talked (she used a dictionary to translate what he said). She alleged that he cried about his problems with his ex-wife. The accused alleged that she spoke about her abusive marriage to her ex-husband.

The complainant testified that while he was crying, he asked for a hug, which initiated physical contact. She then alleged that while they hugged, he pushed her into a corner of the 
couch and inserted his penis into her vagina. The complainant testified that she did not think it was a rape at that time. She also believed that as they had sex, she was now in a relationship. During the following days, she sent multiple texts to him stating that she loved him, missed him, and had a genuine interest in being in a relationship with him. However, the complainant testified at trial that she did not mean what she said in the texts. She only sent them to please the accused.

After two weeks, the complainant attempted to break up with the defendant. He responded by sending her insulting text messages. He also asked to talk in person about their relationship. After several texts, she acquiesced and agreed to speak to him at her home. He allegedly entered her home, found her in the laundry, and choked her. They went to her bedroom and the second sexual assault took place. Of the sexual offence charges, the defendant was found guilty of sexual violation by rape and two counts of violation by unlawful sexual connection.

\section{Case 2: Young Woman, First Serious Relationship.}

The complainant and accused were in a relationship for a period of time prior to the offending. Some time before the offending the accused put a photo of himself and another young woman on his social network profile page. Some of their mutual friends teased him asking if he had a new girlfriend. The complainant then asked him to take it down. Some time later the offending happened. The complainant and defendant attended a dance a fair distance from home and so made temporary overnight accommodation plans. During the dance, the accused sent a number of texts to another young woman called Kristina. The complainant was unaware of this until they got back to their accommodation.

The accused went to the bathroom when they got back. The complainant got into bed in her pyjamas and tried to go to sleep. However, the accused received several texts during this time, which caused it to vibrate. The complainant, thinking it might be something important, looked at the texts and saw they were from Kristina. She then called Kristina. The defendant then came out of the bathroom and they got into an argument. He went out to the balcony, which the complainant thought might be dangerous. She brought him inside. They got into a physical altercation that resulted in the defendant on top of the complainant. She alleged that he was choking her while the defence alleged that he was holding her for her own safety as she was out of control with anger.

This was when the sexual offending took place. The complainant alleged that she acquiesced to sexual intercourse, as she as she was scared and felt forced into it. The issue 
therefore came down to whether she consented to the sexual activity. She alleged that he made her keep the incident a secret. She therefore did not tell anyone until they broke up many months later. This was when she laid a complaint of rape.

The defence argued that she was an angry woman who had fabricated the charge and that the defence could reasonably believe that she consented to the sexual activity. He was charged with rape. The defendant was discharged under the Crimes Act s347(2): with consent of the Attorney-General, a judge may in his discretion, after perusal of the statements of the witnesses, direct that the accused be discharged.

\section{Case 3: Long-Term On-and-Off Again Relationship.}

The complainant and defendant were in a relationship for a number of years, over which time several sexual offences allegedly took place. During this period, they split up and moved back in together several times. Usually, this was at the defendant's parent's house with their infant child. After the second incident, the defendant's sister Donna - who was living at the house also - asked the complainant why she was upset. The complainant told her about the most recent alleged incident and asked Donna to tell her parent. Donna did so, but the defendant's parent did not believe her.

After this, another incident occurred at the defendant's family home. Like the other incidents, the complainant tried to push the defendant off and said 'no' repeatedly. Some days after this incident, they had an argument by text message. The defendant admitted to raping her, but said no one would believe her. This text was admitted into court as evidence.

Some time later the police heard about the potential offending through someone who was not the complainant. They then approached the complainant to see she wished to press charges. The complainant said 'no', as she and the defendant were in a relationship at the time and she did not want to get him into trouble. The defendant was also on an anger management programme and was taking steps to be a better partner and father to their child. She did not tell the police officer about the other two incidents that had happened that were not recorded in the diary.

Several months after this, the defendant and complainant had another serious argument. She left the defendant and moved to her parent's place with the help of her parent. She then spoke to the police about the four incidents that had happened throughout their relationship. She testified that she decided to tell them because she did not want him getting away with something like that. She did not report this during their relationship claiming that 
she did not have the support to leave, she had nowhere to go, and that he had both isolated her from her family. The defendant threatened to take custody of their child should she leave.

After they separated the complainant and the defendant went to the Family Court for a custody hearing. The complainant filed an affidavit seeking custody which mentioned the sexual allegations against the defendant. However, she was not allowed to discuss them at the Family Court. The defendant's criminal case for his sexual offending occurred after this.

The defence counsel argued that she had fabricated the alleged offending for two reasons. Firstly, that when the complainant had told Donna to tell her parent of one rape, it was to pressure the defendant into going on an anger management course. Secondly, that she fabricated the other incidents to gain custody of her child. The defence also argued that the sex was consensual and that the defendant had a reasonable belief in her consent.

The accused was found guilty of rape and sexual violation in relation to the one incident in which he texted her afterwards confessing that he had raped her. He was acquitted of the charges relating to the other alleged incidents. 


\section{Chapter Three: Sequential Organisation of Questioning}

Chapters three and four present the analysis for this thesis. The first of these chapters identifies recurring features of cross-examination interaction. Primarily it analyses question sequences to see how the defence frame and construct their arguments to challenge the complainant's credibility. The complainant's response to the defence counsel is also examined. Chapter four further analyses these arguments in which question-answer misalignment occurs and explores the affect this has on complainants. Conversation analysis is used understand how the participants progress through the cross-examination. Some insight is then given to the broader social constructs that relate to the participants' descriptions and constructions of the complainant.

In these cases, features of the defence's questing involved drawing attention to inconsistencies in the complainant's character or actions. Two sites are presented from which the defence founded their arguments. One is through noticing failures to act; the other is the emotional state of complainants. From these sites the defence counsel created inconsistencies and made accusations. Some of these accusations suggested the complainant's testimony was fabricated whereas others were character accusations that undermined her credibility.

\section{Failing to Leave the Offending Situation}

This section explores some features of sequential organisation in cross-examination using conversation analysis. Question and answer sequences that notice the complainant's failure to leave are examined, showing how these sequences can build to a direct challenge. Complainants' responses are also analysed and observations are made in instances where the talk shows emotionality. This is achieved by taking a conversation analytic approach to identifying emotionality in talk (Hepburn, 2004).

The following instances showcase defence counsel drawing notice to the fact that the complainant omitted to leave a situation. Noticing a witness' failure to act puts them at fault for not taking an action (Atkinson and Drew, 1979, p. 132). It indicates that there is a normative expectation for something to happen (Schegloff, 1996). By noticing an omission, the defence finds an inconsistency between the complaint and how the complainant behaved. That is, the defence counsel would highlight an instance where the complainant could have removed herself from the situation but did not. 
An example of this is presented in Extract 1, which comes from Young Woman, First Serious Relationship. It begins during a series of questions that establish the sequence of events on the night of the offending. The court had established that the accused had gone onto the balcony leading from the bedroom. At that point, the complainant followed him and pulled him back inside. In Extract 1 the defence counsel takes the complainant through a series of questions about the incident.

Extract 1 [C2P1002946: Opportunity to leave]

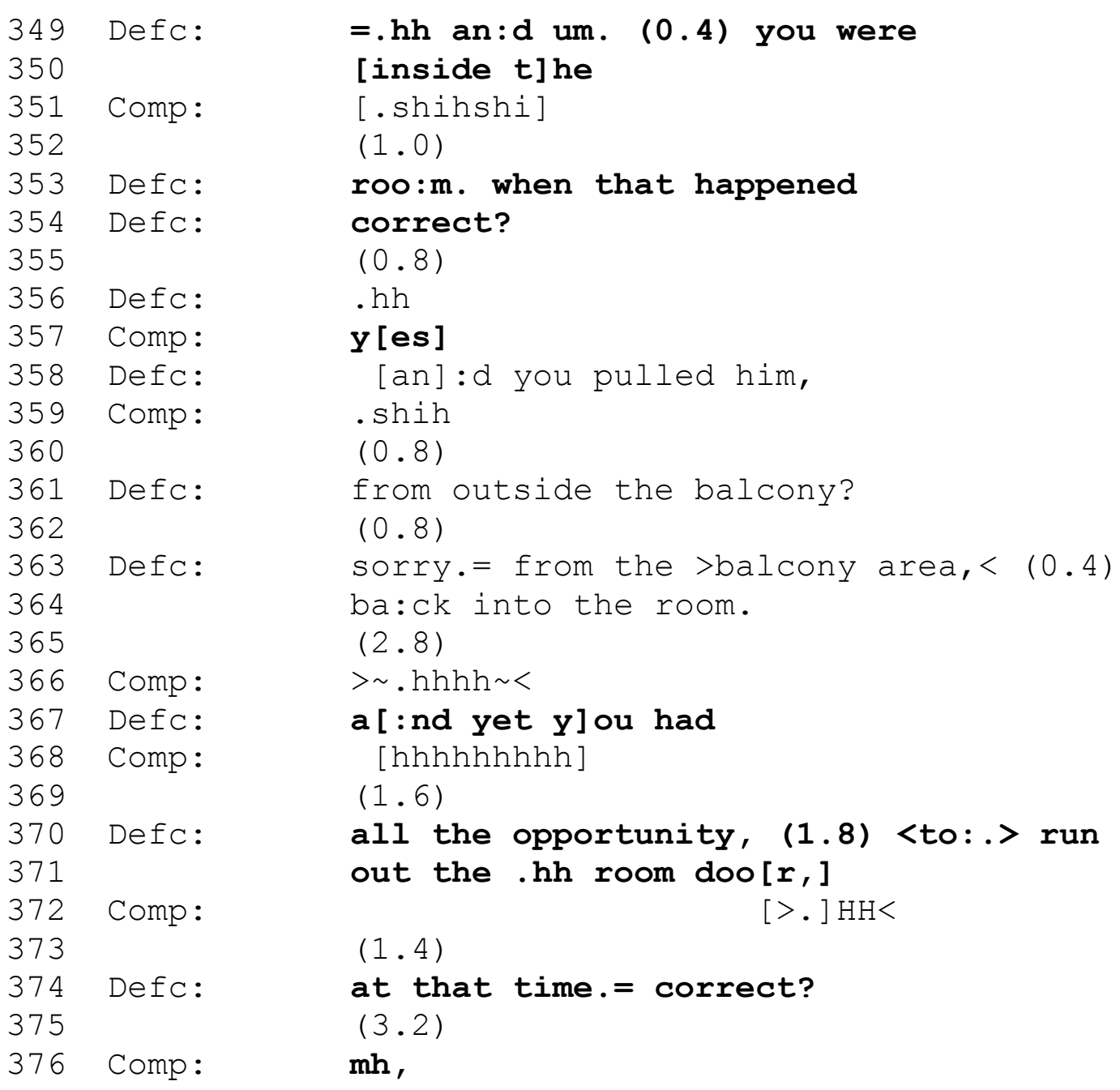

Lines 349-358 exhibit a question and answer sequence. The defence counsel launches a truth tag question. It takes the form of a statement followed by the word 'correct'. It requests confirmation from the complainant and prefers a 'yes' response. The design displays a strong epistemic stance, and indicates that the defence suspects the information to be true (Heritage, 2012). It is accomplished over three turns and establishes that when the accused 
ran onto the balcony the complainant was in the room. The complainant responds with 'yes' at line 358, which confirms the defence counsel's statement.

Having established and confirmed these statements, the defence counsel follows up with a contrastive statement. His turn begins with 'and yet', which indicates the oncoming speech is in spite of the prior sequence. He compares pulling the accused into the room with an opportunity to leave (L369-376). He does this using another truth tag (statement + correct?). This question formulation again requests confirmation and does not seek elaboration from the complainant. The complainant confirms this with bare minimal confirmation ('mh,', L378).

Not running away brings attention to a failure to act on the complainant's part. Doing so has two implications. Firstly it suggests some expectation that she could have taken this action. Secondly it presents this as a realistic option at the time; she had 'all the opportunity' to leave. In rape cases, Ehrlich (2008) also identified that the defence noticed failing to resist or call out for help in their questioning. The defence counsel retroactively constructed resistance as a viable, reasonable option. From there inferences could be made about why she did not act. Either she was culpable for not taking action to prevent the offending or had not left because she did not want to leave - suggesting the complaint had actually consented. The same inference could be drawn from not leaving when she had 'all the opportunity' to leave.

This extract shows the defence counsel proffering agreement from the complainant in two question-answer sequences. Together the sequences create an inconsistency in her actions on the night of the offending. Drew $(1990 ; 1992)$ identified this technique as a contrast device in relation to courtroom interaction; the defence counsel creates a discrepancy by juxtaposing two statements. The discrepancy challenges the complainant's testimony by highlighting a possible inconsistency in her narrative. Usually these remained as inferences for the jury to solve. Doing so denies the witness the turn space to account or explain the discrepancy.

Extract 2 will show an instance where the complainant responds to the discrepancy she is presented with. In her response she provides justification for the discrepancy. It also records an instance in which her response houses audible emotionality. Complainant emotionality is examined in more detail in chapter four. Here it is noted sequentially as a biproduct of cross-examination. The extract begins with the defence counsel further elaborating 
on the inconsistency created by the complainant's failure to act. Extract 2 takes place immediately after Extract 1.

Extract 2 [C2P1002946: Dressed to escape]

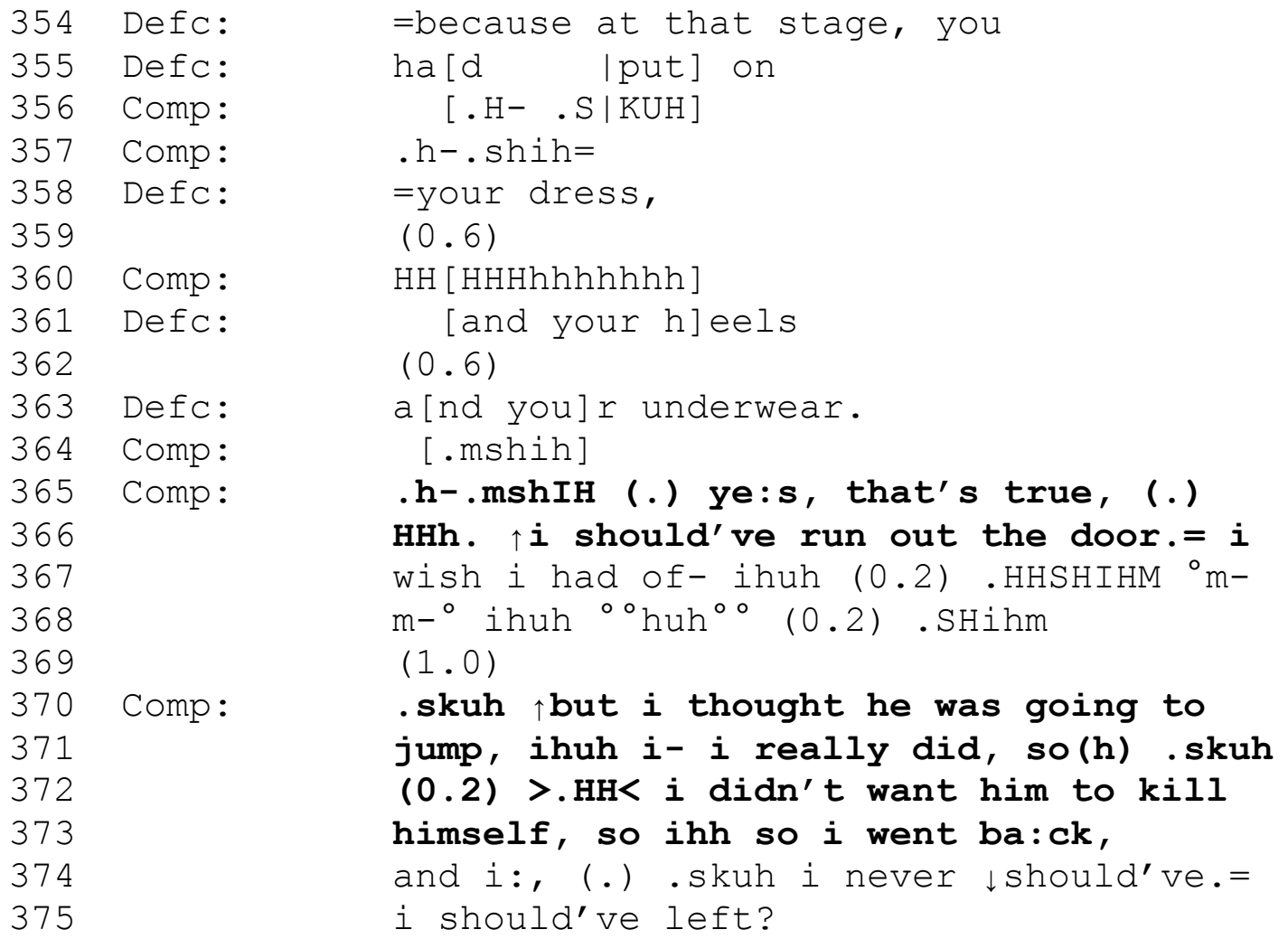

The defence counsel builds on the inconsistency in lines 354-363. He adds that the complainant was fully dressed and therefore had the means to leave. It is spoken as a statement that does not expressly request confirmation. However, confirmation becomes implicitly relevant. If recipients have the better authority over subject matter expressed in a statement, they orient to it as a request for confirmation (Heritage, 2012). This may also be reflective of the nature of the courtroom; where legal counsel ask questions and complainants provide answers.

The complainant takes multiple turns to respond. First she confirms defence's statement with 'yes, that's true'. She then states that she should have run out of the door. By doing so she concedes that she failed to act where there was an opportunity to do so. It is followed by a series of sniffs and quiet sobbing. This indicates that at this point in Extract 2 she is experiencing elevated emotion. It comes just after a concession in her testimony that she should have acted in order to leave the person who raped her. 
The complainant then takes another turn to account for her omission; she stayed because she thought the accused was going to kill himself. This account excuses her omission on the basis that there was a greater problem at hand. She presents the opportunity differently from the defence's construction and highlights a barrier to leaving. However, the complainant also acknowledges to the court that she made an incorrect choice in staying.

Extracts 1 and 2 discuss the principle foundations of cross-examination; questionanswer and accusation-denial sequences. It shows how the defence counsel formulates questions that only request confirmation. In these extracts a factual background is created that highlights a failure to act on the complainant's part. Together, the defence creates a discrepancy from the complainant's readiness to leave, and her omission to do so. This indicates an inferential inconsistency between the complainant's actions and her testimony. She is claiming that she was in a situation where she was assaulted, yet did not behave in a manner consistent with being in danger (i.e., running away from a potentially dangerous situation).

In Young Woman, First Serious Relationship, the complainant's failure was immediately and temporally related to the sexual offending. However in Long-Term, On-andOff Again Relationship the complainant's failure to leave was raised in the broader context and timeframes of their relationship; and therefore not directly temporal to the offending. During the relationship, the complainant developed a pattern where she left the accused and then got back together with him. The complainant often did this with her parent's support. This pattern becomes the basis of a challenge that the counsel puts to the complainant.

Prior to Extract 3, the defence counsel questions her on one count of rape. He suggests that she had told the defendant's parent about a rape to pressure the defendant to attend an anger management course. She had acknowledged that she did want him to do the course, but that her primary goal was to leave him. Extract 3 begins from there. It shows how inconsistencies can lead to explicit accusations.

Extract 3 [C3P1004650: Ring up parent]

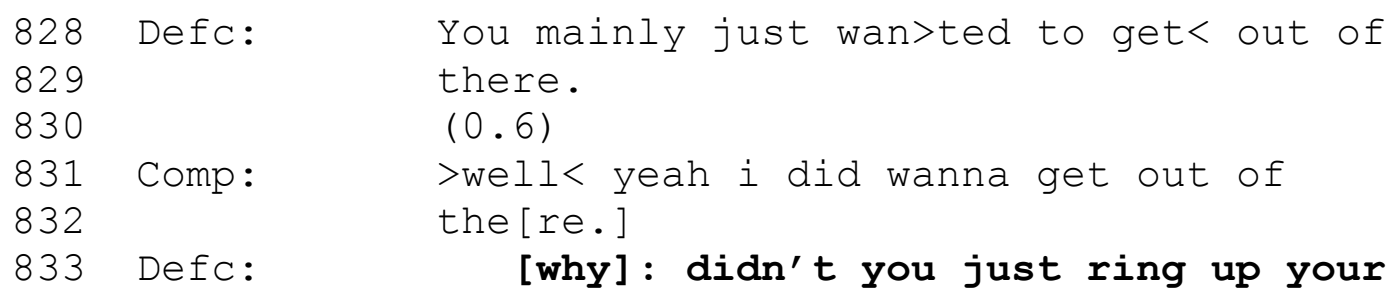


mum and leave.

$$
\text { (0.4) }
$$

Defc:

li[ke you did before. ]

Comp : [because $i$ wasn't talk]ing, i wasn't talking to my \#mum\# at that $\uparrow$ point $(0.2)$

Defc: but you ha:d

$(4.6)$

Defc: $\quad$ you could've left at any time. $(0.6)$

Comp: $\quad i$ didn't hrave any support to get \#out\# and I was $t \uparrow o l d$ that if I lefthe would take our child off me:, and $i$ would never see them again.=

In Extract 3, the defence counsel uses a similar sequential pattern seen in the first two extracts to mount an accusation. By performing a full repeat of the complainant's previous turn 'you mainly just wanted to get out of there' in lines 828-829 (not shown in this extract). This is another statement that makes the recipient's confirmation relevant. Relative to the defence counsel, she has primary access to her internal states of being - such as 'wanting'. She confirms this with two turns at line 831-832.

Once the complainant confirms that she wanted 'get out of there', the defence counsel notices a failure to act. The question takes the form of a wh-question 'why didn't you just ring up your mum and leave?' (L833). This notices an absence founded in her previous turn. It calls her to account for the discrepancy between her wanting to leave and omission to leave. The defence makes her culpable for not acting in a manner consistent with her wants. The defence counsel further adds an increment at lines 836 'like you did before'. The increment builds the facticity of his observation. It uses her precedent for leaving to construct it as a viable option.

The increment is produced in overlap with the complainant's account: 'because I wasn't talking, I wasn't talking to my mum at that point'. Her account excuses her failure by explaining that her parent was not available; it was a matter of not being able to call her parent - as opposed to choosing not to call them. This minimises her agency to act; it was a lack of resources, not a failure on her part. Atkinson and Drew (1979) found that excuses are an account in courtroom talk. They often limit the witness' agency and diminish their ability to act. Like Extract 2, this emotion comes during an account after the defence noticed a 
failure to leave a situation. There are signs of early stages of emotion with a croaky voice around \#mum\# and a raised pitch at 'point'.

After abandoning a turn at L840 the defence counsel launches an accusation: 'You could've left at any time'. It rejects the complainant's account that she could not leave due to her circumstances. It denies her the excuse that her circumstances prevented her from acting. The complainant responds in lines $844-847$ by providing another account. First she restates that she did not have any support to get out. Then she adds another component to her account; that the accused would assume custody of her child. It is another excuse that restricts her capacity to act. The threat of losing her child reduced her agency to take action.

Her second account is also produced with audible emotionality. She speaks with a wobbly voice through her statement: I didn't have any support to get \#out\#. Hepburn (2004) found that tremolo speaking can precede crying. Her next turn is also spoken at a higher pitch, which can indicate speaking in spite of crying (Hepburn, 2004). It is worth noting that complainants can blame themselves for the offending (Bechhofer \& Parrot, 1991; Thomas, 1994). Sometimes victims blame themselves for not doing more to prevent the offending. In Extracts 1-3 the complainant displays emotion during failures to escape or negate a situation they did not want to be in. In particular, the complainant's concession along with her emotionality in Extract 2 is consistent with self-blame. It is therefore possible that the failure to act, and her acceptance of responsibility for failing to leave, is driving her emotions in this situation. However, as mentioned courtroom emotionality will be discussed in more detail in chapter four.

In summary, Extracts 1-3 demonstrate the key features of defence counsel questioning. In particular they also show the question-answer sequences used in crossexamination to identify inconsistencies. Firstly, the defence counsel launches first pair parts that request confirmation. Once the complainant confirms, the defence contrasts this with a failure to act. These failures to act indicate an inconsistency with the complainant's actions. In both these cases, the sequences relate to a failure to either leave the situation or leave the relationship. 


\section{Failure to Tell, and Delayed Reporting to Police}

The prior section showed some of the basic question-answer and accusation sequences. This section will include an analysis of other features of defence questioning used to build an argument against the complainant. It focuses on further types of failure to act that are apparent in defence counsel's questioning, including instances where the complainant had failed to report or tell someone about the offending. This happened in two of the three cases in this study. In both of these cases the complainant went to the police once the relationship ended - sometime after the alleged offending took place. These examples show a failure to tell, and are used in relation to having motive to complain. Together they can bolster an accusation that the complaint is false.

The first example in Extract 4 is taken from Long-Term On-and-Off Again Relationship. The defence counsel refers the complainant to one of the alleged violent rapes. He then asks her to confirm that she did not tell anyone. Prior to this extract, the defence counsel asks the complainant if the accused raped her. She confirms this with 'yep'. The extract picks up from there.

Extract 4 [C3P2000612: Violent offending]

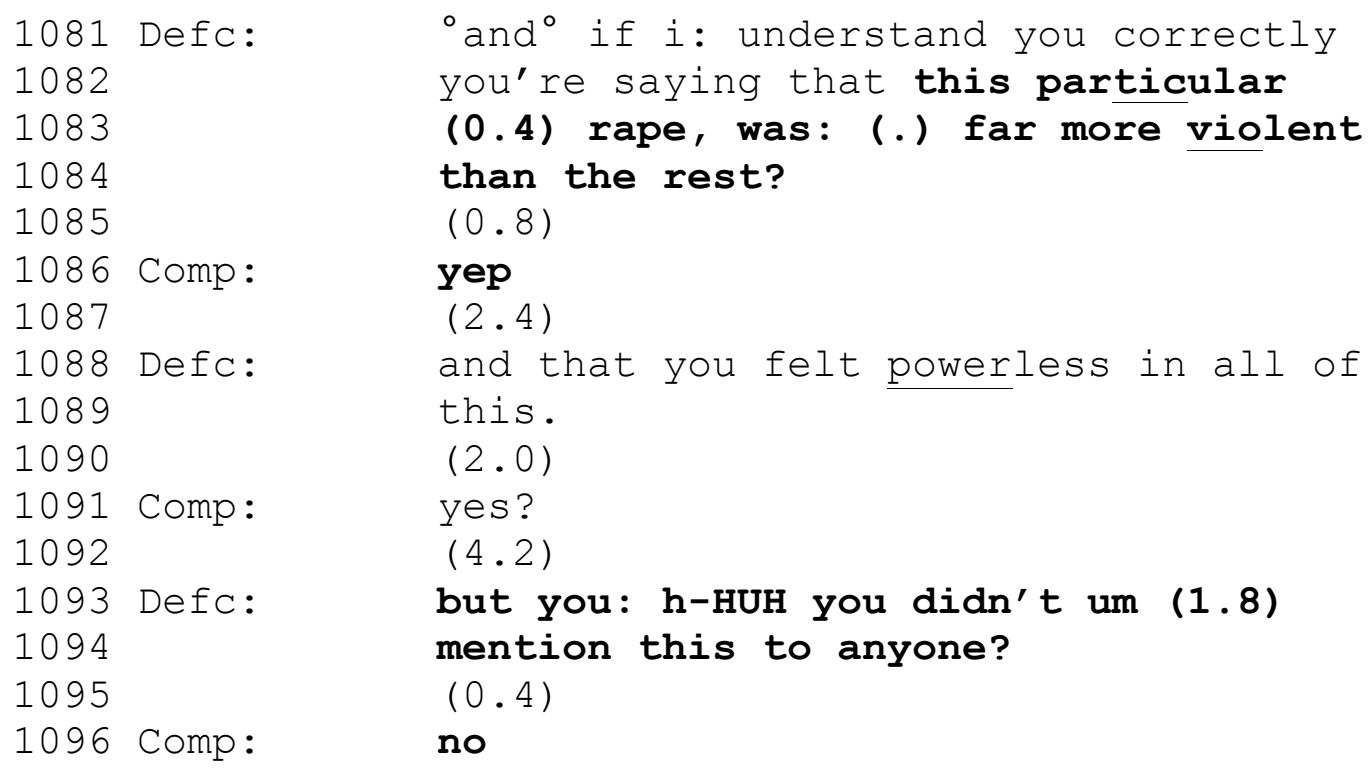

Like Extracts 1-3 the defence makes statements for the complainant to confirm before drawing attention to a failure to act. First he requests confirmation that the rape was 'far more 
violent than the rest' (L1081-1084). The complainant provides confirmation at line 1086. It establishes the first part of the contrastive device.

The defence counsel makes another statement that requests confirmation. He states that she felt powerless in all of this. It is another instance where the recipient has greater epistemic access to confirm the subject matter (Heritage, 2012). She subsequently confirms the statement at line 1091. Once the complainant provides confirmation, the defence concludes the contrastive device by noticing a failure to act: 'but you didn't tell anyone' (L1093-1095). It is negatively formulated statement that implicitly requests confirmation. Statements like these exert a firm epistemic stance, as speaker displays that they suspect the statement to be true (Heritage, 2013).

This illustrates another example of contrastive devices used in the courtroom. The defence counsel juxtaposed a violent rape where the complainant felt powerless with not telling anyone. There are two things to note about the formulation. Firstly, by noticing an absence the defence counsel indicates that there is a normative expectation to tell people about violent offending. Secondly, as a result it constructs an inconsistency between the complainant's behaviour and the facts of the case. It therefore undermines her testimony.

By drawing attention to this absence, the defence constructs the complainant's omission as deviant from normative behaviour. The same contrast is observed in Young Woman, First Serious Relationship. This shows that puzzles inferences regarding failures to tell someone took place in more than one case. In Extract 5, the defence contrasts the complainant's proximity to other people with her omission to tell someone about the offending. Prior to this extract the defence counsel asks the complainant if she was living at home at the time of the offending. The complainant has a problem with hearing him and asks him to repeat the question.

Extract 5 [C3P1001857: Living at home]

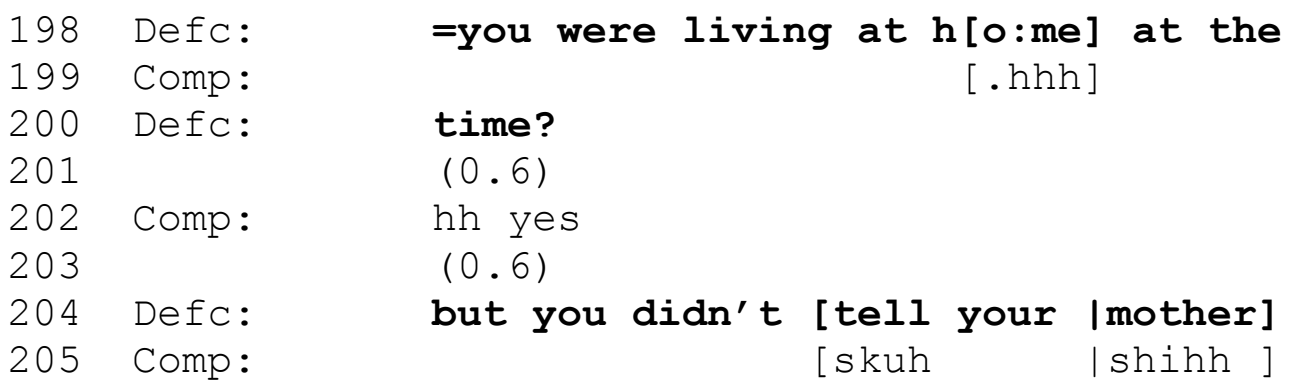




$\begin{array}{lll}206 & & (.) \\ 207 & \text { Comp: } & { }^{\circ h i h}{ }^{\circ} \\ 208 & & (1.2) \\ 209 & \text { Comp: } & \text { hm. }\end{array}$

As with the previous extracts, the defence makes a declarative statement that implicitly requests confirmation. (L198-200). It establishes the first part of the contrast: the complainant was living at home. Once the complainant confirms this statement, the defence counsel utters the second half of the contrastive device. He notices that she did not tell her mother (L204). The defence contrasts 'living at home' as being inconsistent with 'not telling her mother'. It is another example of a discrepancy founded in a failure to tell. As mentioned, noticing an absence suggests the complainant deviated from a normative course of action. In this case, it is inferred that if you live at home with other people you would tell someone about an assault. As mentioned, Drew (1992) observed that contrasts are usually left as inferences for the jury to solve. However, in Extract 6 the defence counsel in First Serious Relationship later made inconsistency explicit in his questioning. This shows exactly what work the defence counsel did with the contrastive device in Extract 5; there is an expectation that victims of sexual assault will tell someone they trust about sexual violence.

Extract 6 is also taken from 'Young Woman, First Serious Relationship'. It takes place about half an hour after Extract 5. Prior to Extract 6, the defence counsel restated the fact that the complainant failed to tell her mother. He established two facts: a) that the complainant has a good relationship with her mother and b) that she didn't tell her. The extract picks up from there, where he begins with 'don't you think that's inconsistent'.

Extract 6 [C2P200738: Great relationship with mother]

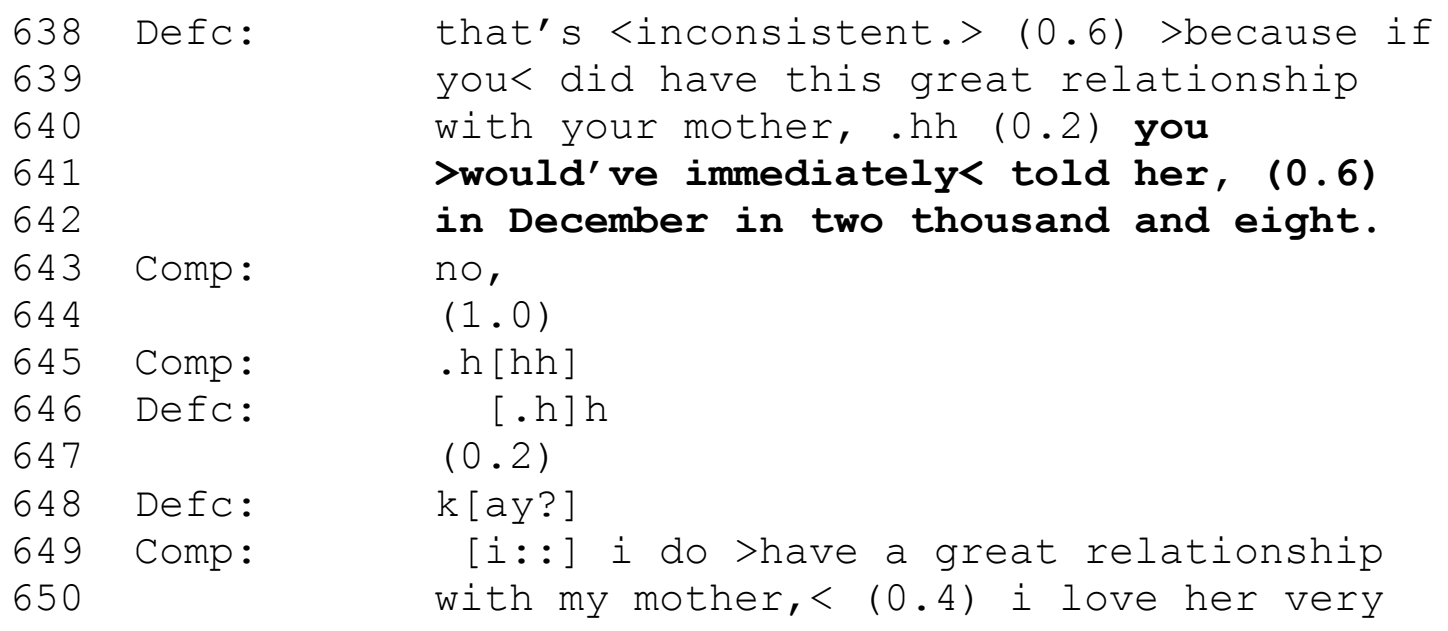


Extract 6 begins with the defence counsel drawing attention to the complainant's actions as being inconsistent. He states that it is inconsistent and then goes on describe why this is the case; that if she had a great relationship with her mother she would have immediately told her (L638-642). It adds another dimension to failing to tell: if a victim has a great relationship with someone, they will confide in them about the offending. The complainant responds saying 'no', which explicitly disagrees with the defence counsel's suggestion. Following this at line 649 she takes a series of turns to account for and rebut the defence's statement.

The complainant's turns have two components. First, she states that she has a great relationship with her mother and that she loves her. This rebuts the possible inference that she does not love her mother. Secondly, she gives an excuse for not telling her mother. She states that the accused would not let her tell anyone. Her account therefore seeks to shift responsibility for not telling someone back onto the accused. Like other accounts it reduces her agency to act - meaning she could not act rather than that she chose not to act. This extract illustrates the expectation that victims of sexual crimes immediately tell a trusted person.

The next two extracts show how failing to act is associated with having a motive to falsely complain. Atkinson and Drew (1979) first identified how defence counsel can do work to establish background facts before making an accusation. This practice makes accusations harder to rebut. The witness must address multiple points in order to successfully respond to the legal counsel. In On-And-Off-Again Relationship the defence counsel connected failing to complain and motive to complain with an accusation of false complaint. Extracts 7 will show the defence using motive in order to found an accusation. Extract 8 shows how failing to complain bolsters having an ulterior motive to report a crime.

As mentioned, Extracts 7 and 8 come from Long-Term On-and-Off Again Relationship. Prior to the extract the defence counsel made a suggestion to the complainant. He stated that the complainant told the accused's mother about the offending to pressure the accused into doing an anger management course rather than just disclosing the rape to her.

Extract 7 [C3P1004345: Anger management course]

777 Defc: $\quad>$ well< he didn't wanna do the course 
791 Comp:

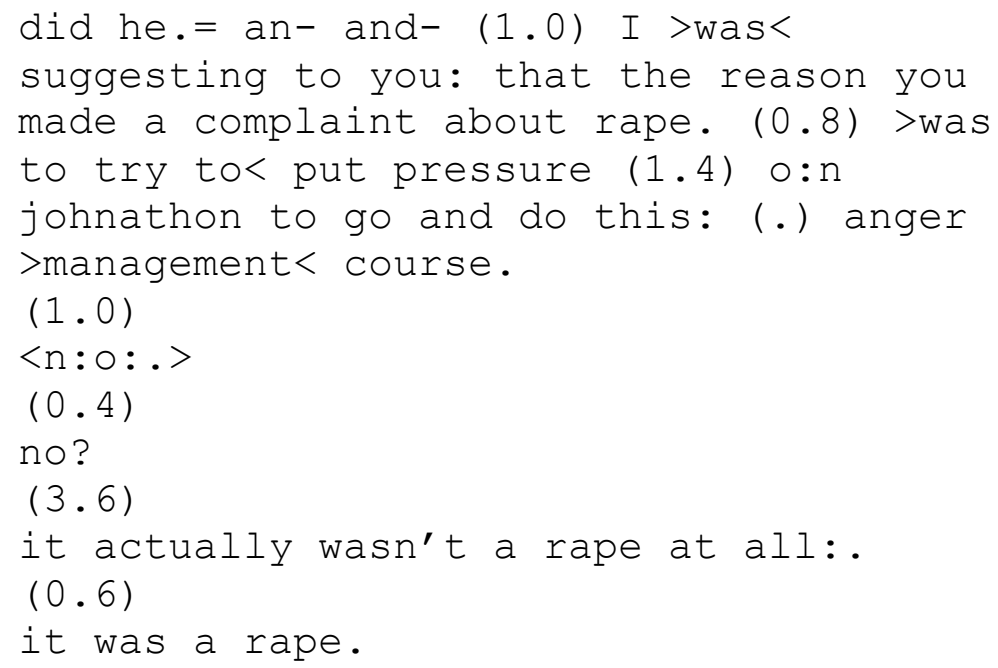

The defence counsel launches a reverse polarity tag question 'well he didn't wanna do the course did he'. Reverse polarity tags are questions that begin with one polarity ('he didn't') and end on another ('did he') (McGregor, 1995). Like other questions shown here, it only requests confirmation; however the defence does not wait for a response before continuing. Instead he refers back to a suggestion he had put to the complainant earlier. He suggested that the reason she complained was to pressure the accused to go on an anger management course.

The complainant disagrees by saying 'no', which is a dispreferred response (L785). The defence subsequently repeats her lexical turn and then launches an accusation (L787789). The accusation is that no rape occurred. It appears to be founded in the complainant using rape to pressure the accused into doing a course and therefore seems to ignore the complainant's denial. Defence's accusation infers that having an ostensible reason to report a rape is indicative of a false complaint. Together they suggest that the complainant fabricated the complaint in order to pressure the accused into attending the course.

The complainant responds with a flat denial by stating that it was a rape (L791). The defence follows up by appearing to re-frame his accusation. This is shown below in Extract 8 . Extract 8 takes place directly after Extract 7 . The defence counsel uses delayed reporting in conjunction with a second reason for making a complaint. This illustrates the connection between delayed reporting, motive and accusations of false complaint.

Extract 8 [C3P1004650: Child custody] 


$\begin{array}{ll}848 \text { Defc: } & \text { right. } y^{-} y^{-} \text {you- you never complained } \\ 849 & (0.2) \text { <about }(0.6) \text { ra:pe until after } \\ 850 & \text { you separated and (.) you then used } \\ 851 & \text { these allegations of rape (0.4) in the } \\ 852 & \text { family court case to get custody.= } \\ 853 & \text { didn't you. } \\ 854 & (1.2) \\ 855 \text { Comp: } & \text { we weren't allo\#wed\# to discuss that in } \\ 856 & \text { the f\#amily court?\# }\end{array}$

The defence counsel launches a negative polarity tag question containing two components; 1) the complainant never complained (to the police) until after they separated and 2) that she used the allegations in the family court. The two statements together notice a failure to act coupled with a personal motive for complaining. Together, they infer that the complainant did not complain until it would personally benefit her. The subsequent tag question 'didn't you?' requests blanket confirmation for both of these statements.

The complainant responds by implicitly disagreeing with the defence counsel (L856). She states that she was not allowed to discuss the allegations in the family court. It suggests that the allegations were not beneficial to her in the hearing. It corrects the defence counsel's presupposition that she used them successfully as evidence in the family court. Drew (1992) identified this implicit disagreement in his analysis of cross-examination. In his data complainants would answer with alternative descriptions in order to avoid confirming questions or to correct presuppositions that discredit them. In this extract, she avoids confirming that she brought the allegation to obtain custody of her children. She does this by stating that she could not use them in the family court. She therefore minimises the alleged motive.

To briefly sum up, this research found that the defence created inconsistencies from the complainant's failure to act. They did so by creating a discrepancy from two or more facts, which were confirmed by the complainant. This included the fact that the complainant lived at home, but she did not tell her mother. Noticing a failure illustrated a normative expectation for victims to disclose the crime. However when they did tell someone, the defence counsel used this to suggest the disclosure was motivated by personal gain. In OnAnd-Off-Again relationship the defence used both of these facts - that the complainant had an ulterior motive and did not disclose the crime to the police - as a basis for claiming the complaint was false. 


\section{Emotion Categories in Defence Questioning and Accusations}

This research identifies that inconsistencies are also formed using categories and descriptions of emotion, illustrating another way the defence counsel uses contrastive devices to challenge the complainant. The next analysis looks at defence counsel uses of emotion categories to create an inconsistency in the complainant's testimony. The inconsistency is similarly used to found an accusation that the complaint is false. This study also finds that emotion categories and descriptions are used to make accusations toward the complainant's character.

\section{Inconsistent emotions.}

Extract 9 and 10 show the clearest example of the defence using emotions as the basis for an inconsistency. The defence counsel constructs the complainant's expressions of happiness for someone who assaulted her as inconsistent. They then use this to allege that the complaint is fabricated (Extract 10). Extract 9 comes from Long-Term On-and-Off Again Relationship. It takes place during a line of questioning on a sentimental card the complainant gave the defendant. This occurred after the alleged offending. In the card the complainant expressed that she was happy and desired more children with the accused. The defence counsel uses these statements to found an inconsistency.

Extract 9 [C3P2000923: Sentimental card (1)]

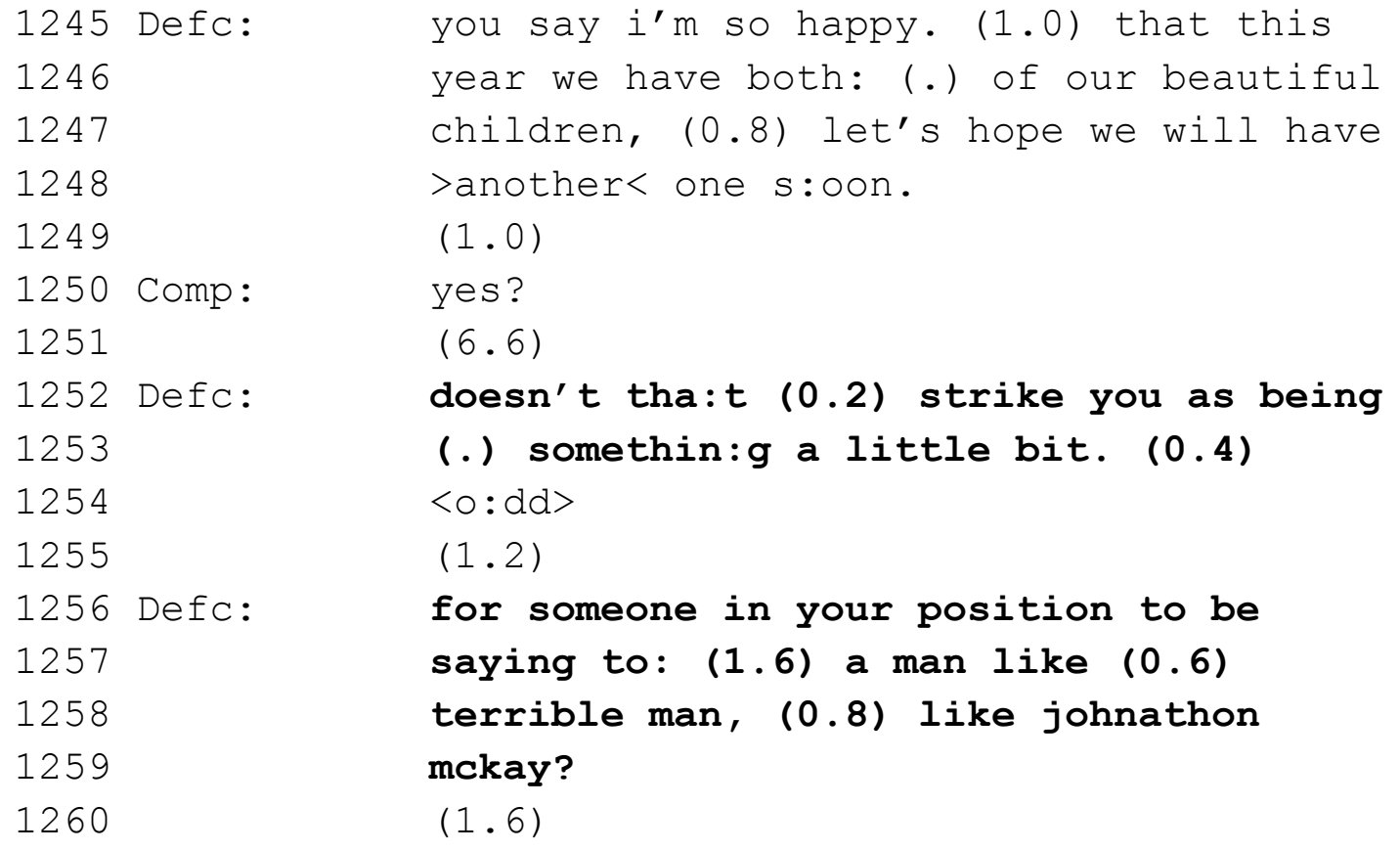




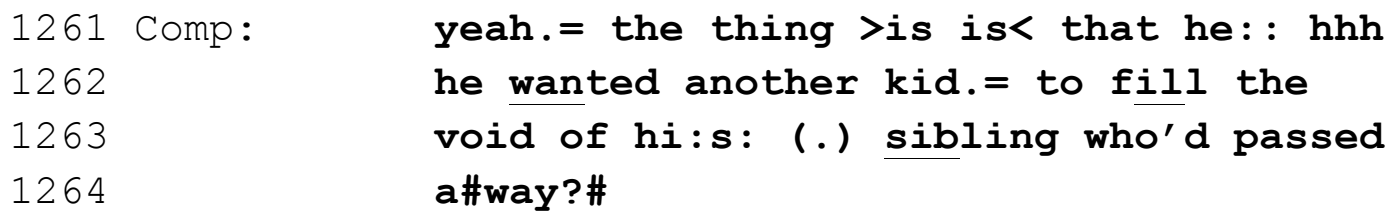

First the defence counsel reports the writing in the card. It contains two pieces of information: that the complainant is happy and desires another child with the accused. The complainant orients to this as a statement requiring confirmation; she confirms the contents at line 1250. After she provides confirmation, the defence counsel launches a negative interrogative question ('doesn't that...'). Heritage (2002) found that recipients can orient to negative interrogatives as assertions, rather than requests for information. The negative interrogative describes the card contents as 'odd' to say to a 'terrible man'. The repair from 'a man like' to 'terrible man' indicates that 'terrible' is necessary to construct the description of the accused. It creates juxtaposition between being happy with someone who is terrible.

The complainant orients to the negative interrogative as an assertion that requires an account. She first agrees with the defence counsel - conceding that the card contents are odd. Then she takes another turn to account for the discrepancy. She uses the accused's desire for another child to justify the discrepancy.

This extract shows the defence counsel using the fact of saying she was happy and wanted a child as a contradictory statement to say to a 'terrible man'. The complainant creates an account by saying that she wrote it in order to align with the accused's desire for a child. The discrepancy presupposes that happiness is an inconsistent feeling for a rape victim to have towards their alleged rapist. It implicitly challenges the veracity of the rape claim. However Gavey (2005) notes that women do emotion work like this to protect the feelings of their partners. The complainant seems to align with this research by using the accused's feelings to account for what she wrote in the card.

Extract 10 occurs directly after Extract 9 and shows how the defence follows up this line of questioning. The defence counsel specifically refers to the category 'happy' once more. He then accuses the complainant of bringing an unfounded rape claim. Again, the inconsistency comes from the complainant being happy with someone who had allegedly assaulted her.

Extract 10 [C3P2001242: Sentimental card (2)]

1271 Defc: an:d u-HUH that ca:rd reco:rds (1.4) 
1274 Comp:

1275

1276

1277 Defc:

1278 Comp:

1279 Defc:

1280

1281 Defc:

1282

1283

1284

1285 Comp:

1286

1287

1288 Comp:

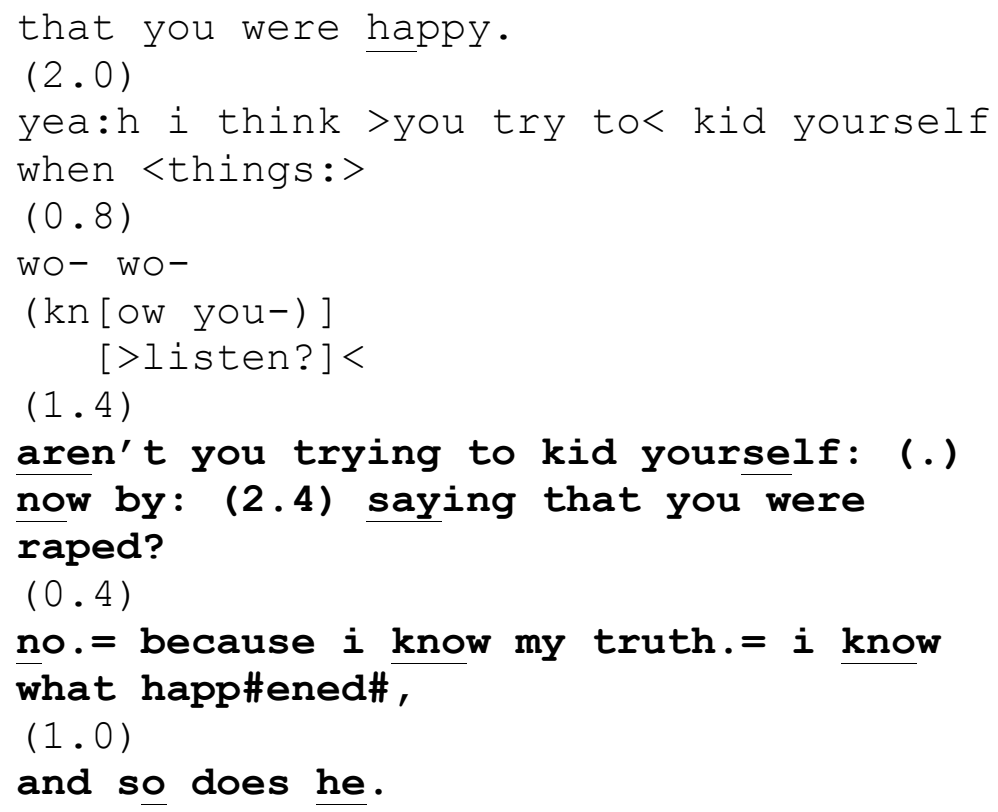

In his first turn, the defence restates that the card recorded that she was happy. At line 1274 the complainant provides confirmation and another account. Her account appears to be the first half of an excuse. She states that she tried to 'kid' herself when things (are bad). However she does not complete her turn.

The defence counsel does not wait until she has finished her account. He self-selects in overlap with her at lines 1277-1279. The overlap is resolved when they both drop out; the defence then self-selects to launch an accusation. The accusation is formed as an interrogative with a negative preface ('aren't you', L1281) (Heritage, 2002). The defence counsel uses the complainant's admission that she 'kid(s) herself' to reinforce an accusation is that she is deluded about the offending.

The complainant denies the accusation that she is kidding herself. She asserts that she knows 'her truth' and she knows what happened; in other words, she knows that she was raped. She then takes another turn to add 'and so does he'. This asserts her epistemic authority over both the defence counsel and the accused. She claims that that she knows what happened and she knows the accused knows what happened.

Together, Extracts 9 and 10 show another way the defence mounts an accusation. The defence used an emotion category as part of a contrast device. The contrast device then served as a foundation for mounting an accusation. The defence asserted that it is inconsistent for the complainant to feel happiness towards some who had allegedly raped her. The temporal context is important here. The defence constructs liking the accused after the 
alleged assault as being particularly contradictory; the inference is that it is inconsistent for the complainant to express romantic feelings for her partner that allegedly raped her.

\section{Excessive emotion.}

Other emotion categories are also used to make a different sort of accusation. The defence uses categories such as 'hate' and 'anger' to make character accusations against the complainant. Legal practitioners comment on the ease with which the defence can undermine the complainant's character (Mossman, MacGibbon et al., 2009). This research is therefore also interested in how the defence categorise and construct the complainant's character. As will be shown, the purpose of 'excessive' emotions in defence arguments is not immediately obvious. For example, they are not used to create contrastive devices or to accuse the complainant of making a false complaint. Rather, defence uses this to categorise the complainant as a certain type of person.

Extract 11 is taken from Long-Term, On-and-Off Again Relationship. The defence counsel asks the complainant about text messages she sent to the accused. The context for the texts is that she and the accused had gotten into an argument about groceries. They ended with the complainant texting 'I fucking hate you' to the accused. The defence uses those texts to found a character accusation based on the argument of 'excessive' emotion.

Extract 11 [C3P1001717: Ferocious woman]

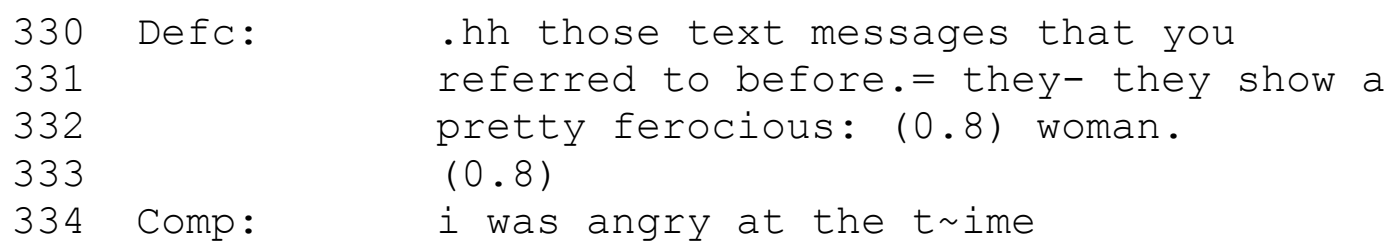

The defence counsel makes an assessment of the complainant over lines 330-332. He uses the previous texts to evaluate and construct the complainant as a 'ferocious woman'. The description includes both her mentality ('ferocious') and her gender ('woman') (L332). The (0.8) second pause at line 332 could indicate a word selection problem. It could indicate a problem with categorising the complainant. When gendered words in self-repair it could indicate that gender is doing work (Stokoe \& Smithson, 2001). Here the defence counsel chose 'woman' over other categories such as 'person'; indicating that her gender may be 
relevant to the assessment. Woman is also a relatively stable state of being. By attaching 'ferocious' to that category, it shows that she has a general disposition to be ferocious.

The complainant responds at line 334 by reworking the defence's dispositional description. Her response conforms to the topical agenda of her emotions (Heritage, 2003; Hayano, 2013). However it resists the question constraints by providing an alternative description. As mentioned, Drew (1992) found that this was a technique witnesses use to rework presuppositions without expressly indexing disagreement. She provides an alternative description of her emotion as being 'angry at the time'. This simultaneously downgrades her emotion and isolates it to a moment in time. By restricting her emotion, she resists anger as being a dispositional character trait. This question-answer sequence also occurred in Intense Short Term Relationship (Extract 12). The defence counsel constructs the complainant has having an excessive disposition for hating men. The complainant responds by isolating her emotion to a moment in time. Prior to Extract 12 the defence counsel had asked the complainant about texts she and the accused sent to each other during their break-up. The complainant had finished her series of texts with one that said, 'I hate men'. These texts were sent after the first sexual offence but before the second. The defence counsel confirms that she sent this text, which is where Extract 12 begins.

Extract 12 [C1P2005724: I Hate Men]

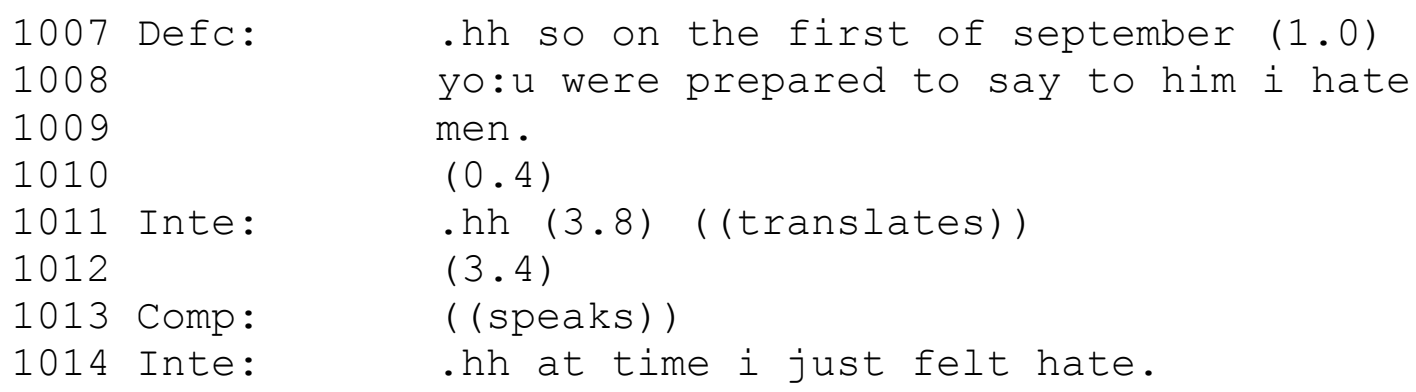

The defence counsel's first turn constructs the complainant as excessive by having a general hatred of men. Firstly, the defence's use of 'prepared' indicates a readiness to take an extreme action. Secondly, he cites that she said 'I hate men', inferring that the complainant has a hatred against men in general - not just the accused. The complainant orients to the statement by resisting its 'excessiveness'. She downgrades her hatred to a particular moment in time. 
In Extract 11, the character description is based on texts the complainant sent the accused. In Extract 12 the defence similarly portrays the complainant's 'hate' for all men as being an excessive statement to make in a text message. There are two observations to be made about the defence's character assessment. The assessment is founded in observable actions, which build up the facticity and they also demonstrate that the complainant had acted on her anger. Edward (1999) reported that emotions can be either passive or controlled. In both these cases the defence counsel links emotions such as 'angry' and 'hate' to the action of sending text messages.

In Young Woman, First Serious Relationship the defence counsel exhibited a clear case of constructing the complainant's excessive emotion based in her actions. Extract 13 takes place during a series of questions about an encounter between the accused and the complainant. The accused changed his social network profile picture to include a picture of him with another woman. The complainant had requested that he take it down.

Extract 13 [C2P2001052: Take down the photo]

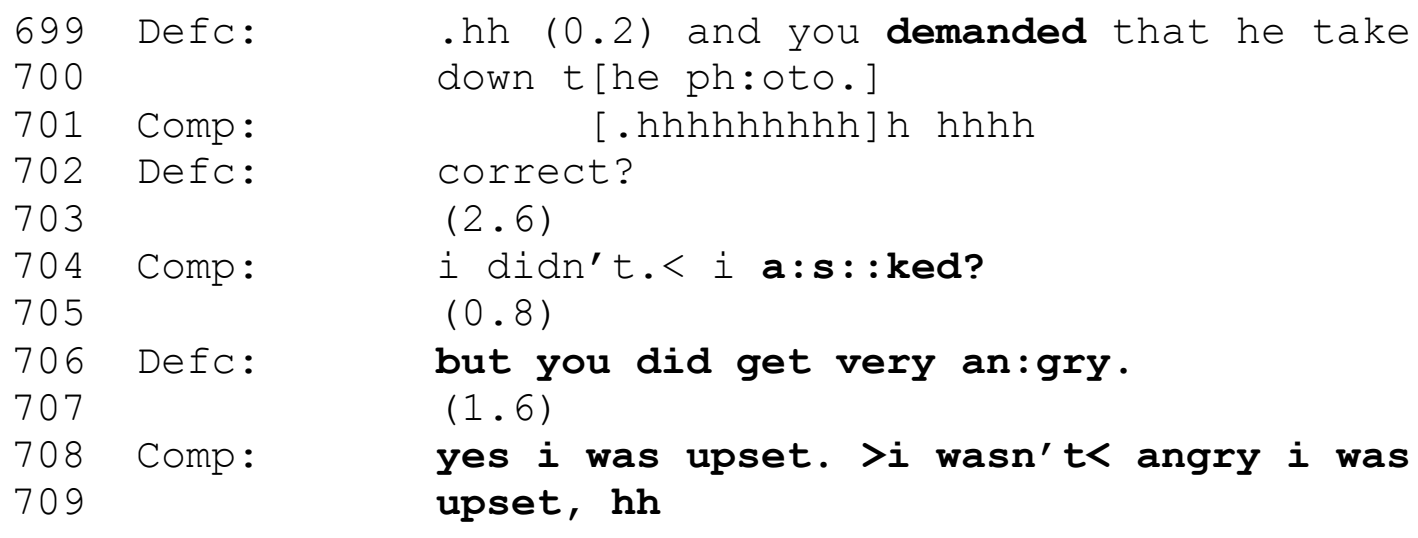

The defence counsel begins by describing the complainant's actions with the verb 'demanded'. He does this using a truth tag (statement + correct?), which requests confirmation from the recipient (L699-700). The complainant gives a dispreferred response. She disagrees with the defence counsel and then identifies 'demand' as a source of trouble. She replaces 'demand' with 'asked', which is a relative downgrade.

Participants' descriptions of events show how they simultaneously evaluate and construct occurrences. This illustrates an instance where participants' descriptions of the same event are at odds. The defence counsel describes her actions as being 'demanding', which is an extreme way to describe a person making a request. The complainant describes her action as having 'asked', which seeks to soften the way the action is portrayed. 
At line 706 the defence counsel implicitly disagrees with her by categorising her emotion as 'very angry'. It seemingly maintains the extremity of her action, driven by her emotion. It also creates a link between being 'angry' and acting on one's anger (being very angry and demanding). The complainant again resists the assertion by constructing her emotion as having been 'upset' (L709); this study suggests that 'upset' is relatively more passive than anger. Upset is used to describe an state of mind generally felt as reaction to a result of another's action or inaction. Anger on the other hand is a dynamic emotion that people act on.

In Extract 13, defence counsel simultaneously constructs and places the complainant within a category as a very angry and demanding woman/person. He achieves this by associating an allegedly unreasonable action ('demanding') to excessive emotion, 'very angry'. The complainant subsequently denies this and instead constructs her behaviour and emotions as more neutral and/or passive. The defence counsel also draws a connection between her behaviour and her emotions; indicating that she acted on her emotions.

To summarise, Extracts 11-13 saw the defence constructing the complainant as having a disposition for being angry. In response complainants minimised the emotion to an isolated incident. Doing so resisted the defence's construction and thus avoid being labelled an angry or ferocious woman. Whether the complainant was angry or not at particular times has little or no bearing on issues of consent in law. The matter of excessive emotionality is therefore left to undermine complainant credibility, in general, as an inferred character flaw only. The category 'women' also appeared to be doing work. It could mean that there is something particular about angry women that challenge the complainant's general credibility.

\section{Summary of Defence Questioning Approaches}

This chapter analyses several features of the defence counsel's organisation of question sequences during cross-examination. It finds that the defence counsel used contrasting facts in order to create inconsistencies in the complainant's testimony. This research finds that two kinds of 'failures to act' were used as a basis for undermining the complainant. The first finds an inconsistency in the complainant not leaving a situation when she wanted to/was able to. It constructs the complainant as having committed a social breach for omitting to act. The defence counsel also noticed 'failures to report' the crime. The 
noticing also constructed the complainant as having deviated from a normative expectation. Failing to report was used in connection to having an ulterior reason for bringing a complaint. Ulterior motives were used to make an accusation that the complaint was false. Together these components made a case against the complainant that challenged her general credibility. When complainants responded, two of them displayed audible emotion in their accounts. This study notes that emotionality occurred in times that aligned with victim selfblaming.

Describing and categorising the complainant's character was also an important feature of the defences' questioning. The defence counsel constructed the complainant's behaviour as unusually 'excessive' and also dispositional in nature. This study finds that defence uses emotions associated with 'anger' to cast the complainant as being a generally angry or hateful person. To bolster their arguments defence also found or attached actions to these emotions. By doing so they accomplish two things; firstly, it links their assessments of the complainant's emotion to observable facts (such as sending text messages and demanding the accused to do something); and secondly, it illustrates specific instances where the complainant had acted on emotion (anger). Acting on anger has relevance in rape trials; it aligns with the rape myth that women can be motivated by anger to make a false complaint of rape in order to get revenge on a man. 


\section{Chapter Four: Questioning Approaches to Non-Aligned Responses}

The previous chapter analysed recurring features of defence counsel questioning practices that sought to challenge the complainant. Firstly it identified how the defence counsel created factual inconsistencies to undermine the complainant's credibility. The defence counsel would request confirmation for declarative statements. When the complainant aligned with the statement, the defence then followed up with a contrasting statement. The contrast created an inconsistency around the complainant's actions at the time of the alleged offence. Such contrasts became components in the argument to the effect that that the rape had not occurred.

This chapter looks at how the defence counsel progresses the cross-examination when complainants did not align with their questions. In particular, it studies instances when the defence pursued alignment by reframing the question. This chapter also looks at the impact of redoing questions on complainant emotionality. The first section of this chapter explores when the defence counsel orients to complainant's misaligned answers as being somehow insufficient or inadequate. Two separate cases are studied in a sequence of extracts. The case studies show the points at which pursuit leads to complainant emotionality.

The second section of the chapter presents one way the defence concluded series of continual misalignment. Defence counsel used a conversational technique known as threepart lists. Three-part lists of common properties are used to make generalisations. Drew (1990) identified this as a technique used in court to describe an action, scene or element of the testimony. In both cases the three-part lists were used to characterise the complainant in a negative light.

\section{Case Study One: Intense Short-term Relationship}

The first case study, set out over two extracts, displays two things. It shows the defence counsel claiming the complainant's answers are insufficient. It also shows the complainant's subsequent emotionality that builds quickly in response. In Intense Short-term Relationship the complainant was allegedly sexually assaulted twice. The first was on the 
first night they began a relationship. The second was after the relationship ended. Prior to the Extract 14, the defence counsel had asked the complainant about a number of some text messages that she sent to the accused. The texts contained expressions of love for the accused. The defence asked if the texts were honest representations of her feelings. The complainant responded by saying she sent them to make him feel loved to make him feel better about himself. The defence then moves to ask her about when she said she loved the accused in person, which is the substance of Extract 14.

\section{Extract 14 [C1P1004542: Truth or lies (1)]}

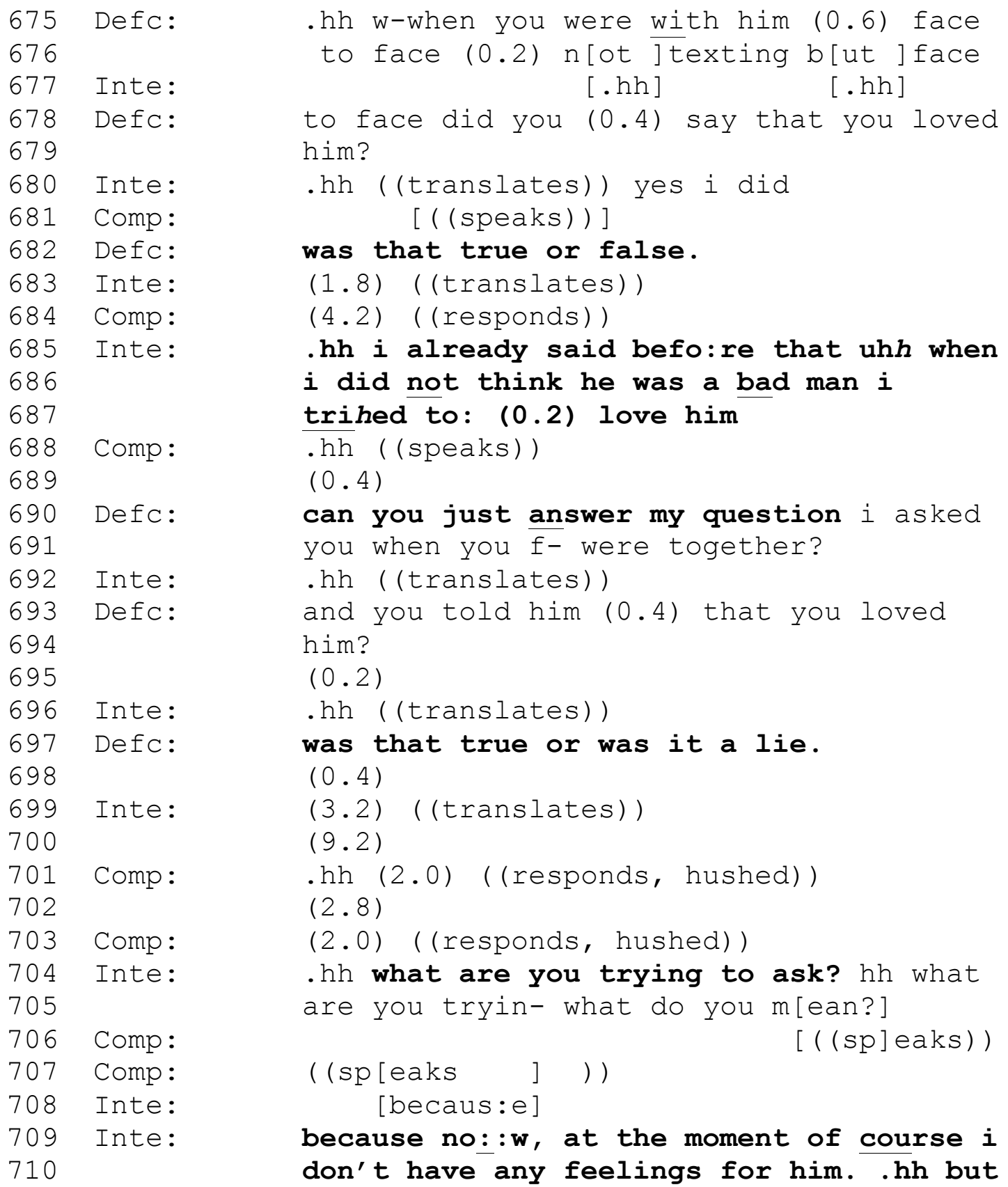


First, the defence counsel launches a positively formulated yes/no interrogative. He asks if she said 'I love you' face to face with the accused. The interpreter provides a preferred response at line 679. After she confirms this, the defence counsel follows up with 'was that true or false' (L682). This provides a binary selection of one of two answers as the preferred response. The defence presumes that feelings can be categorised into either 'true' or 'false'. His question sets the action agenda confirming whether the complainant's expression of love was genuine or not (Hayano, 2013).

The interpreter's response conforms to the topical agenda of the complainant's expression of love ('I tried to love him', L687). However her response resists the dichotomy of 'truth' and 'lies'; it constructs love as something she tried to do - not a feeling she had (L685-687). It therefore resists the action agenda through not following the formal constraints of the question. Implicitly, her use of 'tried to love' could align with 'lies'. The use of 'tried' to love suggests a divergence between what she had said and what she then felt.

However, the defence counsel orients to her response as being insufficient. In news interviews, participants orient responses that resist question agendas that are inadequate and subsequently reissue the question (Clayman, 1993). A similar feature occurs in this extract. The defence calls the complainant into account for not answering his question (L690). It shows that he is orienting to a response outside of the question constraints as inadequate. He then reissues the question with the same options of 'truth or lies'. The question results in trouble for the complainant. At line 704-705 the interpreter displays a problem in understanding on behalf of the complainant. This is indicated through the turn "what do you mean?'. However before the defence can clarify the interpreter continues to elaborate on the cause of the trouble. The complainant provides a variation of her previous response at line 685-687; saying there was a possibility for feelings, but not anymore. This again conforms to the topical agenda, but resists the formal constraints of the question.

Extract 14 firstly shows the defence launching an alternative choice question. When the complainant responds outside of the given options, the defence claims the complainant's answer is insufficient. Secondly, it shows the defence counsel pursuing a response by re- 
issuing his question. He does this when the complainant's answer does not align with the questions parameters and presuppositions.

Extract 15 occurs shortly after Extract 14. Between the two extracts, the defence counsel continues to pursue alignment from the complainant on the same action agenda. He further sought a response of 'truth' or 'lies' in relation to her having said 'I love you' to the accused in person. The complainant responded outside of these constraints by saying 'in a relationship it's hard because I don't like seeing people getting hurt'. In Extract 15 the defence makes a second claim that the complainant is not answering his question, which is where the extract begins.

Extract 15 [C1P1004632: Truth or lies (2)]

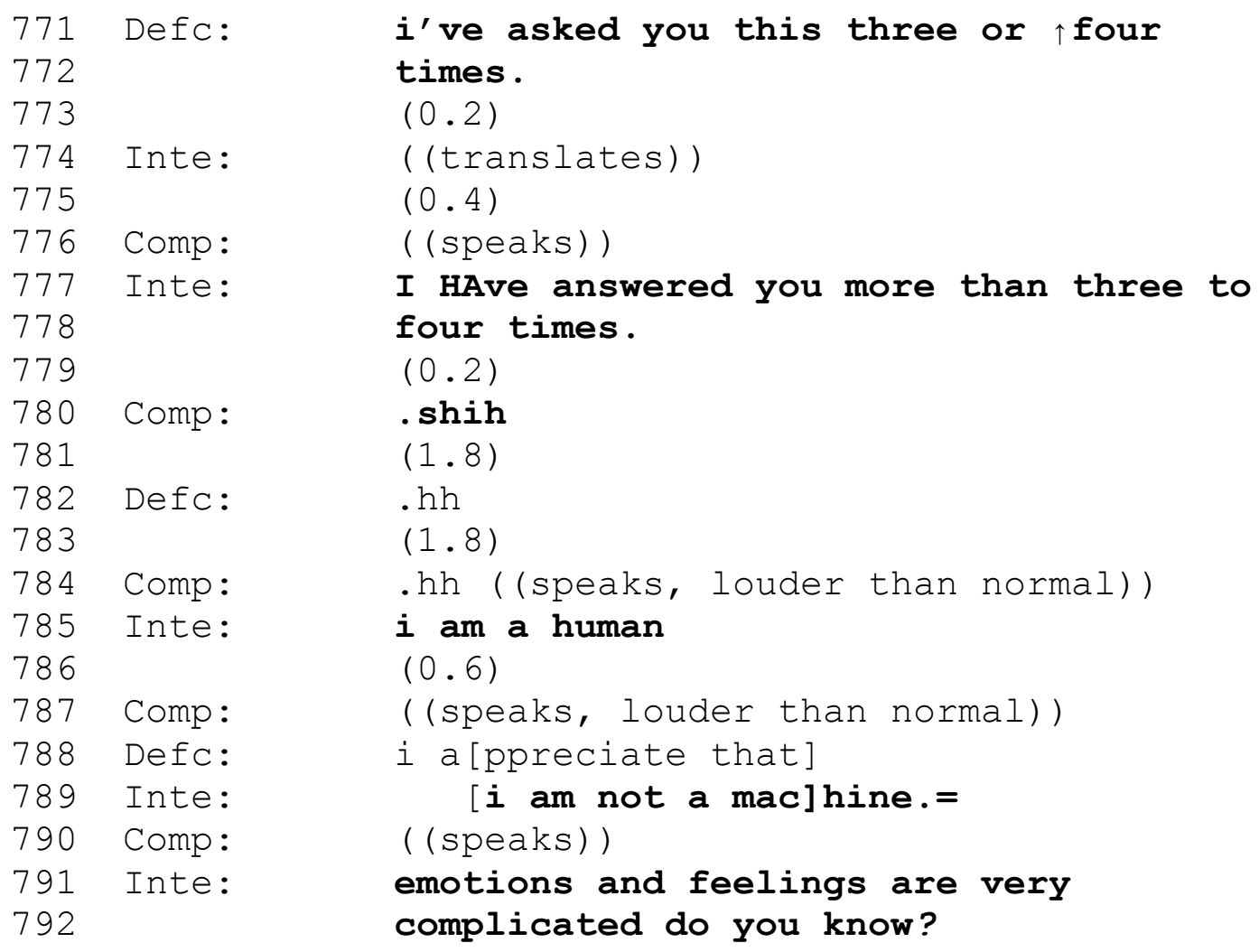

The extract begins with the defence counsel claiming that he has asked her the question 'three or four times' (L771). It shows that he has oriented to each of her responses as being insufficient. The interpreter denies the accusation by saying she has answered him more than three to four times. By answering him 'more' than three to four times, her denial is upgraded from the defence counsel's accusation (L776). The complainant then utters a 
sniff (.shih), indicating and signalling upset. The emotionality occurs after an accusation that she has not answered his question.

The complainant takes another turn to state that she is a 'human' and another to say she is 'not a machine'. The volume level of her voice increases in this turn. Her reference to being human rather than a machine categorises the question terms as problematic; that defence is asking her to be a 'machine'. She elaborates on this by stating that emotions and feelings are complicated. It infers that 'truth or lies' is inadequate to explain her 'human' emotions.

Extract 14 shows an example of defence counsel categorising emotions into a binary. When the complainant resists the question's action agenda, the question is reissued. However, pursuing a type-conforming response in this instance is problematic for the complainant. In essence the way the question is framed puts the complainant in a double bind. She cannot answer the question without undermining her credibility. She is either a liar, which does not align with being an honest witness. Alternatively she is being inconsistent by feeling love for a man whom sexually assaulted her. As seen in the last chapter, the defence counsel constructed feelings of love as an inconsistency in the complainant's testimony.

Extract 15 shows the defence explicitly orienting to the complainant's nonconforming responses as inadequate. The defence counsel accuses her of not answering his questions. When he does this, the complainant becomes loud and challenges the premise of the question. It is possible that the re-issued questions, and the calling to account for not answering adequately in this situation, trigger the complainant's emotionality.

\section{Case Study Two: Young Woman, First Serious Relationship}

The next case study is set out over four extracts taken from Young Woman, First Serious Relationship. They demonstrate a second example of re-issuing questions when the complainants do not adhere to the question parameters. Like the previous case study, the defence counsel's pursuit appears to drive the complainant's emotionality. The line of questioning concerns the complainant's disposition to be angry. The complainant's emotionality in the courtroom builds progressively as the defence pursues her alignment.

Extract 16 begins with a question about the complainant's emotional state on the night of the offending. The defence counsel uses the emotion category 'angry' to describe the complainant. Prior to this extract the defence established a factual narrative about what 
happened in the hotel room before the offending took place. They ascertain that the complainant found texts from another woman on the accused's phone while he was in the bathroom. The accused then entered the room and the extract picks up from there.

Extract 16 [C2P2 003327: Degrees of anger repeats (1)]

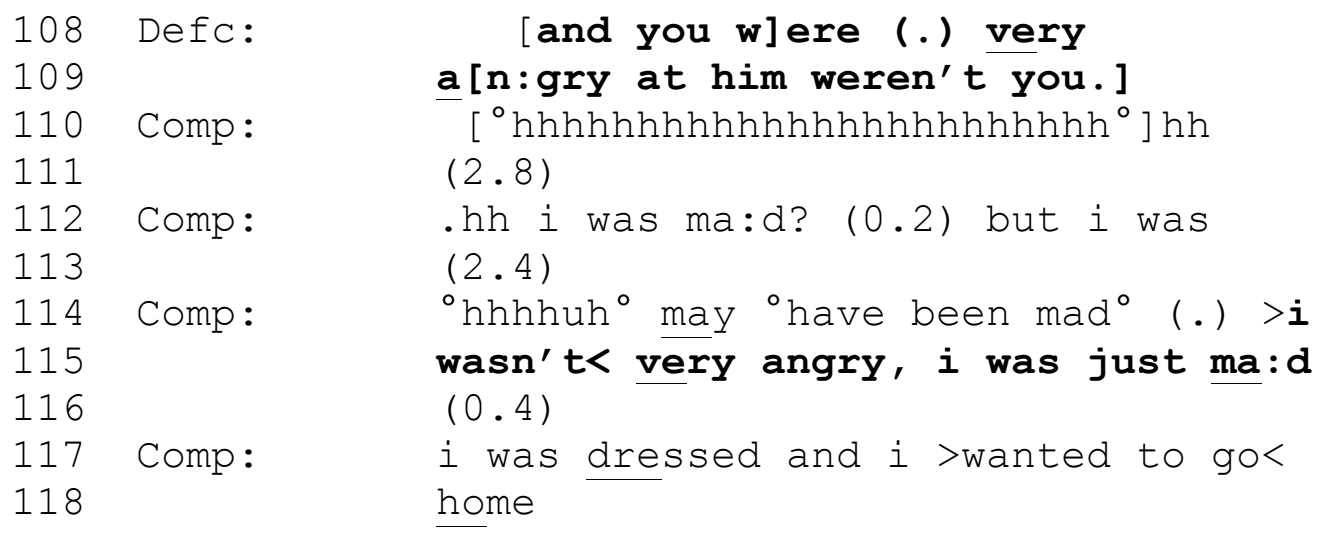

The defence launches a reverse polarity tag question at lines 108-109. As mentioned tag questions display a stronger epistemic stance from the speaker (Heritage, 2012). The question requests confirmation. However, the complainant does not provide confirmation. The complainant initially responds to the question's topical agenda: her emotional state on the night of the offending. However she resists the action agenda by responding outside of the formal constraints of the question ('I was mad', L112). By providing an alternative description she implicitly disagrees with the defence's question (Drew, 1992). She replaces 'angry' with 'mad', indicating trouble with the defence's construction of her emotions.

After initially downgrading her epistemic stance (L114), she explicitly disagrees with the defence. She states that she was not very angry, she was just mad. It minimises the excessiveness of her emotions and resists the defence's description of her. She then builds on her turn by saying she was dressed and she wanted to go. This part of her response becomes relevant later in extract 18.

The defence counsel orients to her response as inadequate in Extract 17. He displays this by re-issuing the question in pursuit of the action agenda. As mentioned, answers that resist the questioner's agenda can be seen as requiring a follow-up question (Clayman, 1993; Heritage, 2003). Extract 17 begins just after the defence counsel refers her back to their break-up. It starts with the defence counsel describing the complainant's violence during their break-up. He uses this as a foundation for reissuing his question. 
Extract 17 [C2P2003340: Degrees of anger repeats (2)]

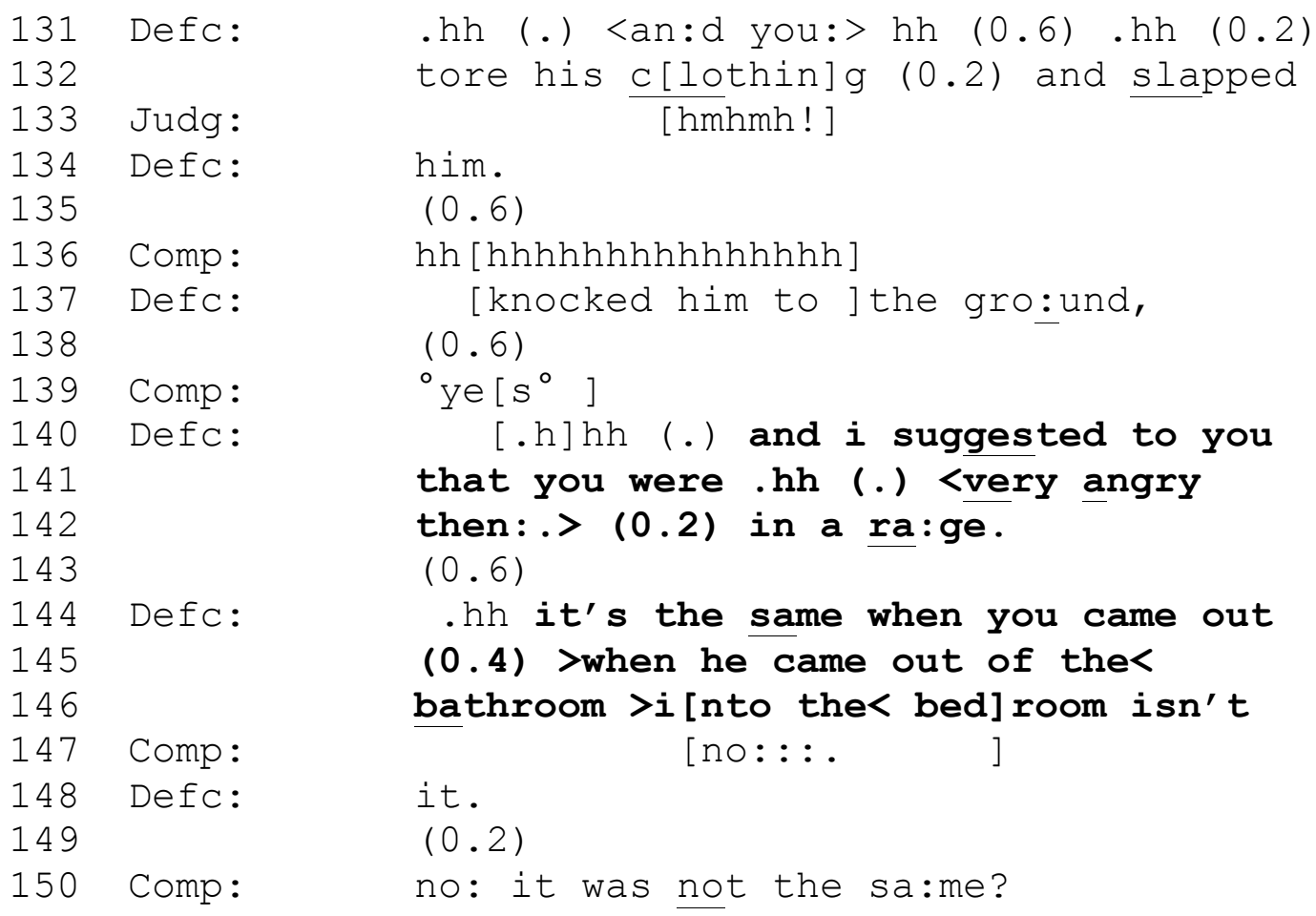

The extract begins with the defence counsel's description of the complainant's violent actions (L131-137). He describes her actions as having torn the accused's clothing, slapped him and knocked him to the ground. As we shall see in the next section, these three actions together form the elements of a 'three-part list'. Lists like this can be used in the courtroom as rhetoric devices to make generalisations about a subject (Drew, 1990). Tearing, slapping and knocking are acts of violence, inferring that the complainant has violent tendencies. The list of items implicitly requests confirmation as the complainant has better epistemic status. She provides confirmation with 'yes'.

After the complainant's confirmation the defence counsel takes another turn to describe her as having been 'very angry' and in a 'rage' during the break-up (L140-142). It is an observation made after the complainant confirms a three-part list with violent properties. It displays a precedent for her having violent/angry behaviour. In this way, the description 'very angry/rage' is used to build the facticity of his previous question (Extract 16). It also adds 'rage' to the emotion 'angry', which is a relative upgrade. It shows the defence counsel upgrading an emotion category when he pursues a response.

At lines 144-146 the defence reissues his question to the complainant. It is asked as a negative tag question 'isn't it'. Because it has a negative formulation, it is spoken more as an 
assertion than a question (Heritage, 2002). He uses the break-up as a foundation to assert that the complainant was also violent and angry on the night of the offending (L144-146). By reissuing the question, defence counsel shows that he is pursuing an answer that aligns with his question; that the complainant is prone to anger.

Before he can finish the complainant disagrees with a type-confirming, but dispreferred, 'no'. Once she is in the clear she repeats 'no it was not the same'. It is a flat, explicit denial. It resists the defence counsel's assertion that she was very angry and in a rage on the night of the offending.

The defence counsel reissues the question again about forty lines later in Extract 18. In this extract, the complainant begins to exhibit signs of emotionality during her response. Prior to this extract the defence had asked a series of questions about the order of events on the evening of the alleged rape. The accused went into the bathroom and while he was there, the complainant had checked his phone. She saw that he had received texts from another woman. Then the accused came out of the bathroom.

Extract 18 [C2P2003412: Degrees of anger repeats (3)]

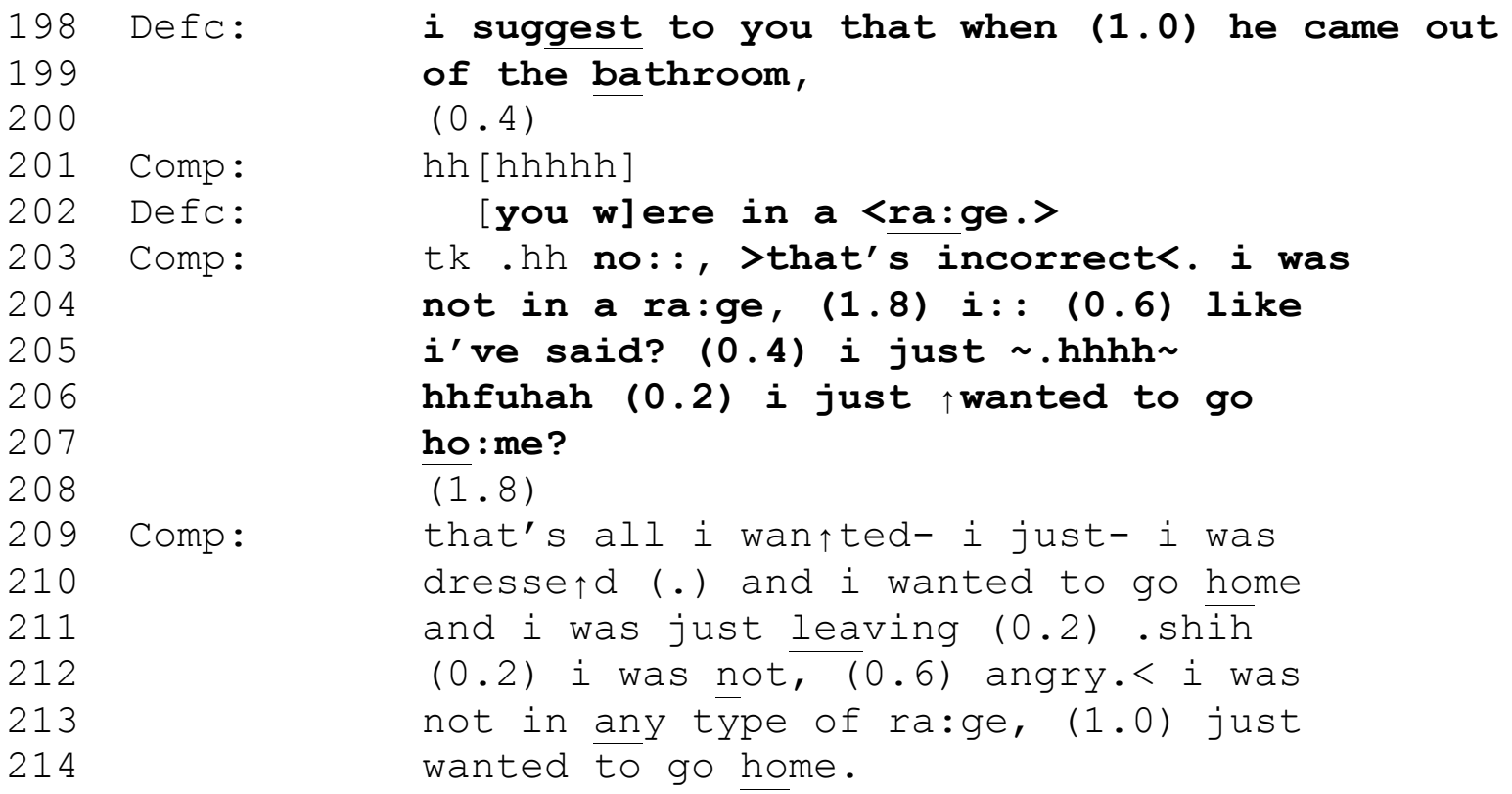

Through lines 198-202 the defence counsel reissues his question - although this time, he puts it to her as a suggestion. It is more assertive than the negative tag question. To say 'I suggest' shows the speaker is making a point for a recipient to accept or reject (Heffer, 2005: 137). Again, defence counsel upgrades the alleged emotion to 'rage'. It shows that when re- 
framing the emotion, the defence attempts to upgrade to a more extreme level than that stated by the complainant.

The complainant rejects the suggestion explicitly by stating 'no that's incorrect'. She then takes another turn to provide an alternative version of her emotional state. First she states that she was not in a rage. Then she continues to expand on her denial. She orients to her oncoming speech as having been recycled from a previous turn by prefacing it with 'like I've said' (L205-206). It implicitly casts the defence's question as seeking the same information - and is therefore repetitive. It is here that her emotionality becomes audible in her speech.

After saying 'like I've said', she repeats part of her turn from Extract 16 ('wanted to go home', L207-208). This turn is interrupted with a wobbly in-breath and a sigh, which indicates emotionality. 'Wanted to go home' is spoken at a higher pitch, which is also indicative of upset. She displays audible distress during a turn where she repeats part of a previous response. The emotionality here may be a result of repeating her answer.

The complainant repeats 'that's all i wan $\uparrow$ ted-'(L209). This also contains a pitch rise mid-word. It indicates that she is experiencing upset at this point. She also sniffs (.shih, L211), which is an indication that she is crying. After she sniffs she readdresses a previous assertion from Extract 16 - that she was not angry and not in any type of rage. This is concluded with another repeat of 'just wanted to go home.' This study suggests that her response indicates that the defence's pursuit drives her emotionality. Her turn displays an increase in repetition and emotionality.

Extract 19 takes place forty lines after Extract 18. Again, defence counsel reissues a question pertaining to whether she was angry in the hotel room on the night of the offending. Prior to Extract 19 the defence counsel asked the complainant to confirm that she had an opportunity to leave the hotel before the alleged offending (see Extract 1). She confirmed that she had. However she went on to state that the accused was on the balcony and required her assistance first. The extract picks up from there.

Extract 19 [C2P2003454: Degrees of anger repeats (4)]

$\begin{array}{ccc}253 & \text { Defc: } & \text { tk (.) but [you we]re angry and cr- } \\ 254 & \text { Comp: } & \text { [.shih ] } \\ 255 & \text { Defc: } & (0.2) \text { and crying [weren]'t you } \\ 256 & \text { Comp: } & \\ & & {[. \text { shih] }}\end{array}$


The extract begins with the defence counsel launching a reverse polarity tag question. Relative to other question types, it indicates a stronger epistemic stance (Heritage, 2012). However it is weaker than the previous assertions. He also downgrades the category 'very angry' and 'rage' to simply 'angry'. The defence is still pursuing a response. But it appears the strength of his pursuit has subsided.

Despite the downgrade from the defence, the complainant upgrades her response again from Extract 18. She does so in both her words and her emotions. The study suggests that this could be attributed to the repetitious nature of the defence's line of questioning. Like the previous extract, the complainant begins her turn with an explicit denial that she was not angry (L258). She replaces 'angry' with the description 'begging to go home' (L259-264). 'Begging' takes her internal state of 'wanting to go home' from Extract 18 and makes it an observable action. 'Begging' is also an extreme form of making a request. Her formulations become even more extreme after the defence's fourth attempt at pursuing a response.

The complainant takes another turn, restating that she wasn't angry or in a rage. She replaces 'angry' and 'rage' with alternative emotions. This time she replaces 'angry' with 'terrified' and 'so so scared'. She further ends her turn with 'I just wanted to go home', which is the third time she has repeated it. Relative to anger, 'terrified' and 'scared' are reactive emotions that are a result of someone else's aggressive behaviour.

To briefly sum up, this study looks at the defence's pursuit of a response when the complainant did not align with the question. In Intense, Short-term Relationship the defence asked the complainant if her expression of love was 'true or lies'. The complainant's response adhered to the topical agenda of the question; however it did not conform to the choice of 'true or lies'. The defence explicitly called her into account for her inadequate 
responses. As a result the complainant quickly became loud and challenged the question premise. It suggests that her emotion was driven by the non-acceptance of her answers.

In Extracts 16-19 the defence counsel pursued confirmation that the complainant was very angry/in a rage/angry four times over a series of questions. The extracts show the complainant becoming increasingly emotional and extreme in her responses. This study suggests the defence counsel's pursuit of a response drives her emotionality. It points to the steady increase in emotionality and repetition to support this finding.

\section{Concluding Complainant Resistance: Three-part Lists}

The previous sub-section showed two cases where defence counsel reissued questions in pursuit of alignment. This study now turns to the culmination of pursuit and counsel/complainant non-alignment. In two cases the defence followed up complainant resistance with three-part lists. Three-part lists are a device that express a generalisation about an action, character or other element of someone's testimony (Drew, 1990; Lakoff, 1987: 5). By using three examples in talk, a behaviour is constructed as a trait rather than a consequence of circumstances. In two cases, the defence used three-part lists after complainants continually did not adhere to the question constraints. Specifically, the defence counsel used three-part lists to generalise a negative characteristic or action to the complainant. Negative generalisations can diminish her credibility as a witness. Examples of three-part lists being used in this way are set out below.

Extract 20 comes from On-and-Off Again Relationship. In this case, the complainant had alleged four separate instances of sexual offending. They were all formally reported to police after their relationship ended. During the relationship, a police officer became aware of the first instance of offending. The officer asked the complainant if she wanted to press charges. The complainant said she did not. At this point three alleged incidents of rape had already occurred. This completes the scene for the three-part list.

Prior to this extract, the defence counsel asked the complainant about possible motivations for bringing a complaint (see Extract 7 and 8). Three times the defence asked her a tag question. Each of the complainant's responses distanced herself from aligning with the defence. As a result, the defence launches a three-part list about not reporting the crimes to a police officer. 
Extract 20 [C3P2005422: You did not talk to police]

885

886

887

888

889

890

891

892

893

894

895

896

897

898

899

900

901

902

903

904

905

906

907

908

909

910

911

912

913

914

915

916

917

918

919

920

921

922

923

924

925

926

927
Defc: a police officer TALKing to you about
$(0.4)$ a rape. (1.4) You: say that you have been raped on (2.0) three occasions.= by this point in time. $(0.6)$

Comp: $\quad$ ye:s, i wa $^{\circ}: s ?^{\circ}$

$(5.6)$

Defc:

Defc:

you do NOt TEll the police officer, that you want to make a complaint (0.4) in relation to the rape that she is there to talk to you about do you. $(0.6)$

no $i$ told her ${ }^{\circ} n\left[\right.$ ot $\left.t-{ }^{\circ}\right]$

[you do] not talk to

the >police< officer (.) about the two

OTHEr rapes, that occurred in that

house where you lived with him.

$(0.4)$

Defc: $\quad$ with his mother.= did you.

$(0.2)$

Comp :

Defc:

no:.= cause $i(j u[s t)]$

[you] did not talk to:

(0.2) the officer about the fourth

incident. $(0.6)$ did you.

$(0.8)$

Comp :

$>$ no, $<$

$(5.4)$

Defc: and you told the officer, (2.8) (that)

shortly after, (1.6) you told donna

about this, >and had been dis<cussed

with his mum, $(0.4){ }^{\circ}$ about this ${ }^{\circ}$ rape,

(2.8) that john $(0.4)$ went, and

completed the cou:rse (0.4) n:NOt (.)

because he is violent physically, but

more emotional $\overline{l y \cdot}=$ that's what you told

the officer didn't you.

(1.4)

Comp :

becau:s:e (0.2) he would be \#qui:te\#, $(0.2)$. shshih $(0.2) \overline{\text { hhh }}(0.2)$ quite controlling, (1.2) an:d he wou:ld (0.2)

be abusive in that \#wa:y, \# (0.8)

ps [ychol] ogically:,

The defence counsel sets the scene for his three-part list in lines 885-889. It shows a unique instance in this study where the defence counsel also exhibits emotionality. His 
speaking voice becomes louder than it was before. This also continues throughout his threepart list. He uses the complainant's reported speech, which implicitly requests confirmation. She provides confirmation at lie 891 .

The defence counsel begins the first part of his list at line 893. The first part is produced as a reverse polarity tag question. It requests confirmation that she did not make a complaint of rape when talking to the officer. The tag question notices an absence, indicating that there is an expected course of action that was not taken (Schegloff, 1996). Here the absence infers that rape victims normally make a formal complaint when a police officer talks to them about the offending. It makes her accountable for not reporting when she had a prime opportunity.

The complainant confirms the tag question at line 898. She then takes another turn to make what seems to be an account. In courtroom talk, accounts are typically associated with noticing failures (Atkinson \& Drew, 1979). However, she drops out when the defence counsel begins a turn in overlap with her. The defence begins his turn when the complainant is not hearable as complete. It could indicate that her account is not necessary for the progressivity of the interaction; only her alignment is needed.

The defence counsel launches the second part of his three-part list. He uses another reverse polarity tag question, which requests confirmation. This tag question notices another failure to act. The defence notes that she also did not tell the officer about the second and third alleged incidents. This implies that when police ask victims about sexual offending, they disclose other sexual offences as well. More than that, it makes her accountable for not informing the officer about other allegations.

The complainant confirms the tag question (L906). Again, she begins to produce what seems to be an account (shown by the 'because' preface). However the defence counsel speaks in overlap again and she drops out before she can finish. Again, it could possibly indicate that her account is not necessary for the progressivity of the interaction.

The defence launches the third part of his list at lines 889-904. Like the other two parts it is a negative reverse polarity tag question. It notices a failure to report for the third time. The complainant confirms the final tag question. Unlike her two previous responses, she does not account for the alleged transgression. There is space for her to answer, evidenced by the (5.4) second silence after her turn. 
After the defence counsel finishes the list, he then states what the complainant did tell the police officer (L913-921). He houses it within another reverse polarity tag question. The tag question requests confirmation for a number of statements. They include telling the officer the alleged rape was the reason the accused went on an anger management course. This illustrates an example of the complainant revealing the alleged rape, but not for the purpose of reporting the crime. He then requests confirmation that she said this to the police officer.

The complainant responds with an account, ' becau:s:e (0.2) he would be \#qui:te\#, (0.2) .shshih (0.2) hhh (0.2) quite controlling'. It does not conform to the terms of the question. While she gives the account, she speaks with a croaky voice and several sniffs. The sniffs occur between \#quite\# and 'controlling'; the emotion before 'controlling' could indicate this is a source of emotionality for the complainant. It is interesting that 'controlling' seems to be a point of distress for the complainant. It is arguable that the defence behaved in a controlling manner during this three-part list; he inhibited her accounts by speaking over her, thus controlling how she responded.

The three-part list noticed multiple failures to act on the complainant's part. The defence set a scene where an officer was talking to her about rape. Yet the complainant did not make a complaint, nor did she inform the officer of the other offences. Describing her behaviour this way constructs her failure as a significant transgression. By using multiple instances he condemns her moral character for not acting where she ought to have. Doing this in a three-part list undermines her character more so than if she had committed a single transgression (Buttny, 1993). He then links this transgression to another condemnable behaviour: using a rape allegation for some reason other than reporting a crime. This shows the defence counsel challenging her general credibility using multiple failures to report a crime.

Constructing the narrative this way makes the complainant accountable for the omission. The overall effect of describing absences this way undermines the complainant's moral character (Drew, 1998). She is condemned for not making a complaint of rape when she had the prime opportunity. By summating this in a three-part list it inflicts additional damage on her character for making multiple transgressions.

A similar pattern occurred in First Serious Relationship (Extract 21, shown below). The defence launches a three-part list after the complainant resisted aligning with him 
multiple times. This was shown in Extracts 16-19. Extract 21 begins after shortly after Extract 19; where the witness distanced herself from the defence's suggestion that she was 'angry' a number of times. Prior to this extract the complainant disagreed with the defence counsel's description of her as being 'angry'; she stated that she was not angry. The defence then launches a three-part list in response to her disagreement.

Extract 21 [C2P2003455: Angry woman in three parts (1)]

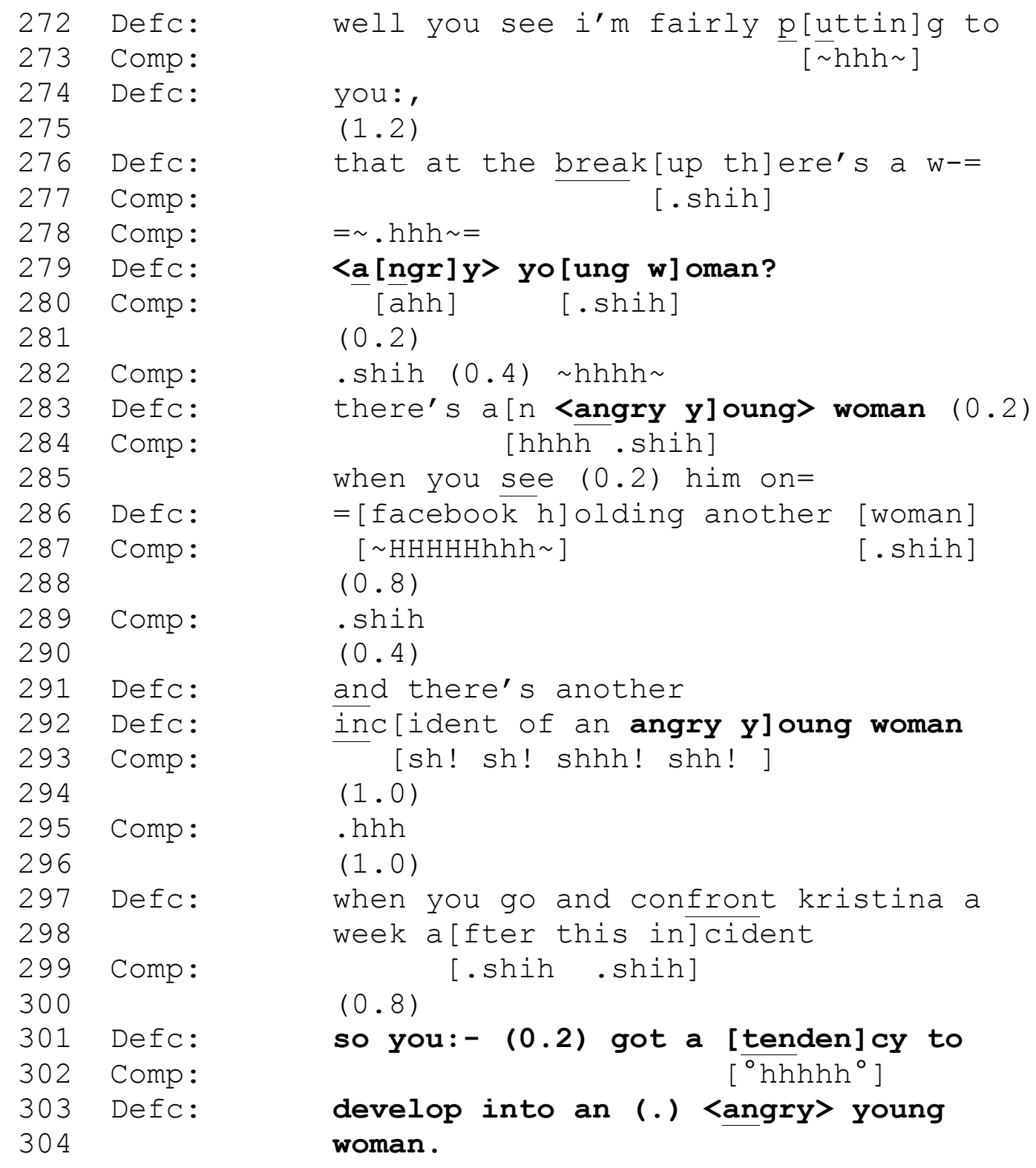

The defence counsel frames his first turn with ' well you see i'm fairly $\mathrm{p}$ [uttin]g to you'. It shows that his oncoming speech asserts a point (Heffer, 2005). The three-part list is completed over a series of turns. During these turns the complainant displays sniffs, 
indicating emotionality throughout the defence's turns. This could be ongoing crying from the pursued questions through extracts 16-19.

The first part of the list is that 'at the break-up there's a w- angry young woman' The sound cut-off at ' $w-$ ' indicated a trouble source for the defence counsel. His solution is to insert 'angry young' before 'woman', showing that 'woman' by itself was a source of trouble. This indicates that 'angry young' are necessary to his construction of 'woman'. 'Woman' is a relatively more neutral construction than 'angry young woman'. 'Angry' and 'young' do work to construct and evaluate the gender category. 'Angry' in particular is a negative character assessment. 'Young' may infer a propensity to be impulsive or irrational. Unlike the previous three-part list the defence states his list instead of housing it within requests for confirmation.

The defence counsel launches the second part of his list at lines 283-286. There he evaluates and constructs a second, separate instance of when she was an 'angry young woman'. This happened when she saw a photo of the accused holding another woman. It constructs her anger as reactive to an event that happened, distinguishing it from the anger at the break-up. The third part of the list also refers to her as an 'angry young woman'. It occurs when she confronts Kristina after the alleged rape (297-299). Parts two and three of the list both describe and categorise her anger by making observations about her actions. This both bolsters the facticity of the defence's observed description and constructs her as someone who acts on anger.

All three examples make reference to her anger in terms of her relationship with the accused. Yet the defence describes her as having a 'tendency to be an angry young woman' generally (L301-304). This three-part list reveals the defence counsel working towards a general characterisation of the complainant as being an angry young woman.

There is some similarity to the previous three-part list. The defence in this example also uses three descriptions of the complainant in order to make an unfavourable generalisation about her character. It therefore has the potential to undermine her general character, and her credibility as a witness. By constructing her as an angry young woman the defence arguably aligns with broader social constructs about rape. There is a belief that women are motivated by anger to 'get revenge' on a man who has wronged them - especially ex-partners (Jordan, 2004). 
Extract 22 follows on directly from Extract 21 in the Young Woman, First Serious Relationship case. It shows the complainant's response to the three-part list above.

Throughout this particular section the complainant's crying can be heard to subside. She also challenges his construction of the category 'angry young woman'.

Extract 22 [C2P2003412: Angry woman in three parts (2)]

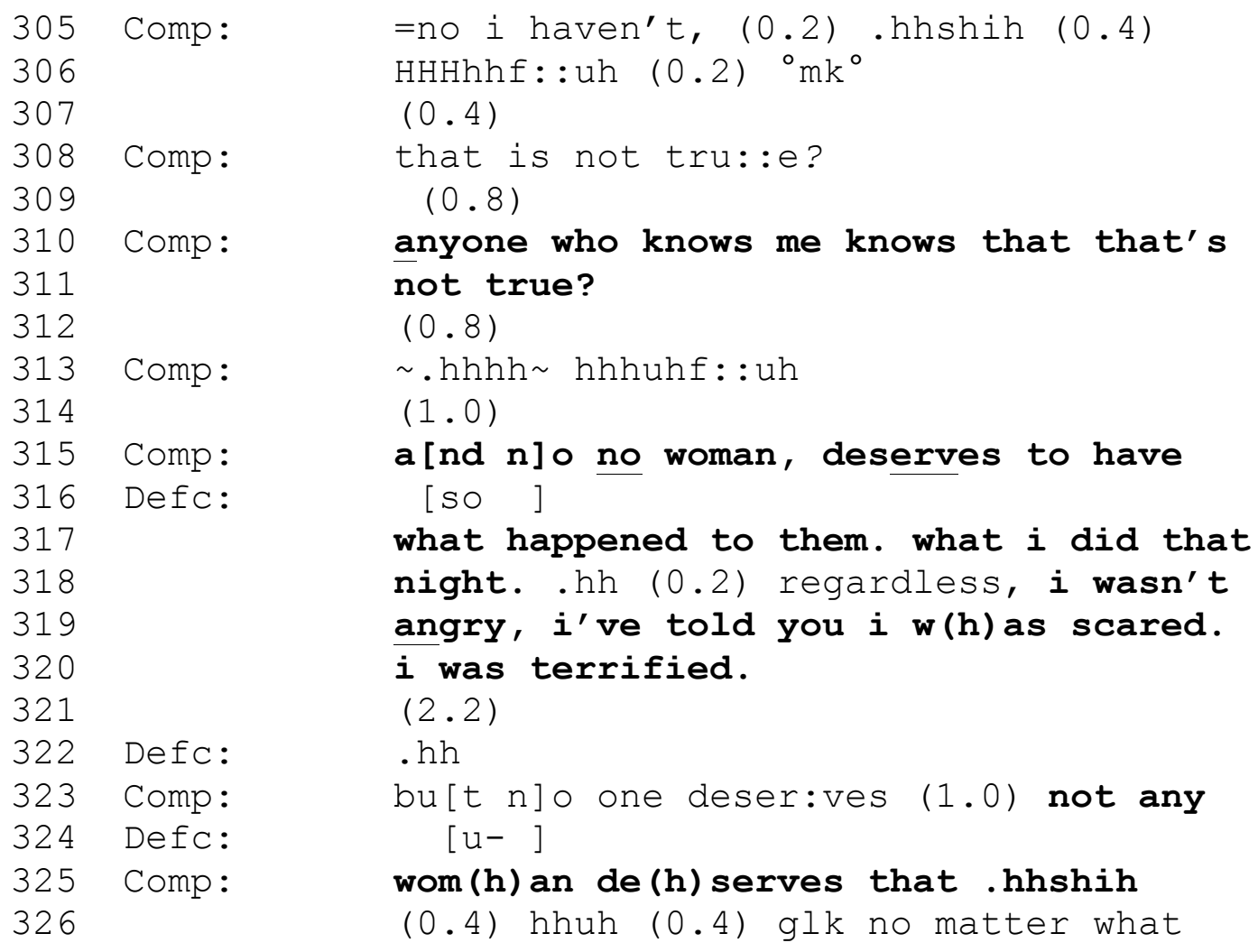

The complainant begins her response by denying the assertion that she has a tendency to be an angry young woman (L305). This is followed by a sniff and a long sigh. It marks her final sniff for the next twenty turns - indicating that her emotionality has subsided for the time being. At line 310 the complainant claims epistemic authority over the defence's construction of her character. She says that 'anyone who knows me' knows that she is not an angry young woman. By implication, because the defence constructed her as 'angry' he cannot claim to know her.

The complainant continues her turn to make a second rebuttal (L315-320). In this turn she also evaluates and constructs the category 'woman'. She states that 'no woman' deserves rape. Her construction possibly orients to the belief that angry women somehow 'deserve' rape. It may refer to the rich social inferences derived from the category of 'angry young 
woman'. There are broader stereotypes prescribing that women who behave certain ways 'deserve' rape. The complainant could be orienting to that belief.

As seen before, the complainant responded to assertions that she was 'angry' by providing alternative descriptions. Here she takes another turn to state that she was 'scared' and 'terrified' instead (L319-320). The alternative emotion 'terrified' provides a relatively more extreme replacement over 'angry'. Her formulation of ' $w(h)$ as scared' contains aspiration, as does her next turn. Aspiration can indicate speaking in spite of emotionality and can precede crying (Hepburn, 2004). It indicates that she is experiencing upset when producing her denial. The complainant finishes her turns by recycling part of her previous turn. Here she exhibits increasing signs of emotionality again.

She restates that ' $n$ ]o one deser:ves (1.0) not any wom(h)an de(h)serves that'. In laughter, aspiration can occur between and within words to indicate a problem with that word (Potter \& Hepburn, 2010). When the complainant says 'wom(h)an de(h)serves' she could be marking her turn as problematic - indicating that her denial here is somehow insufficient. The complainant also repairs from 'no one' and inserts 'not any woman'. The repair goes from a generic reference to a gendered reference. This suggests that the category 'woman' is doing work for the complainant (Stokoe \& Smithson, 2001). Together, these features could mean the complainant is orienting to - and denying - the belief that women in particular can 'deserve' rape.

\section{Summary: Pursuing and answer and emotionality}

This chapter analyses series of questions where defence counsel oriented to the complainant's answers as insufficient. It presented two case studies detailing where the defence re-issued questions in pursuit of alignment from the complainant. It occurred when complainants disagreed or resisted the defence counsel's agenda. In Intense Short-Term Relationship, the defence set an agenda around the complainant's expressions of love being dichotomous; either 'true or false'. The complainant responded to the topical agenda, explaining her feelings for the accused. However she did not respond to whether they were 'true' or 'false'. The defence subsequently treated this as being an inadequate answer. He called her into account for not adhering to the question's terms. When the defence counsel accused her of giving insufficient answers the complainant sniffed and her voice became 
louder. She claimed that her answers were sufficient and that instead the defence's question premise was unanswerable.

In Young Woman, First Serious Relationship the defence described the complainant as 'very angry'. He then requested confirmation from the complainant. The complainant disagreed and downgraded 'very angry' to 'just mad'. The defence counsel oriented to her answer as being inadequate and he pursued alignment from her four times. With each redoing of the question, the complainant became increasingly emotional and repetitive. It suggests that this practice of redoing questions in the face of misalignment drove her distress.

This study also looks at three-part lists as a technique for concluding continual resistance from the complainant. In two cases the defence counsel used descriptive three-part lists to undermine a complainant's general credibility. This occurred after the complainant had continually not adhered to the formal constraints of the question or where she disagreed with the defence counsel. The three-part lists had the effect of putting the complainant's general character on trial. On-And-Off-Again Relationship constructed the complainant as having made multiple moral transgressions through not reporting the crime. In Young Woman, First Serious Relationship the defence counsel drew from three incidents where she displayed 'angry young woman' characteristics. He suggested she had a tendency to become an 'angry young woman'. 


\section{Chapter Five: Discussion}

Cross-examination has been identified as a significant barrier in prosecuting sexual offending. This research sought to reveal how rape complainants are cross-examined in New Zealand courtrooms. The barriers to prosecution are two-fold; firstly, legal practitioners find that the complainant's credibility is easy to undermine (Mossman, MacGibbon et. al, 2009); the perception is defence counsel have too few limitations on how they challenge the complainant. Secondly, complainants report that the cross-examination itself is traumatic, with some referring to it as being worse than the offending itself (McDonald, 1996; Konradi, 2007). On the stand, complainants report feeling as though they are the ones put on trial. Such treatment during cross-examination deters both future victims and legal practitioners from pursuing a case. The perception is that the risk of retraumatisation is not outweighed by the likelihood of a conviction (Mossman, MacGibbon et al., 2009).

This study explored these issues by using both discursive psychology and conversation analysis, applying them to three cross-examinations. Firstly it analysed how defence counsel conduct themselves in terms of how they ask questions and make accusations to the complainant. It also focussed on how the complainant's testimony and character were challenged by the defence. Several different approaches to cross-examination in which the defence pursued a response from the complainant were observed. Two of these approaches were used in the pursuit of alignment including that the defence reissued questions and used three-part lists. The effect of such questioning approaches on the complainant and how she displayed emotionality during the conversation was also described.

\section{How Defence Counsel Asked Questions}

Cross-examination is an opportunity for the opposing counsel to challenge and test a witness' testimony. The cross-examination is a fair and necessary part of the justice system. Yet there is something questionable the process when the crime is sexual violence. When the witness is a rape complainant, legal practitioners report that the complainant is very easy to discredit (Mossman, MacGibbon, et al., 2009). Chapter three analysed how the defence counsel issued questions, created inconsistencies and made accusations. It also looked at how the defence counsel and complainant evaluated and constructed their version of events. In 
essence, defence's overall questioning approach was to use a sequence of questions, in parts, to build a foundation of facts which was then used to expose inconsistencies in, and make accusations against, the complainant.

As with other studies, this research found that the defence progressed crossexamination using tag questions, limited choice questions and statements for the complainant to confirm. Questions of this nature made minimal answers relevant thus minimising the complainant's responsive turn-space. Doing so effectively reduced the scope of possible answers that confirmed to the terms of the question. It was also noted that such questions also displayed a strong epistemic stance from the questioner. Limited choice questions indicate that defence already believe they know the answer (Heritage, 2012). The result of reducing the complainant's scope for responses and enhancing defence's epistemic stance works in favour of establishing the factual foundations for defence's arguments.

In terms of the types of challenges made by the defence, the complainant's general credibility was a dominant feature of defence questioning in all three cases. The defence scrutinised the complainant by noticing inconsistencies which were built using contrastive devices. For example, the defence contrasted statements such as 'being happy' with 'a terrible man'. Together the statements created a puzzle inference as to why the complainant expressed happiness toward her alleged rapist. These findings support Drew's $(1990 ; 1992)$ work. He found that contrastive devices were a technique used by cross-examining counsel to challenge a witness' testimony. In this study, the discrepancies were created over the complainant's general credibility - not the facts related to the offending itself.

Atkinson and Drew (1979) found that failures to act were used to shift blame onto the witness. In this study, inconsistencies were founded on observations of failures to act; in particular, failing to report the alleged crime occurred in two cases. The technique of noticing an absence highlights a normative expectation that something should happen (Schegloff, 1996). For example, noticing that a complainant did not tell someone creates a normative expectation that victims tell other people about being assaulted. It implies that she committed a social breach by deviating from 'normal' victim behaviour and therefore subsequently inferred that her claim was more likely to be false (Quilter, 2011). This was, and continues to be, a significant presumption reflected by the courts and legal counsel (Van de Zandt, 1998). Complainants were considered more credible if they had laid a complaint as soon as practicable (Ellison \& Munro, 2009). In New Zealand, recent reform of the Evidence Act 
2006 (NZ) made changes to address this stereotype, which provided for judicial discretion to warn juries that delays in reporting do not necessarily imply that the claim is false. This is relevant as this study shows that defence counsel continue to use such a myth as the basis for challenging the complainant.

Furthermore, in these cases, the noticing of a failure to report was used by defence to introduce ulterior motives for bringing a false complaint. This approach involved using questions in series; the defence asked the complainant to confirm that she had failed to report the crime. Once she did the defence then confirmed that she had an ostensible reason to complain. The defence then launched an accusation and in one case stated that, in fact, no rape had occurred. The accusation relied on a combination of stereotypes; firstly that rape is an easily fabricated crime; and secondly, that women will make false complaints for personal gain (Torrey, 1991). Van de Zandt (1998) also found that motive was a significant feature of defence counsel questioning. This reasoning is also applicable in New Zealand. A judge recently stated that if there were a possible reason to bring a complaint, he would find her less credible. In two of the cases in this study, child custody, revenge, and coercion to attend an anger management course were all cited or implied as being motives for false claims. This illustrates another instance of extra-legal stereotypes being used in cross-examination to challenge the complainant's credibility.

A focus on character was a common theme in this study. Character accusations undermine the complainant's general credibility as a witness. Being angry was attributed to character categories in all three cases. In these data, defence used excessive descriptions of anger and hate to evaluate and construct the complainant's character. Defence counsel questioning centred around the claim that the complainants had a disposition for being generally angry, hateful, or jealous, and had each acted on those emotions on various occasions. In all three cases, the instances of complainant anger were unrelated to the alleged sexual offending events. In court, the questions did not result in an explicit accusation; rather they were constructions of the complainant's character. There were several different characterisation of woman - angry, violent, and young. These examples align with myths that anger motivates women to fabricate complaints of rape in order to seek revenge.

Overall, it was found that defence counsel used limited answer questions that reduced the complainant's turn space to challenge complainants as described in chapter three. The study shows that some inconsistencies and accusations are founded in extra-legal cultural 
stereotypes. The consequence is that they lower the complainant's general credibility - even though stereotypes are no indication that a complaint is false.

\section{Defence Pursuing Responses and Complainant Emotionality}

Instances of complainant non-alignment and disagreement were analysed in chapter four. Questions in which the defence actively pursued alignment from the complainant were analysed. This study analysed the design of the questions as well as the responses during the cross-examination. Repetitions of the same, or similar, questions occurred in these data. This study found that defence counsel generally oriented to non-aligning answers as being inadequate, with the defence reissuing questions in order to elicit alignment.

Previous studies found that witnesses can resist questions and presuppositions in the way they deliver answers (Drew, 1992). One way witnesses can respond is by providing alternative descriptions that rework any problems with the defence's question (Drew, 1992; Ehrlich \& Sidnell, 2006). This research also found that complainants used alternative descriptions to re-work the defence's question; such as replacing emotions like 'angry' with 'just mad'. Sometimes this was prefaced with strong disagreement markers such as 'no' and 'that is incorrect' as identified in Pomerantz's (1984) work. As the person who experienced those emotions, she is the epistemic authority on her feelings. In spite of this the defence pursued agreement by asserting that she was very angry and in a rage. By pursuing an answer it casts the complainant's response as insufficient.

When defence counsel oriented to complainant responses as being insufficient, complainants displayed differing, and elevated, emotions. In one case the defence counsel claimed the complainant had not answered a question he had asked three or four times. The complainant responded by raising her voice, and claimed that she had in fact answered him more than three to four times. In another case, the complainant became increasingly upset and her answers became more extreme with each reissued question. This study preliminarily identified a possible link between the reissuing questions in this manner and heightened emotionality of the complainant. In Konradi's (2007) study, complainants reported feeling stress and fatigue when the defence repeated questions. They also expressed hightened awareness that the questioning techniques would trap them into answers they would later regret. This study provides early confirmation of the observations and self-reports of past 
complainant's experiences; that the way defence counsel conducts cross-examination may drive the trauma complainants experience.

In analysing repetitious questions, this study found that the defence concluded their lines of questioning in three-part lists in two of the cases. Drew (1990) found that defence counsel used three-part lists to make a generalisations about elements of a witness' testimony. In this research, defence counsel used three-part lists to conclude continual resistance from the complainant.

In these two cases, the defence used three-part lists to describe the complainant's actions. Put together, the actions made a comment on her moral character. In one case, the defence counsel used three separate instances of anger during the complainant's relationship with the accused. By using three incidents the defence was able to evaluate her as being an 'angry young woman'. The list asserted that she had a general disposition to be angry, rather than her anger being as a result of a one on-off incident. This indicates that she is angry by nature, and perhaps also young and impetuous.

It is worth noting that the character dispositions constructed in the three-part lists did not speak to a legal issue such as matters of consent. Instead they undermined her general credibility for being someone of unfavourable moral character. Importantly, the character dispositions also relied on cultural beliefs about sexual offending. The defence is therefore undermining the complainant's credibility in ways that possibly have no bearing on the facts of the case. This research also found preliminary evidence to support legal commentators' current concerns with cross-examinations in New Zealand (McDonald \& Tinsley, 2011). Defence counsel has the ability to make general character assessments that undermine complainant credibility - even where such an assessment has no bearing on the crime.

\section{Strengths, Limitations and Future Research}

In terms of research ideologies, this work added to the tension between 'purer' ethnomethodologies and discursive psychology. The study exposed problems in crossexamination using members' inference rich constructions of events. Participants appeared to be doing work with and orienting to descriptions, events and categories. Participants' versions of the criminal narrative are fundamental to how courtroom talk is accomplished. In these cases, the defence counsel's challenges to the complainant's narrative appeared to have 
no immediate bearing on the case. Instead the challenges often housed inference rich categories that worked as a vehicle for introducing rape mythology into the courtroom. The questioning seemed to focus on factors such as her moral character or her omissions to act. Both of these have been linked to wider social beliefs about sexual offending. Specifically, that having a bad moral character and omitting to act are indicative of a false complaint. This study therefore demonstrates the benefit of acknowledging the rich social inferences that are invoked by participants' use of social categories.

However there were several limitations in conducting this study. This research relied on data recorded by the court, which is audio-only. It therefore studied only the vocal part of the interaction. Courtroom talk takes place with co-present participants, meaning they orient to both verbal and non-verbal interaction. In order to have a full understanding of courtroom interaction, it would be ideal to have access to both video and audio recordings. The use of video and audio together would greatly aid research in the area of investigating trauma in the court. Showing how complainants are stressed using video media could help in pinpointing the particular parts of cross-examination are causing trauma. However, this is unlikely for the foreseeable future, as video-recorders and cameras are currently prohibited for use by the general public in the courtroom.

This study used New Zealand courtroom data to observe sexual offending crossexamination talk. Only three cases were available for study, which is too few for drawing firm, generalised conclusions. The robustness of the study is therefore somewhat limited. Nonetheless, with more cases, this research represents a promising approach to understanding the questioning mechanisms and approaches used during the cross-examination of rape complainants.

Finally, while rape myths are used by defence counsel in the cross-examination, there is no data on how the arguments are interpreted and received by the judge or jury. However, for future research this may always present a problem as the jury deliberations are always held in a closed room, well outside of the gaze of the public.

There are therefore two key areas for future study. Firstly, more cross-examination cases should be studied to verify the results of this study with respect to defence counsel and complainant interactions. Secondly, there should be work to inform the way in which judges perceive and implement their role in cross-examination talk. Finally, the work could be 
supplemented with New Zealand-based analysis of jurors' attitudes and perceptions about sexual offending; perhaps through further mock jury studies.

\section{Recommendations in the Legal Context}

A purpose of the Evidence Act 2006 (NZ) is to promote fairness to parties and witness - which covers complainants (s6(c)). The Evidence Act 2006 (NZ) also empowers judges to exclude unfairly prejudicial evidence (s8(1)(a)) and to intervene if questions are misleading or needlessly repetitive (s85(1)). Judges therefore have the necessary controls and tools to manage both the manner and content of courtroom business. Therefore New Zealand statute has existing provisions that may remedy some of these problems.

With respect to 88 of the Evidence Act 2006 (NZ) a judge may exclude evidence if its probative value is outweighed by any unfairly prejudicial effect on the proceedings. While the court must acknowledge the defence's right to an effective defence it must also acknowledge fairness to the complainant. This study found a consistent use of rape myths during cross examinations in the three cases. Rape myths are stereotypes that do not reflect the reality of sexual offending and victims. Temkin (2000) argued that rape myths therefore fall under this section as being 'misleading' and could be discouraged and/or excluded from the examination if challenged by judges and/or prosecution.

Other potentially misleading pieces of evidence are incidents that are long separated in time for the purpose of evaluating the complainant's character. In First Serious Relationship the complainant was with the accused for some years. There the defence counsel used three separate events to categorise the complainant as an 'angry young woman'. The three incidents spanned several weeks and over a year apart. It is arguably unfair to then allow isolated incidents across the entirety of a relationship to be the focus of character categories without providing the temporal context. It potentially makes the complainant accountable to unfavourable isolated behaviour over several years - even though this behaviour may have no bearing on the legal issue. This practice is also arguably unfairly prejudicial and misleading and could be disallowed.

McDonald and Tinsley (2011b) proposed clarifying judges' power in a new provision. They recommend amending the Evidence Act 2006 (NZ) by including a specific power to disallow unduly intimidating questions. The preliminary findings in this study support this 
recommendation; there was evidence to suggest that the way defence asked questions drove the complainant's stress. This is a deterrent that dissuades prosecuting counsel and complainants pursuing a case to court; meaning that offenders are often not prosecuted.

Even with these provisions, wider use of the powers available to judges may require some education and awareness. They could benefit from training on the use of questions that house rape myths in the cross-examination. Finn, McDonald and Tinsley (2011) recommend that judges and lawyers be given special training before they are allowed to conduct and take part in rape trials. By educating legal practitioners they may have a better understanding of rape myths and how they affect the trial process. On top of this, they recommend that some trials could be run as judge alone trials. This research lends preliminary support to this recommendation.

As well, as is done in other jurisdictions, Tinsley (2011) also recommended establishing a Sexual Violence Advisory Group that would be tasked with addressing specialist training within the wider justice system. The Advisory Group would have the specific task of addressing rape myths within the broader justice and law enforcement communities. This research also lends weight to the need for this type of broader reform.

\section{Conclusions}

This research was motivated by problems identified in the justice system regarding sexual offending. Rape complainants report being retraumatised by the process; legal practitioners report that they would not recommend a loved one go through the trial process. They perceive the odds of convicting are too low considering the trauma associated with complaining. Legal practitioners and rape complainants report that cross-examination is a significant issue for prosecuting sexual offending. In order to understand how crossexamination contributes to these problems, this research analysed three rape complainant cross-examinations.

This study identified several features of how defence counsels ask questions and formulate arguments. Preliminary analyses indicate that prejudicial stereotypes about rape and rape victims are introduced during cross-examination. Defence counsels achieve this by housing rape myths within inconsistencies, suggestions and accusations. These inconsistencies can then support an accusation of false complaint. It demonstrates those 
inconsistencies founded in cultural beliefs undermine a complainant's credibility. A second preliminary finding was that the way defence counsel manage questioning may drive complainant emotionality. When defence counsel repeated questions complainants displayed loudness and crying in two cases as a result.

Recommendations include using current legislation to alter how cross-examination is conducted. It also provides support for other reform proposals about creating new policies regarding sexual offending. However, the number of cases it used to draw these observations limits this work. This research proposes that further research ought to be conducted to expand on these findings. Another future study could examine judge, jury and lawyers perspectives on New Zealand sexual offending processes. 


\section{References}

Atkinson, J., \& Drew, P. (1979). Order in court - The organisation of verbal interaction in judicial settings. Atlantic Highlands, NJ: Humanities Press.

Bechhofer L., \& Parrot, A. (1991) In A. Parrot \& L. Bechhofer (Eds.) Acquaintance rape: The hidden crime (pp. 9-25). New York: Wiley.

Billig, M. (1999). Whose terms? Whose ordinariness? Rhetoric and ideology in conversation analysis. Discourse and Society, 10, 543-558. doi: 10.1177/0957926599010004005.

Brereton, D. (1997). How different are rape trials? A comparison of the cross-examination of complainants in rape and assault trials. The British Journal of Criminology, 32(2), 242-261. Retrieved from: http://bjc.oxfordjournals.org/

Burt, M. R. (1991). Rape myths and acquaintance rape. In A. Parrot \& L. Bechhofer (Eds.). Acquaintance rape: The hidden crime (pp. 26-39). New York, NY: Wiley.

Buttny, R. (1993). Social accountability in communication. New York, NY: Sage.

Clayman, S. (1993). Reformulating the question: A device for answering/not answering questions in new interviews and press conferences, Text, 13(2), 159-188. Retrieved from:

www.sscnet.ucla.edu/soc/faculty/clayman/Site/Publications_files/Clayman\%2520199 3\%2520ReformulatingTheQ.pdf

De Ruiter, J. (2012). Introduction: Questions and what they do. In J. P de Quiter (Ed.), Questions: Formal, functional and interactional perspectives (pp. 1-10). Cambridge, UK: Cambridge University Press.

Dillon, J.T. (1990). The practice of questioning. London: Routledge.

Drew P. (1990). Strategies in the contest between lawyer and witness in cross-examination. In J. N. Levi \& A.G. Walker (Eds.). Language in the judicial process (pp. 39-64). New York, NY: Plenum Press. 
Drew, P. (1992). Contested evidence in courtroom cross-examination: The case of a trial for rape. In P. Drew \& J. Heritage (Eds.), Talk at work: Interaction in institutional settings (pp. 470-520). Cambridge, UK: Cambridge University Press.

Drew, P. (1998). Complaints about transgressions and misconduct. Research on Language and Social Interaction, 31(3-4), 295-325. doi: 10.1080/08351813.1998.9683595

Dupret, B. (2011). Adjudication in action: An ethnomethodology of law, morality and justice. Surrey, UK: Ashgate Publishing, Ltd.

Edwards, D. (1999). Emotion discourse. Culture Psychology, 5, 271-291. doi: $10.1177 / 1354067 X 9953001$

Ehrlich, S. (2008). Perpetuating - and resisting - rape myths in trial discourse. In S. Brennan \& A. Taylor-Butts (Eds.), Sexual assaults in Canada 2004 and 2007 (pp. 407-426). Ottawa: Canadian Centre for Justice Statistics.

Ehrlich, S., \& Sidnell, J. (2006). "I think that's not an assumption you ought to make": Challenging presuppositions in inquiry testimony. Language in Society, 35(5), 655676. doi: 10.1017/S0047404506060313.

Ellison, L., \& Munro, V.E. (2009). Reacting to rape: Exploring mock jurors' assessments of complainant credibility. British Journal of Criminology, 49(2), 202-219. doi: 10.1093/bjc/azn077.

Finch, E., \& Munro, V. (2005). Juror stereotypes and blame attribution in rape cases involving intoxicants: The findings of a pilot study. British Journal of Criminology 45, 25-38. doi: 10.1093/bjc/azh0055

Finn, J., McDonald, E., \& Tinsley, Y. (2011). Identifying and qualifying the decision-maker: The case for specialisation. In E. McDonald \& Y. Tinsley (Eds.), From "real rape" to real justice: Prosecuting rape in New Zealand (pp. 221-278). Wellington, NZ: Victoria University Press.

Freckelton, I. (1998). Sexual offence prosecutions: A barrister's perspective. In P. Easteal (Ed.), Balancing the scales: Rape, law reform and Australian culture (pp.143 - 158). Sydney: Federation Press. 
Garfinkel, H. (1967). Studies in ethnomethodology. Los Angeles, CA: Polity Press.

Gavey, N. (2005). Just sex: The cultural scaffolding of rape. London, UK: Routledge.

Gerger, H., Kley, H., Bohner, G., \& Siebler, F. (2007). The acceptance of modern myths about sexual aggression scale: Development and validation in German and English. Aggressive Behavior, 33(5), 422-440. doi: 10.1002/ab.20195.

Goffman, E. (1981). Forms of talk. Philidelphia, PA: University of Pennsylvania Press.

Hayano, K. (2013). Question design in conversation. In J. Sidnell \& T. Stivers (Eds.), The handbook of conversation analysis (pp. 395-414). Sussex, UK: Blackwell Publishing Ltd.

Heffer, C. (2005). The language of the jury trial: A corpus-aided analysis of legal-lay discourse. New York, NY: Palgrave Macmillan.

Hepburn, A. (2004). Crying: Notes on description, transcription and interaction. Research on Language and Social Interaction, 37(3), 251-290. doi: 10.1207/s15327973rlsi3703_1

Hepburn, A., \& Potter, J. (2007). Crying receipts: Time, empathy, and institutional practice. Research on Language and Social Interaction, 40(1), 89-116. doi: $10.1080 / 08351810701331299$

Hepburn, A., \& Wiggins, S. (2005). Developments in discursive psychology. Discourse and Society, 16(5), 595-601. doi: 10.1177/0957926505054937

Heritage, J. (1984). Garfinkel and Ethnomethodology. Cambridge, UK: Polity Press.

Heritage, J. (2002). The limits of questioning: Negative interrogatives and hostile question content. Journal of Pragmatics, 34(10), 1427-1446. doi: 10.1016/S037821669(02)00072-3.

Heritage, J. (2003). Designing questions and setting agendas in news interview. In P. Glenn, C. LeBaron \& J. Mandelbaum (Eds.), Studies in language and social interaction (pp. 57-90). Mahwah, NJ: Lawrence Erlbaum. 
Heritage, J. (2005). Conversation analysis and institutional talk. In K. L. Fitch \& R. E. Sanders (Eds.), Handbook of language and social interaction, 103-147. Mahwah, NJ: Lawrence Erlbaum.

Heritage, J. (2012). Epistemics in action: Action formation and territories of knowledge. Research on Language and Social Interaction: 45(1), 1-29. doi: 10.1080/08351813.2012.646684.

Heritage, J. (2013). Epistemics in conversation. In. J. Sidnell \& T. Stivers (Eds.), The handbook of conversation analysis (pp. 371-394). Sussex, UK: Blackwell Publishing Co.

Heritage, J., \& Raymond, G. (2012). Navigating epistemic landscapes: Acquiescence, agency and resistance in responses to polar questions. In J. P. deRuiter (Ed.), Questions: Formal, functional and interactional perspectives (pp. 179-192). Cambridge, UK: Cambridge University Press.

Jefferson, G. (2004). Glossary of transcript symbols with an introduction. In G. Lerner (Ed.), Conversation analysis: Studies from the first generation (pp. 13-34). Philadelphia, PA: John Benjamins Publishing Co.

Jordan, J. (2004). Beyond belief? Police, rape and women's credibility. Criminology and Criminal Justice, 4(1), 29-59. doi: 10.1177/1466802504042222.

Kimps, D. (2007). Declarative constant polarity tag questions: A data-driven analysis of their form, meaning and attidunal uses. Journal of Pragmatics, 39(2), 270-291. doi: 10.1016/j.pragma.2006.08.003.

Kitzinger, C. (2000). Doing feminist conversation analysis. Feminism \& psychology, 10(2), (pp.163-193). doi: 10.1177/0959353500010002001.

Kitzinger, C. (2013). Repair. In J. Sidnell \& T. Stivers (Eds.), Handbook of conversation analysis, (pp. 229-256). Sussex, UK: Blackwell Publishing Ltd.

Komter, M. (2013). Conversation analysis in the courtroom. In. J. Sidnell \& T. Stivers (Eds.), The handbook of conversation analysis (pp.612-629). Sussex, UK: Blackwell Publishing Ltd. 
Konradi, A. (2007). Taking the stand: Rape survivors and the prosecution of rapists.

Westport, CT: Greenwood Publishing Group.

Lakoff, G. (1987). Women, fire and dangerous things: What categories reveal about the mind. Chicago, IL: University of Chicago Press.

Matoesian, G. M. (1993). Reproducing rape: Domination through talk in the courtroom. Chicago, IL: University of Chicago Press.

Matoesian, G. M. (2001). Law and the Language of Identity: Discourse in the William Kennedy Smith rape trial. Oxford, UK: Oxford University Press.

McDonald, E. (1994). Her sexuality as indicative of his innocence: The operation of New Zealand's 'Rape shield' provision. Criminal Law Journal, 18, 321-335.

McDonald, E. (1996). Women Rape Complainants' Experience of the Court Process. Rape Ten Years' Progress - An Inter-Disciplinary Conference, (pp. 84-96). Wellington: DSAC.

McDonald, E., \& Souness, R. (2011). From "real rape" to real justice in New Zealand Aotearoa: The reform project. In E. McDonald \& Y. Tinsley (Eds.), From "real rape" to real justice: Prosecuting rape in New Zealand (pp. 31-84). Wellington, NZ: Victoria University Press.

McDonald, E., \& Tinsley, Y. (2011a). From "real rape" to real justice: prosecuting rape in New Zealand. Wellington: Victoria University Press.

McDonald, E., \& Tinsley, Y. (2011b). Evidence issues. In E. McDonald \& Y. Tinsley (Eds.), From "real rape" to real justice: prosecuting rape in New Zealand (pp. 279-378). Wellington: Victoria University Press.

McGregor, W. (1995). The English ‘tag question': A new analysis, is(n’t) it? In R. Hasan \& P. H. Fries (Eds.), On subject and theme. A discourse functional perspective (pp. 91121). Philidelphia, PA: John Benjamins Publishing Co.

Ministry of Justice. (2008). Improvements to sexual violence legislation in New Zealand: Public discussion document. Wellington, NZ: Ministry of Justice. 
Ministry of Justice. (2010). The New Zealand crime safety survey 2009: Technical Report. Wellington, NZ: Ministry of Justice.

Mossman, E., Jordan, J., MacGibbon, L., Kingi, V., \& Moore, L. (2009). Responding to sexual violence: A review of literature on good practice. Wellington, NZ: Ministry of Womens' Affairs.

Mossman, E., MacGibbon, L., Kingi, V., \& Jordan, J. (2009). Responding to sexual violence: environmental scan of New Zealand agencies. Wellington: Ministry of Women's Affairs.

Perakyla, A., Antaki, C., Vehilainen, S., \& Leudar, I. (2008). Conversation analysis and psychotherapy. (Cambridge, UK: Cambridge University Press).

Pomerantz, A., \& Heritage, J. (2013). Preference. In J. Sidnell \& T. Stivers (Eds.). The handbook of conversation analysis (pp. 210-228). Sussex, UK: Blackwell Publishing Ltd.

Pomerantz, A. (1984). Agreeing and disagreeing with assessments: Some features of preferred/dispreferred turn shapes. In J. Atkinson \& J. Heritage (Eds.), Structures of social action: Studies in conversation analysis (pp. 57-101). Cambridge, UK:

University of Cambridge.

Potter, J. (2005). Making psychology relevant. Discourse \& Society, 16, 739-747. doi: $10.1177 / 0957926505054944$

Potter, J., \& Hepburn, A. (2010). Putting aspiration into words: 'Laugh particles', managing descriptive trouble and modulating action. Journal of Pragmatics, 42, 1543-1555. doi: 10.1016/j.pragma.2009.10.003

Potter, J., \& Wetherell, M. (1987). Discourse and social psychology: Beyond attitudes and behaviour. London: Sage.

Quilter, J. (2011). Reframing the rape trial: Insights from critical theory about the limits of legislative reform. Australian Feminist Law Journal, 35, 23-56. Retrieved from: http://heinonline.org.helicon.vuw.ac.nz/HOL/Page?handle=hein.journals/afemlj35\&di 
$\mathrm{v}=3 \&$ collection $=$ journals\&set_as_cursor $=0 \&$ men_tab $=$ srchresults\&terms $=$ quilter $\mid 201$ $1 \&$ type $=$ matchall

Raymond, G. (2003). Grammar and social organisation: Yes/no interrogatives and the structure of responding. American Sociological Review, 6(6), 939-967. Retrieved from: http://www.jstor.org/stable/1519752

Ruusuvuori, J. (2013). Emotion, affect and conversation. In J. Sidnell \& T. Stivers (Eds.), The handbook of conversation analysis (pp. 330-349). Sussex, UK: Blackwell Publishing Ltd.

Sacks, H. (1992). Lectures on conversation, volumes I and II- edited by G. Jefferson with introduction by E.A. Schegloff. Oxford, UK: Blackwell Publishing Ltd.

Sacks, H., Schegloff, E. A., \& Jefferson, G. (1974). A simplest systematics for the organiszation of turn-taking for conversation. Language, 50, 696-735. doi: $10.2307 / 412243$.

Schegloff, E. A. \& Sacks, H. (1973). Opening up closings. Semiotica, 8(4), 289-327. Retrieved from: http://www.degruyter.com.helicon.vuw.ac.nz/view/j/semi.1973.8.issue4/semi.1973.8.4.289/semi.1973.8.4.289.xml

Schegloff, E. A. (1996). Goffman and the analysis of conversation. In P. Drew \& A. Wootton (Eds.), Exploring the Interaction Order (pp. 89-135). Cambridge, UK: Polity Press.

Schlegoff, E.A. (1997). Practices and actions: Boundary cases of other-initiated repair. Discourse Processes, 23, 499-547. doi: 10.1080/01638539709545001.

Schlegoff, E. A. (2007). Sequence organization in interaction: A primer in conversation analysis, Vol 1. Cambridge, UK: Cambridge University Press.

Speer, S. (2005). Gender talk: Feminism, discourse and conversation analysis. New York, NY: Routledge. 
Stokoe, E., \& Edwards, D. (2008). 'Did you have permission to smash your neighbour's door?' Silly questions and their answers in police-suspect interrogations. Discourse Studies, 10(1), 89-111. doi: 10.1177/1461445607085592

Stokoe, E., \& Smithson, J. (2001). Making gender relevant: Conversation analysis and gender categories in interaction. Discourse \& Society, 2, 217-244. doi: $10.1177 / 0957926501012002005$.

Temkin, J. (2000). Prosecuting and defending rape: Perspectives from the bar. Journal of Law and Society, 27(2), 219-248. doi: 10.1111/1467-6478.00152.

Temkin, J. (2010). "And always keep a-hold of nurse, for fear of finding something worse": Challenging rape myths in the courtroom. New Criminal Law Review, 13, 710-734. Retrieved from: http://www.jstor.org/stable/10.1525/nclr.2010.13.4.710 .

Thomas, Justice E. W. (1994). Was eve framed; or was she forsaken? New Zealand Law Journal, 368, 426-432.

Thomas, Justice E. W. (2008). The Evidence Act 2006 and women. New Zealand Law Journal,169, 1-7. Retrieved from: http://www.lexisnexis.com.helicon.vuw.ac.nz/nz/legal/results/enhPubTreeViewDoc.d o? nodeId=TAAHAAIAAP\&backKey=20_T20086491330\&refPt=\&pubTreeWidth=2 92.

Tinsley, Y. (2011). Investigation and the decision to prosecute in sexual violence cases. In E. McDonald \& Y. Tinsley (Eds.), From "Real rape" to real justice: Prosecuting rape in New Zealand (pp. 120-167). Wellington, NZ: Victoria University Press.

Torrey, M. (1991). When will we be believed? Rape myths and the idea of a fair trial in rape prosecutions. U. C. Davis Law Review, 24, 1013-1071. Retrieved from: http://heinonline.org/HOL/LandingPage?handle=hein.journals/davlr24\&div=32\&id= \&page $=$.

Triggs, S., Mossman, E., Jordan, J., \& Kingi, V. (2009). Responding to sexual violence: Attrition in the New Zealand criminal justice system. Wellington: New Zealand Ministry of Women's Affairs. 
Van de Zandt, P. (1998). Heroines of fortitude. In P. Easteal, (Ed.). Balancing the scales: Rape, law reform and Australian culture. Sydney: The Federation Press.

Woodbury, H. (1984). The strategic use of questions in court. Semiotica 48(3-4), 197-228. Retrieved from: http://www.degruyter.com.helicon.vuw.ac.nz/view/j/semi.1984.48.issue-34/semi.1984.48.3-4.197/semi.1984.48.3-4.197.xml

Wooffitt, R. (2001). Researching psychic practitioners: conversation analysis. In M. Wetherell, S. Taylor, \& S. Yates, (Eds.). Discourse as data: a guide for analysis. London: Sage.

World Health Organisation. (2010). Preventing intimate partnerand sexual violence against women: Taking action and generating evidence. Geneva: WHO. 


\section{Appendix}

\section{Appendix A: Transcription Conventions and Symbols}

This work used standard conversation analysis conventions and symbols. The style adopted was that of Jefferson (2004). Crying in talk is a relatively understudied area of conversation analysis. Hepburn and Potter (2004) has developed a useful transcription approach for transcribing emotion and crying.

Feature of Talk (Jefferson, 2004)

Pauses or gaps in talk

No breaks or gaps

Short gap or interval

Material speed up

Material slow down

Large shifts in intonation, indicating high or low pitch

Stress indicating emphasis on pitch or loudness

Falling intonation at the end of Turn Constructional Unit (TCU)

Continuing/slightly raised intonation at the end of TCU

Rising intonation at the end of a TCU

Intonation contour indicating part of the word is 'punched up'

Intonation contour indicating down to up intonation

Overlapping talk

\section{Convention}

(0.0) Represents time lapse of silence in millisecond intervals.

$=$ Equal signs indicate no break or gap. A pair of equal signs at the end of one line and one at the beginning of a next, indicate no break between the two lines.

(.) A dot in parentheses indicates a brief interval (+/-) one tenth of a second within or between utterances.

$><$ Right/left carats bracketing an utterance indicate that the bracketed material is speeded up.

$<>$ Left/right carats bracketing an utterance indicate that the bracketed material is slowed down.

$\uparrow$ Large upwards pitch rise. $\downarrow$ Large lowering of pitch. word

,

$?$

wo:rd The emphasis is on the 'o' and is of a higher intonation than ' $r d$ '

wo:rd The 'rd' is of a higher intonation than the 'wo'

wo[rd ]

[wo]rd Square parentheses encompass overlapping 
talk between participants.

Breaths

Breathiness within a word

Gutteralness

Loud talk

Sound stretches

Sound cut-off

Un-gotten material

Unclear talk

Transcribers descriptions .hhh represents inhalation. Hhh represents exhalation. The number of ' $h$ 's represent the length of the breath

Wohhrd A row of ' $h$ 's within a word indicates breathiness at that point.

Wghord A 'gh'inside a word indicates guttural quality.

WORD Speech in capitals indicates loudness

wor:: d Colons indicate a sound stretch. The more colons, the longer the sound stretch. They do not appear after hard consonants.

wor- A dash indicates where a word is cut off

(blrdgh) Nonsense syllables are sometimes provided, to give an indication of various features of un-gotten material.

( ) If talk is heard but words cannot be identified or (word) indicates where the transcriber is unsure.

((note)) The note could be a physical action or facial expression

\section{Features of Crying (Hepburn \& Potter Convention}

2007)

Whispering

Wet sniff

Snorty sniff

Sobbing

Wobbly voice

Blowing nose

Croaky voice
${ }^{\circ}$ maybe ${ }^{\circ}$ Enclosed by double degree signs. Softer and hoarser than single degree signs.

.shih

.skuh

Huhh .hih hkyuuh $<$ hhhhh $>-$ combinations of some "hhs" with full stops indicating inhilation; may have voiced vowels and consonants

$\sim$ support $\sim$ Enclosed by tildes

This particular research project captured blowing nose as 'SHH! SH!'.

This particular research project captured croaky throat speaking with \#word\# 